ANDRÉ TEIXEIRA NUNES

\title{
EMPREGO DE UM SISTEMA DE INFORMAÇÃO GEOGRÁFICA (SIG) PARA SUPORTE AO PLANEJAMENTO DO PRODUTO HOTELEIRO, APRESENTANDO UM CASO PARA UMA REGIÃO DA CIDADE DE SÃO PAULO
}

Dissertação apresentada à Escola Politécnica da Universidade de São Paulo para a obtenção do título de Mestre em Engenharia. 
ANDRÉ TEIXEIRA NUNES

\section{EMPREGO DE UM SISTEMA DE INFORMAÇÃO GEOGRÁFICA (SIG) PARA SUPORTE AO PLANEJAMENTO DO PRODUTO HOTELEIRO, APRESENTANDO UM CASO PARA UMA REGIÃO DA CIDADE DE SÃO PAULO}

Dissertação apresentada à Escola Politécnica da Universidade de São Paulo para a obtenção do título de Mestre em Engenharia.

Área de concentração:

Gerenciamento de Empresas e

Empreendimentos na Construção Civil

Orientadora:

Prof. a Doutora

Eliane Monetti

São Paulo 


\section{FICHA CATALOGRÁFICA}

Nunes, André Teixeira

Emprego de um sistema de informação geográfica (SIG) para suporte ao planejamento do produto hoteleiro, apresentando um caso para uma região da cidade de São Paulo / A.T. Nunes. -- São Paulo, 2004.

$95 \mathrm{p}$.

Dissertação (Mestrado) - Escola Politécnica da Universidade de São Paulo. Departamento de Engenharia de Construção Civil.

1.Planejamento estratégico 2.Sistema de informação geográfica 3.Hotelaria I.Universidade de São Paulo. Escola Politécnica. Departamento de Engenharia de Construção Civil II.t. 
A Deus,

que

"se compraz na verdade no íntimo e no recôndito me fazes conhecer a sabedoria." 
AGRADECIMENTOS

A Deus, por tudo.

Aos meus pais, pelo apoio incondicional.

A Simone, pelo incentivo em todos os momentos.

A Eliane Monetti, orientadora e amiga, per suscitare una mente creativa.

A Ana Beatriz P. Veronezi,

Michael W. Asmussen

Rogerio F. Santovito,

Yoakim P. de Melo Jr.,

pelo apoio, ajuda e companheirismo.

Aos colegas e professores, pela sabedoria e amizade. 


\section{RESUMO}

Empreendimentos imobiliários e de base imobiliária em geral e empreendimentos hoteleiros em particular tem seus desempenhos, em primeiro lugar, associados à localização. $\mathrm{O}$ produto hoteleiro possui elevada rigidez estrutural, o que significa reduzida capacidade de readaptação sem provocar quebras irreversíveis na qualidade do investimento. Portanto, o processo de decisão com relação aos investimentos em empreendimentos hoteleiros depende de um sistema de informações que contemple atributos de expressão espacial, que considere fatores como localização e posição, dispersão e concentração, forma, interrelacionamentos, conectividade e facilidade de acesso. A estruturação de um sistema de informação geográfica para o suporte ao planejamento do produto hoteleiro é mais do que um aplicativo ou sistema de computação. Ela envolve desde a coleta, o armazenamento, a manipulação e a análise até a apresentação das informações. Num empreendimento hoteleiro, a localização e a vocação da região em estudo e a escolha do produto estão intrinsecamente ligados. Em função da importância que a demanda por viagens de negócios representam dentro do universo dos produtos hoteleiros, estabeleceu'se o foco desse trabalho na estruturação de um sistema de informação geográfica para planejamento do produto hoteleiro em cidades de demanda expressiva por viagens de negócios. Considerando-se a relevância dessa demanda na cidade de São Paulo e de sua intensa competitividade interna, foram coletados dados para esse município, do setor hoteleiro e da economia. 


\begin{abstract}
Real estate projects and real estate backed investments in general, and lodging projects in particular have its performance firstly associated with the location. The lodging investment has high structural rigidity, meaning little readjustment capacity without irreversible losses in the quality of the investment. Therefore, the decision process related to the investments in lodging projects depends on the information system that consider geographic attributes as location, position, dispersion and concentration, shape, inter-relationships, connection and accessibility. The structure of a geographic information system to support the lodging project planning is more than computer software. It involves the collection, the storage, the manipulation, the analysis and the presentation of geographic information. In lodging projects, the location and the vocation of the region in study and the selection of the best project works together. As the importance that business trips means in the universe of lodging projects, this study aims to build up a structure of a geographic information system for the planning of a lodging enterprise in cities with expressive demand for business trips. Considering the relevance of such demand in the city of São Paulo and its intense internal competitiveness, statistical data on the city regarding its business aspects were collected and also statistical data from the lodging industry and from the city economic aspects.
\end{abstract}


SUMÁRIO

LISTA DE FIGURAS

LISTA DE TABELAS

LISTA DE ABREVIATURAS E SIGLAS

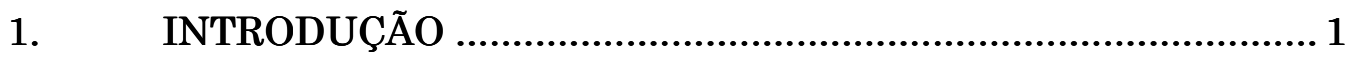

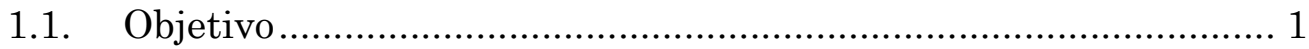

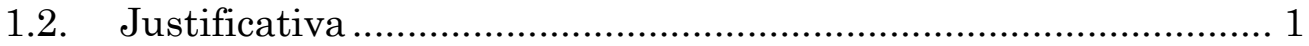

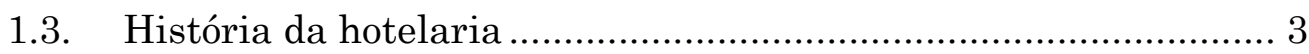

1.3.1. A hotelaria no Brasil............................................................... 4

1.4. Estágio de desenvolvimento de SIG no desenvolvimento de empreendimentos hoteleiros .......................................................... 5

1.5. Estrutura da dissertação............................................................. 6

2. SISTEMAS DE INFORMAÇÃO GEOGRÁFICA (SIG) ................. 8

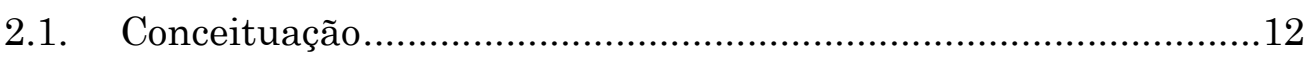

2.2. Componentes de um SIG ........................................................

2.3. Escolha do software de sistema de informações geográficas ........16

2.4. Processo de estruturação de um SIG ............................................17

3. EMPREENDIMENTOS DE TIPOLOGIA DE HOTÉIS.............. 20

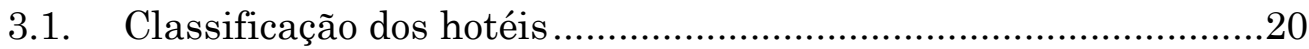

3.2. Empreendimentos voltados a viajantes a negócios........................21

3.2.1. Viajantes individuais ................................................................23

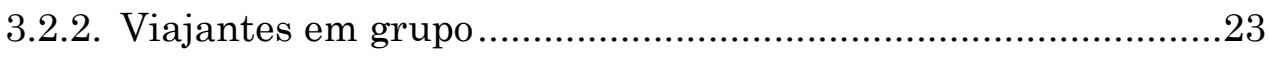


3.2.3. Viajante com contrato empresarial .....................................24

3.2.4. Viajante em estadia de longa permanência..........................24

3.3. Indicadores de desempenho em hotéis ...................................25

3.3.1. Diária Média ...................................................................26

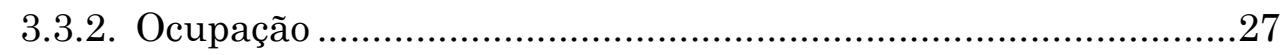

3.3.3. Índice de penetração de mercado ............................................ 31

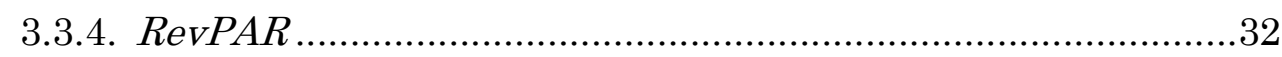

3.4. Aplicação do processo de estruturação de um SIG no suporte ao planejamento de hotéis de negócios ........................................34

4. APRESENTAÇÃO DO CASO DE SUPORTE À PESQUISA ..... 39

4.1. Construção da base de dados relacional .....................................40

4.2. Delimitação de uma região de estudo........................................4 41

4.2.1. Características da região de estudo ...................................4 43

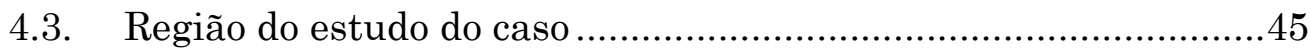

4.3.1. Zona de influência como resultante do conjunto da oferta competitiva ......................................................................... 45

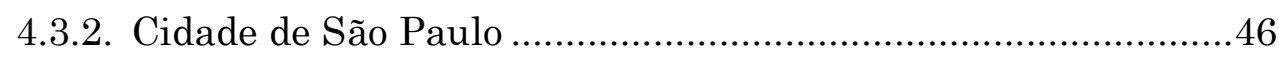

4.3.3. Configuração da oferta e da demanda para São Paulo ...........49

4.3.4. Região alvo do estudo ..................................................50

5. CARACTERIZAÇÃO DA DEMANDA NA ZONA DE INFLUÊNCIA ............................................................. 55

5.1. Fator gerador de demanda ...............................................5

5.2. Análise da demanda pela oferta competitiva instalada..............58

5.3. Demanda latente ................................................................6 60

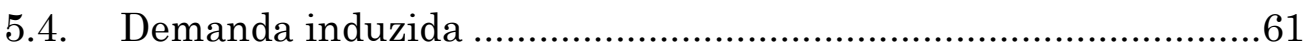

5.5. Análise da demanda na zona de influência primária .................61

5.6. Arbitragem da demanda para o horizonte do projeto .................68 
6.1. Resultados possíveis a partir do uso do SIG ................................73

6.1.1. Estudo da demanda .................................................................

6.1.2. Estudo de eventos macroeconômicos...........................................75

6.1.3. Estudo da possibilidade de alteração no perfil da região ..........76

6.1.4. Estudo aplicado à dinâmica do mercado imobiliário de hotéis 77

6.1.5. Estudo sobre movimentos de difusão geográfica da demanda. 78

6.1.6. Monitoramento e controle no planejamento, através de SIGs.79

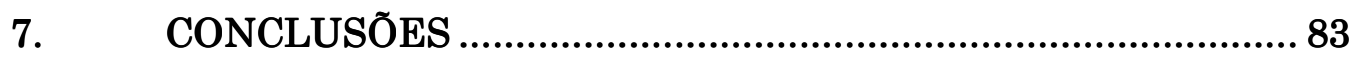

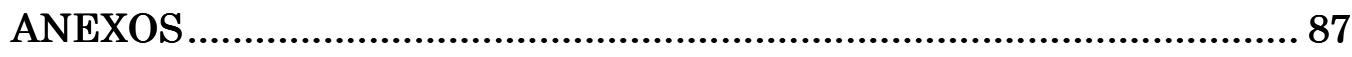

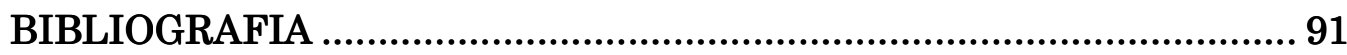




\section{LISTA DE FIGURAS}

Figura 1: SIG: Fases de ganho de valor em organizações........................10

Figura 2: Ciclo de informação de um SIG.............................................13

Figura 3: Exemplo do início de operações de um novo hotel......................30

Figura 4: Diagrama de fluxo dos eventos operacionais de um SIG para o planejamento de hotéis de negócios ................................................... 35

Figura 5: Graus de tolerância em diferentes origens e destinos .............42

Figura 6: RMSP 1991: Divisão administrativa: municípios, distritos e

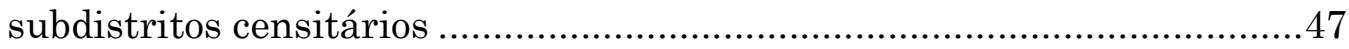

Figura 7: Configuração da oferta e demanda em São Paulo......................49

Figura 8: Região alvo do estudo .................................................50

Figura 9: Empresas instaladas na Região da Berrini e Chácara Santo

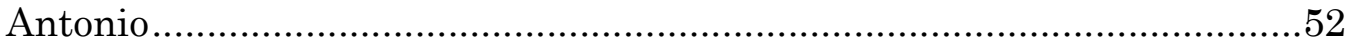

Figura 10: Espaços para eventos na Região da Berrini e Chácara Santo

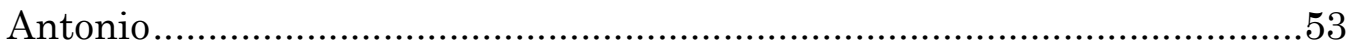

Figura 11: Posição da oferta competitiva .............................................55

Figura 12: Definição da zona de influência.............................................62

Figura 13: Zona de influência na região ..................................................64

Figura 14: oferta competitiva instalada através da manipulação de dados e apresentação de informações........................................................65

Figura 15: Evolução da oferta de hospedagem comercial transeunte em São Paulo 69

Figura 16: Faixas de intervalo para diária média, ocupação e RevPAR ...71

Figura 17: Intervalo de Confiança para Diária Média e RevPAR .............72

Figura 18 - Fases dos ciclos de Real Estate..........................................81 


\section{LISTA DE TABELAS}

Tabela 1:ANO-Op [1], configuração sem novo hotel................................31

Tabela 2: ANO-Op [1], configuração com novo hotel................................ 32

Tabela 3: Espaços para eventos na região de influência.........................54

Tabela 4: Relação de hotéis, data de inauguração e número de UHs .......59

Tabela 5: Sensibilidade da demanda (empresas) em relação ao preço, para hospedagem de funcionários e visitantes ...............................................63

Tabela 6: Caracterização de segmento de mercado para hotéis de cidade66

Tabela 7: Oferta competitiva instalada .............................................. 74

Tabela 8: Oferta competitiva instalada com um novo hotel [12] ...............74 


\section{LISTA DE ABREVIATURAS E SIGLAS}

\begin{tabular}{|c|c|}
\hline $\mathrm{ABIH}$ & Associação Brasileira da Indútria de Hotéis \\
\hline \multirow[t]{2}{*}{$\mathrm{CAD}$} & Computer Aided Design, desenho assistido por \\
\hline & computador \\
\hline \multirow[t]{2}{*}{ EMBRATUR } & Instituto Brasileiro de Turismo (antiga Empresa \\
\hline & Brasileira de Turismo) \\
\hline FRA & Fundo para Reposição dos Ativos \\
\hline $\mathrm{IBH}$ & Instituto Brasileiro de Hospitalidade \\
\hline ICMS & Imposto sobre Circulação de Mercadorias \\
\hline PIB & Produto Interno Bruto \\
\hline \multirow[t]{2}{*}{$\operatorname{RevPAR}$} & Revenue Per Available Room - receitas por quarto \\
\hline & disponível \\
\hline RMSP & Região Metropolitana de São Paulo \\
\hline SIG & Sistema de Informação Geográfica \\
\hline SIGs & Sistemas de Informação Geográfica \\
\hline
\end{tabular}




\section{INTRODUÇÃO}

\subsection{Objetivo}

Esse trabalho tem por objetivo discutir a estruturação de um sistema de informação geográfica (SIG) para suporte ao planejamento do produto hoteleiro, permitindo melhorar a qualidade dos cenários tanto para análises de novas oportunidades de negócios, quanto para análises das transações correntes e futuras, vinculadas à operação do empreendimento.

O decisor de investimentos em empreendimentos imobiliários e de base imobiliária trabalha com informação. Quanto melhor a qualidade da informação disponível no momento da decisão, tanto melhor suportada será a decisão. As informações são constituídas a partir de modelos de simulação financeira que empregam cenários associados a padrões de desempenho operacional que se esperam sejam alcançados. Os sistemas de informação geográfica permitem avaliar atributos espaciais ${ }^{1}$ com maior qualidade, que irão compor os cenários empregados para análise do negócio.

No entanto, trabalhos sobre o uso de SIG para o planejamento de empreendimentos são escassos e não foram encontradas referências ao uso de SIG em planejamento do produto hoteleiro para o Brasil, apesar do mesmo ser extremamente dependente de atributos espaciais.

\subsection{Justificativa}

Apesar da difusão de conhecimento sobre SIGs nos últimos anos, com a evolução de ferramentas analíticas, existe uma lacuna em estudos

${ }^{1} \mathrm{O}$ termo espacial, neste trabalho, é usado como sinônimo de geográfico. 
que apresentem maior profundidade sobre o impacto dos atributos de expressão espacial em investimentos e, em particular, em empreendimentos hoteleiros. Krugman; Fujita; Venables (em fase de elaboração), comentam que nos últimos anos tem havido um crescimento intenso de pesquisas sobre "economia geográfica", isto é, o estudo das atividades econômicas associadas à sua disposição geográfica. A razão para esse aumento de interesse é que novas ferramentas de análise em SIG reduziram significantemente as barreiras técnicas, principalmente as relacionadas com a capacidade de processamento de dados.

Fryrear; Prill; Worzala (2001) relacionam as principais razões que tem influenciado o crescimento da utilização de SIGs: redução de preços na indústria de informática, de modo geral e para aplicações de SIGs; avanço tecnológico dos sistemas computacionais; crescimento do número de programadores de aplicativos de SIGs; redução dos custos de mapeamento digital, para suporte ao uso de SIGs e redução nos custos de obtenção de dados de atributos espaciais, por vendedores privados e órgãos públicos.

De todas essas razões, a mais crítica é a última, pois como a chave do sucesso em se tratando de SIG é o uso da informação, a redução dos custos para obtenção dos dados que alimentam o sistema tem efeito direto na disseminação da informação por ele gerada.

O uso adequado de SIG deverá tornar mais aparente a influência do posicionamento geográfico nos indicadores de desempenho, induzindo a uma redução no risco de sobre-investimento pela melhora da qualidade da informação relativa aos atributos da oferta e demanda na zona de influência, ou seja, diminuindo a necessidade de imobilização de recursos para cobertura de riscos, sem contrapartida no aumento da capacidade de geração de riqueza. 
Segundo Rocha Lima (1995), num hotel, o sobre-investimento vinculado, seja à edificação, como ao seu equipamento, só terá sustentação se estiver associado à capacidade de cobrar diárias mais elevadas, ou se, com esses investimentos agregados, o empreendimento aumentar a sua ocupação. Caso contrário, o investimento acima de um determinado limite tem lastro zero, mesmo que se identifique que, do ponto de vista imobiliário, ele tem contrapartida em insumos verdadeiramente aplicados na implantação do projeto.

Os SIGs não devem ser vistos como aplicativos ou algoritmos de computação, mas como sistemas inter-relacionais complexos de base de dados, software, hardware e organização. O conjunto de atributos geográficos que compõe a base de dados, quando estudados, devem ser entendidos como sistemas referenciados espacialmente. A importância de se desenvolver um método sistêmico para coleta, armazenamento, manipulação, análise e apresentação das informações associadas espacialmente se deve à relevância desses atributos para a análise da qualidade de investimentos dessa natureza.

\subsection{História da hotelaria}

Uma das razões para o aparecimento da hotelaria foi o comércio de bens e serviços entre regiões distintas, ou seja, a demanda ${ }^{2}$ específica por hospedagem classificada como demanda provocada por viagens de negócios. Segundo Andrade; Brito; Jorge (2003), as rotas comerciais da Antiguidade e posteriormente da Idade Média, na Ásia, na Europa e na África, geraram núcleos urbanos e centros de hospedagem para o

\footnotetext{
2 Demanda, neste trabalho, caracterizada como o desejo e a capacidade econômica de comprar o serviço (pernoites de hotel) por parte dos consumidores.
} 
atendimento aos viajantes e caravanas, comerciantes e mensageiros, entre outros.

Ainda em se tratando de viagens de negócios, a Revolução Industrial estimulou o surgimento de hotéis na Inglaterra, Europa e EUA, no final do século XIX. Um aspecto a destacar é que desde o início, a chave do sucesso do empreendimento hoteleiro estava vinculada à localização: como ponto de paradas, nas rotas do comércio da Antiguidade; com o advento das estações ferroviárias, o desenvolvimento de hotéis em áreas próximas; com o desenvolvimento do transporte aéreo, hotéis de aeroporto; com o desenvolvimento dos contatos de negócios, hotéis em áreas de intensa atividade comercial e de prestação de serviços. Resumindo, hotéis que fossem próximos de centros geradores de demanda, de influências regionais, nacionais ou internacionais.

\subsubsection{A hotelaria no Brasil}

No Brasil, o desenvolvimento da indústria hoteleira teve seu primeiro grande impulso com a mudança da corte portuguesa para o Rio de Janeiro, em 1808. Mais recentemente, a partir da criação da Embratur em 1966 e da criação do critério de classificação dos hotéis em estrelas, houve um aumento na participação do segmento de hotéis de luxo, que se intensificou com a conquista de incentivos fiscais e alterações das leis de zoneamento nas grandes cidades. Segundo Andrade; Brito; Jorge (2003), segmentos importantes da demanda, como os ligados a negócios e serviços que buscam hotéis de categorias média e econômica foram negligenciados no passado, resultando em uma demanda reprimida e malservida, que necessitava de um atendimento mais adequado. No entanto, nos últimos anos, a tipologia de hotéis de negócios de categoria econômica tem sido alvo de investimentos, indicando uma nova tendência para o setor. Essa tendência é embasada na correta identificação dessa demanda segmentada reprimida, definida por grupos de executivos de nível 
intermediário, técnicos, profissionais e vendedores em viagens de negócios, que priorizam atributos como preço, facilidade de acesso e conforto em relação a atributos como sofisticação em serviços e instalações.

\subsection{Estágio de desenvolvimento de SIG no desenvolvimento de empreendimentos hoteleiros}

A identificação de tendências de comportamento da demanda e da oferta em uma região faz parte do planejamento estratégico de negócios, onde uma das mais importantes características estudadas são os atributos espaciais, campo de atuação de Sistemas de Informação Geográfica (SIG). No entanto, Birkin et al (1996) constataram que SIGs têm tido seu uso limitado à análise descritiva, restringindo seu poder analítico real, quando deveria ser o ambiente de desenvolvimento de ferramentas de modelagem, conjugado à coleta e análise de dados, armazenamento de informações, e tratamento e apresentação de recursos gráficos.

O estudo de empreendimentos hoteleiros depende de informações sobre indicadores de desempenho que estão intimamente ligados a atributos geográficos como localização, facilidade de acesso, posição de entes geradores de demanda, posição da oferta competitiva e integração entre empreendimentos complementares. Os atributos associados à localização, forma, posição, conectividade tornam SIGs relevantes. Rushmore et al (2000) indicam que estudos de empreendimentos hoteleiros e seus correspondentes estudos de mercado serão revolucionados por programas de computador que permitirão avaliar os mercados em micro-regiões, para quantificar a dinâmica da oferta e demanda e produzir projeções com menor margem de risco, da ocupação e diária média, entre outros. 


\subsection{Estrutura da dissertação}

A dissertação está estruturada em sete capítulos: o primeiro capítulo introduz o tema, trazendo um breve panorama histórico sobre a evolução da hotelaria voltada a viajantes de negócios e a aplicabilidade de sistemas de informação geográfica para o desenvolvimento de empreendimentos hoteleiros.

O Capítulo 2 conceitua os Sistemas de Informação Geográfica (SIG) e detalha o processo que será utilizado para a estruturação de um SIG. A lógica em que se baseia um SIG, seus componentes e o aplicativo que será utilizado no estudo de caso são discutidos.

No Capítulo 3 os empreendimentos de tipologia de hotéis são estudados dentro da perspectiva dos hotéis de negócios, ou seja, hotéis voltados a viajantes de negócios.

Para entender hotéis de negócios e seu segmento de mercado, os viajantes de negócios são caracterizados, o que auxilia no entendimento dos atributos do hotel e de características específicas para cada subsegmento do mercado de viajantes de negócios.

Os indicadores de desempenho que serão utilizados ao longo do estudo de caso são apresentadados e comentados - o método de cálculo usualmente aplicado, a importância do indicador e a razão do estudo de um conjunto de indicadores ao invés de um único denominador para o entendimento do desempenho do hotel.

No Capítulo 4 inicia-se a aplicação de um SIG para o planejamento do produto hoteleiro, que norteará os demais capítulos e permitirá a discussão em torno do uso de SIG para essa tipologia de empreendimento. 
O planejamento de hotéis de negócios é apresentado sob a ótica de um caso aplicado de SIG, para que as principais características possam ser discutidas. A discussão, nesse capítulo de apresentação do caso, busca indicar as características do empreendimento e da região que justifica o uso de uma ferramenta de análise espacial, no caso de um SIG.

No Capítulo 5, sobre a demanda na zona de influência, aprofunda-se a discussão do uso de SIG na análise da demanda e discorre-se sobre as formas de demanda que podem ser captadas. O estudo da demanda é importante na sustentação da qualidade do cenário, a partir da oferta competitiva instalada. Seu estudo pelo SIG possibilita, sem a prerrogativa de indicar um determinado terreno ou localização, conhecer as forças atuantes na zona de influência e arbitrar o desempenho ao longo do horizonte de operação do empreendimento hoteleiro.

O Capítulo 6 aborda a questão da flutuação das variáveis do cenário quando da utilização do SIG. O caso serve para ensaio dos efeitos produzidos por distensões nas variáveis da oferta competitiva nos resultados dos indicadores de desempenho para um projeto de hotel na zona de influência, e indica aplicações possíveis com o uso de SIG.

A utilização do SIG para o planejamento de empreendimentos hoteleiros revela-se não somente possível como também permite melhorar a qualidade das análises do cenário, conforme discorrem as conclusões no Capítulo 7. 


\section{SISTEMAS DE INFORMAÇÃO GEOGRÁFICA (SIG)}

Neste capítulo, inicialmente serão apresentados alguns conceitos sobre SIG: sua conceituação, os componentes principais e seu processo de estruturação. As particularidades da estruturação de um SIG serão tratados a partir da análise de um caso na cidade de São Paulo.

É notória a importância da localização em estudos em real estate. ${ }^{3}$ Rodriguez; Sirmans; Marks (1995) comentam que a dimensão espacial em real estate é a principal particularidade que contribuiu para a criação de uma nova área de estudos. No entanto, antes do desenvolvimento de softwares de SIGs era extremamente difícil medir o impacto da localização em modelos de real estate. Com o uso de softwares é possível automatizar muitos dos processos desenvolvidos inicialmente por geógrafos sobre análise espacial.

Sistemas de informações geográficas são o resultado da evolução do uso da cartografia 4 . A cartografia, originalmente compreendendo apenas a elaboração de mapas, antecede a escrita. A cartografia sistematizou a elaboração e preparação de mapas, cartas e projetos, bem como orientou a sua utilização.

3 "Identificação do setor de investimentos nos produtos da construção civil - "estate" para propriedade e "real" para tangível. Numa tradução mais livre, setor econômico de investimento nos "bens de raiz". No Brasil a opção tem sido usar o termo Construção Civil para o setor econômico, com suas derivações para Imobiliário, quando se trata do segmento que trabalha com o produto que se vende - o lote, a casa, o escritório - e De Base Imobiliária, quando referido aos empreendimentos que resultam em explorar um bem de raiz shopping-centers, hotéis, edifícios para locação." (Rocha Lima, 1998)

4 Vocábulo criado em 1839 pelo segundo Visconde de Santarém, Francisco de Barros e Souza de Mesquita de Macedo Leitão, (1791 - 1856). Antes da divulgação e consagração do termo, o vocábulo usado tradicionalmente era cosmografia. Disponível em $<$ http://www.ibge.gov.br/home/geografia/decar/manual_nocoes/introducao.html > Acesso em 18/03/2004. 
Thrall (1998a) comenta que a geografia, da qual a cartografia é parte, é uma das mais antigas disciplinas na história humana - e a geografia econômica, que estuda como a economia se comporta em relação a dimensão espacial e a seus padrões e processos, representa parcela significativa dessa área de estudo. Essa é a área de estudo que mais tem sido beneficiada pelo desenvolvimento de SIGs.

A história do desenvolvimento de ferramentas de programação em SIG começou no início da década de noventa, com o desenvolvimento pela empresa SMI (Strategic Mapping Inc.) de um conjunto de ferramentas de programação compatíveis com o Microsoft Visual Basic. No entanto, o produto tinha um preço elevado, faltava documentação, impunha restrições de licenciamento e apresentava recursos limitados. Como poucas firmas adotaram o produto, a SMI se dissolveu como companhia e a empresa ESRI (Environmental Systems Research Institute, Inc.) adquiriu a divisão de desenvolvimento de SIGs. Durante esse período, outras empresas entraram no mercado e lançaram aplicativos de SIG, como SylvanMaps/OCX e Pepperwhite Inc., com novos recursos e preços menores, forçando empresas como a ESRI a adotarem uma nova estratégia: produtos moduláveis a preços competitivos.

Com o desenvolvimento de novas linguagens de programação, o custo do aplicativo poderá ser significativamente menor e o produto provavelmente terá uma grande penetração no mercado de real estate. (Thrall 1998b). Thrall; Pittman (1992) já apresentavam alternativas para aplicações de SIG em real estate, mas ressaltavam a dificuldade em obterse dados, pois a maioria das empresas não revelava dados do desempenho de seus empreendimentos. Recentemente nos Estados Unidos SIGs começam a ser aplicados a real estate e utilizados fora do ambiente acadêmico, mas o mesmo ainda não ocorre no Brasil. 
Zaddack (1998/1999) comenta que a utilização de SIG ainda é incipiente quando se considera que o uso de aplicativos tem sido possível em computadores pessoais apenas a partir dos anos noventa. Praticamente todos os pacotes de SIG são sistemas abertos não adaptados às necessidades dos clientes, exigindo do usuário conhecimentos de geografia, cartografia, gerenciamento de dados e de gráficos e poucos profissionais reúnem as habilidades necessárias para criar, implementar e tornar SIGs um produto rentável em sua prática diária.

Birkin et al (1996) argumentam que as análises promovidas pelo sistema de informações geográficas podem agregar valor aos dados e informações, às empresas que dele se utilizam. A Figura 1 representa um diagrama das etapas de ganho de valor dentro de uma organização, pela aplicação de sistemas de informação geográfica. Dados diferem de informação na medida em que dados são conjunto de valores, numéricos ou não, sem significado próprio. Agrega-se valor aos dados, através de técnicas de processamento, para a informação, que pode ser entendida como sendo o conjunto de dados que possuem significado próprio para determinado uso ou aplicação (Teixeira et al, 1993 apud Guidara Junior, 1999). A quantidade e qualidade da informação gerada se torna relevante e valiosa na medida em que se aperfeiçoa a habilidade de utilizá-la.

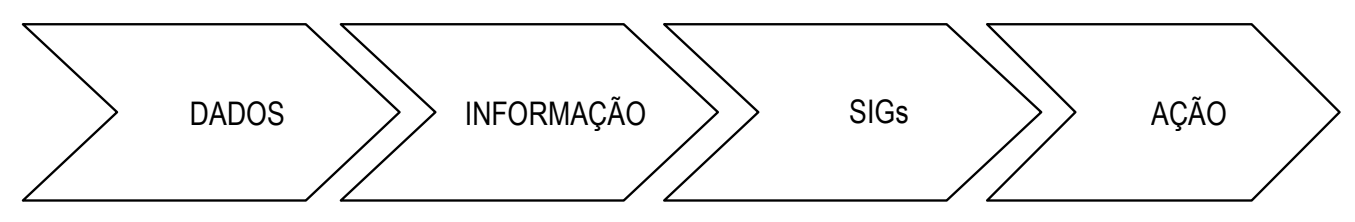

Figura 1: SIG: Fases de ganho de valor em organizações FONTE: adaptado de Birkin et al (1996)

SIGs, stricto sensu, é um programa computacional enquanto que lato sensu, engloba desde o programa computacional, os equipamentos de 
informática, o banco de dados lógico, os procedimentos de entrada e saída de dados, as normas de operação, codificação, e a estrutura organizacional que atenda aos elementos acima descritos (Quintanilha, 2003).

Segundo Guidara Junior (1999), um SIG se propõe a integrar e associar informações às feições do mapa, permitindo consultas e análises espaciais. Feições de um mapa são os diversos aspectos naturais (rios, lagos, oceanos, matas, etc.) e os diversos aspectos culturais (vias, edificações, lotes, etc.) da superfície terrestre. Já as relações espaciais entre feições, também chamadas relações topológicas, são conhecidas como vizinhança, adjacência ou contigüidade (ao lado de, vizinho a), conectividade (ligado a, conectado a), proximidade (perto de) e pertinência (contém, contido em).

Castle III (1993) já relacionava alguns princípios que se verificam quanto ao uso de SIGs e suas implicações, que com o tempo vieram a se confirmar:

$\checkmark$ SIGs são uma tecnologia com grande potencial de crescimento, já percebido pelo setor privado;

$\checkmark$ Devido à complexidade e tipologias dos empreendimentos, é necessária a construção de modelos específicos em SIG para cada situação;

$\checkmark$ SIGs se tornaram uma vantagem competitiva no processo de tomada de decisões;

$\checkmark$ Apesar de parecer um programa de apresentação geográfica de dados, o segredo e a força do aplicativo reside no sistema de gerenciamento do banco de dados relacional;

$\checkmark$ SIG pode atuar independente de outros programas, mas se torna uma ferramenta mais poderosa quando utilizada interagindo com outras tecnologias; 
$\checkmark$ Toda a informação depende da qualidade dos dados utilizados de modo que um descuido em qualquer etapa do uso de um SIG pode trazer imprecisão e inutilidade para os resultados.

\subsection{Conceituação}

Existem várias definições para sistemas de informação geográfica. Na definição do trabalho coordenado por Quintanilha (2003), SIGs podem ser entendidos como aqueles que visam à coleta, armazenamento, recuperação, manipulação, análise e apresentação de informações sobre entes de expressão espacial. Fung; Kung; Barber (1995) acrescentam que a tecnologia de SIGs incorpora o gerenciamento de banco de dados, modelagem espacial e gerenciamento de atributos geográficos. A informação produzida por SIGs é organizada em camadas (layers) de mapas, relacionadas aos atributos do banco de dados.

A troca de informações define a ligação entre o SIG e o sistema do mundo real (SMR): o SIG atua no ambiente, é ferramenta de gestão e operação e permite o monitoramento de eventos analisados. Por outro lado, observa (lê) dados de diversos atributos, assimila novas definições e promove a mensuração e classificação da informação gerada, permitindo seu refinamento ou expandindo sua atuação, fechando o ciclo. (Figura 2) 


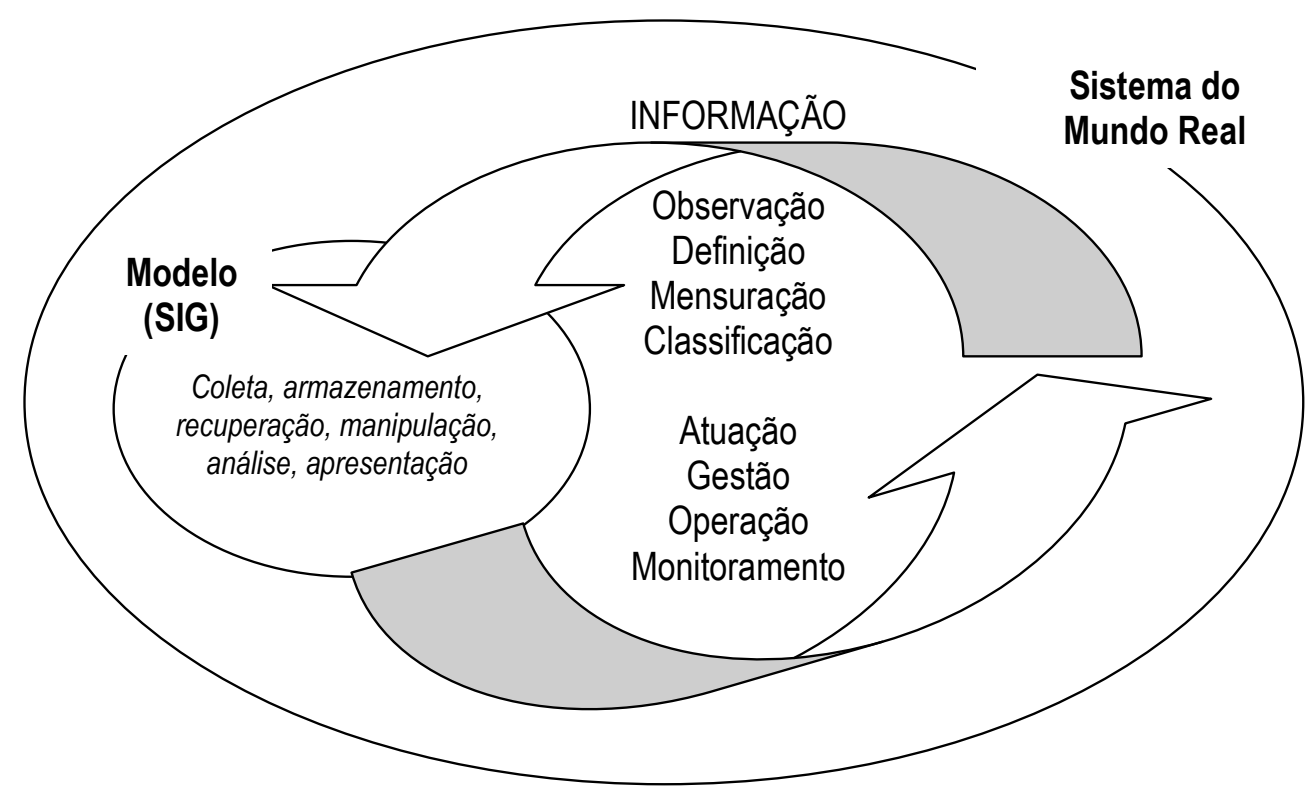

Figura 2: Ciclo de informação de um SIG FONTE: adaptado de Quintanilha (2003)

Weber (2001) afirma que SIGs permitem, através do recurso de mapeamento temático, a avaliação de variáveis qualitativas de atributos espaciais. No processo de estimativa de indicador de desempenho operacional de empreendimentos em real estate (escritórios comerciais, shopping centers, hotéis, etc.) o uso de SIG melhora a qualidade e a velocidade das informações sobre a localização do empreendimento. Já na modelagem probabilística, a utilização de SIGs redunda em melhoras na qualidade da análise de riscos envolvida.

Joerger; DeGloria; Noden (1999), após um estudo sobre o uso de um SIG aplicado à rede hoteleira instalada em Costa Rica concluíram que os hotéis que apresentavam os melhores indicadores de desempenho estavam localizados nas áreas que melhor atendiam a uma série de quesitos, verificados através do uso do SIG. Esses resultados mostraram uma forte correlação entre os atributos (das localizações) levantados e a rentabilidade dos hotéis instalados, para empreendimentos similares. 
Marcondes (2001) comenta que a adição da dimensão temporal em SIGs permite manusear a componente temporal em análises, para que se conheça o comportamento de atributos espaciais no tempo e no espaço. Por exemplo, o estudo do componente temporal permite visualizar o processo de adensamento de áreas urbanas e auxiliar no correto direcionamento de novos investimentos para regiões que apresentam alterações no perfil socioeconômico, conhecendo-se a velocidade das mudanças em curso em tais áreas.

\subsection{Componentes de um SIG}

Segundo Quintanilha (2003) um sistema de informação geográfica é composto por uma estrutura de dados e por seus elementos operacionais.

A estrutura de dados é um conjunto de valores sem significado próprio, mas formada por uma base de dados, agrupados segundo determinados critérios, que pode ser composta por:

- Base de dados gráficos, formada por informações sobre o desenho e seu modelo subjacente, podendo ser dividida em feições (pontos, linhas, polígonos), simbolismos ou anotações;

- Base de dados não-gráficos, com informações sobre os atributos dos dados gráficos, como atributos das feições (por exemplo, área de um lote e a área construída);

- Base de dados referenciados espacialmente, contendo informações sobre os entes, eventos e atributos (como dados cadastrais); 
- Índices Geográficos, formados por listas (cadastros de logradouros, setores fiscais, zoneamento, dicionários).

Elementos operacionais, diferente de dados, cumprem uma determinada função dentro do sistema de informação geográfica ao qual pertencem, podem ser classificados em:

[i] - Captura de Dados, que promove a entrada de dados e conversão, a edição de coordenadas, a geração e edição de topologia e a entrada e adição de atributos;

[ii] - Atualização e manutenção de dados torna possível a atualização e manutenção de dados gráficos e não-gráficos;

[iii] - Recuperação de dados espaciais (vetoriais, raster $^{5}$ ) e não espaciais (texto, atributo)

[iv] - Manipulação e análise, que permite uma vasta gama de aplicações, como reclassificações e agregações, operações geométricas (rotação, translação, remoção de distorções, etc.), mensuração (distâncias, comprimentos, perímetros, áreas, volumes, etc.), geração de buffers ${ }^{6}$ (pontos, linhas e áreas) sobreposição (overlay), conectividades, rotas e locação e análises estatísticas;

[v] - Apresentação de dados como mapas, tabelas e gráficos.

\footnotetext{
${ }^{5}$ Um modelo raster, também chamado matricial, define-se como um conjunto de posições ( pixels) em coordenadas (x,y). Já um modelo vetorial é baseado em elementos chamados primitivas (linha, círculo, polígono, arco, etc.), num sistema de coordenadas de duas ou três dimensões.

${ }^{6}$ Um buffer é o entorno de um ente gráfico, ou elemento definido pelo lugar geométrico que atende a um determinado critério, em relação a um ponto, linha ou área préexistente. Neste trabalho aplicado também no conceito de "zona de influência".
} 


\subsection{Escolha do software de sistema de informações geográficas}

Existem diversos programas computacionais de SIGs no mercado. No entanto, optou-se pela utilização do aplicativo ArcView GIS versão 3.2, que se mostrou possível pela facilidade de acesso e disponibilidade na Escola Politécnica da USP. Não obstante essa disponibilidade, procurouse identificar comparativamente as vantagens em sua utilização, concluindo-se, através de pesquisa comparativa de outros autores, que esse é um aplicativo que reúne todas as qualidades necessárias para a consecução do presente trabalho.

Cannon (1996) já ressaltava que o ArcView GIS apresentava excelente qualidade de trabalho, em sua versão 2.1 , indicando que era o aplicativo (entre os aplicativos utilizados à época) que mais se adequava ao uso em SIGs como processo de análise de dados geográficos, mesmo sendo o programa mais complexo e de difícil aprendizagem, provavelmente por evoluir de programas de computadores de grande porte (conhecidos como mainframes).

ArcView GIS, em seu manual Using ArcView GIS (1996), divide o desenvolvimento de um SIG basicamente em: [i] apresentação, onde trata desde a criação de mapas, até a produção de sua impressão; [ii] tratamento dos dados, onde inicia pela recuperação de atributos de dados e finaliza com operações com os dados; e [iii] a criação de dados, onde se discute a criação e edição de dados relacionados geograficamente. No entanto, a ordem de desenvolvimento de um SIG não segue essas linhas didáticas, criadas obedecendo a graus de dificuldade crescentes. O processo se inicia com o desenvolvimento de um plano de ação e segue ordem inversa da exposta acima, como será visto neste trabalho. 


\subsection{Processo de estruturação de um SIG}

No processo de estruturação de um SIG são três as análises mais utilizadas e para as quais, segundo Castle III et al (1998), existe um fluxo de informações que precisa ser tratado separadamente.:

[i] - Estruturação de um SIG para determinação do potencial de uso de um determinado local;

[ii] - Estruturação de um SIG para seleção do local mais adequado a determinado uso;

[iii] - Estruturação de um SIG para seleção do melhor investimento para determinado perfil de investidor.

Ampliando esses conceitos, a estruturação de um SIG tem como produto de saída a determinação do potencial de uso para uma região, através do reconhecimento dos indicadores de desempenho para uma zona de influência, processo este que será desenvolvido no estudo de caso.

Em todos os casos, pode-se identificar os componentes de um SIG: coleta, armazenamento, recuperação, análise e apresentação da informação. A identificação dos atributos de busca para a coleta, no entanto, diferem: enquanto em [i] o trabalho se desenvolve a partir dos atributos do local já determinado, em [ii] são os atributos do produto que se pretende implantar que definem os critérios de busca do melhor local. Em [iii] análises são desenvolvidas para escolha de locais disponíveis, a partir de critérios que definem o tipo de empreendimento e, portanto, pode ser considerado um desdobramento do caso [ii].

O estudo de atributos referenciados geograficamente (ou atributos espaciais), quando não se dispõe do terreno, pode-se iniciar a partir de uma determinada tipologia de empreendimento hoteleiro identificado com 
uma demanda não completamente atendida, ou mal atendida, na região do estudo.

Os atributos identificados através de análise da demanda potencial e análise da oferta competitiva instalada nas regiões do estudo servirão para definir as características desse empreendimento. Nesse nível, é importante que se conheçam as estratégias para captação da demanda e as condições de acesso a essas regiões.

Num segundo nível de detalhamento, a partir de regiões préselecionadas, o estudo se concentra em aprofundar o conhecimento acerca dos atributos espaciais. Nessa etapa, informações como as distâncias e a qualidade de acesso em relação a centros de negócios e de serviços, vias de acesso, pontos turísticos, aeroportos e rodovias têm maior relevância. O estudo permite a identificação, seleção e priorização dos terrenos que atendam aos requisitos estabelecidos no padrão de qualidade almejado para o empreendimento, inclusive com avaliação do valor do mesmo. Ireland; O’Connor (2002) argumentam que a modelagem através do uso de SIG, para avaliação do valor de propriedades e de terrenos tem utilidade para análises tanto de grandes regiões quanto de áreas isoladas, desde que a área esteja relacionada às condições de mercado.

O estudo espacial para a adequação do produto tem uma estrutura semelhante ao estudo para definição do local, ou seja, apresenta as mesmas etapas - estudo dos atributos considerando a macro-região e, num segundo nível, o estudo mais detalhado em relação ao local de implantação. Apesar dos resultados alcançados não tratarem da escolha do terreno, objetivam a correta avaliação do potencial de desempenho operacional de novos empreendimentos. 
No caso da existência do terreno o estudo assume uma nova direção, pois o que se pretende é estudar tanto as relações entre os diversos atributos geográficos para analisar a melhor vocação do terreno quanto a implantação do empreendimento hoteleiro em si para definição da melhor tipologia de hotel que se adeque ao local.

O estudo de caso pretende discutir a estruturação de um SIG para uma região alvo tendo como objetivo o reconhecimento dos indicadores de desempenho dos hotéis dessa região. 


\title{
3. EMPREENDIMENTOS DE TIPOLOGIA DE HOTÉIS
}

\author{
Hotéis são empreendimentos de base imobiliária, de longo \\ horizonte de maturação e elevada rigidez estrutural, que diferem de \\ outros empreendimentos pela intensa participação de serviços e \\ equipamentos na composição de seus custos operacionais e pela \\ formatação das receitas, formada primariamente por contratos diários \\ (pernoites de hotel) e pela sazonalidade anual. Esse capítulo discute \\ algumas características de hotéis voltados a viajantes de negócios para \\ sustentar a aplicação de um SIG.
}

\subsection{Classificação dos hotéis}

Existem várias formas de se definir hotéis: de acordo com o padrão de serviços e instalações7; em função de sua localização (hotéis de praia, de cidade, de campo, de aeroporto); de acordo com o porte (de grandes redes a pequenos hotéis); quando à propriedade (sociedade aberta, sociedade limitada); quanto às cadeias de hotéis (nacionais, internacionais ou independentes); ou conforme o propósito a que se destina (hóspedes em viagem de lazer ou hóspedes em viagens de negócios). Saab; Daemon (2001), num estudo sobre o segmento hoteleiro

${ }^{7}$ A EMBRATUR, através da publicação da Deliberação Normativa n 429 de 23 de abril de 2002, instituiu o novo Sistema Oficial de Classificação dos Meios de Hospedagem e colocou a cargo do IBH Nacional, mantido pela ABIH, o gerenciamento operacional do processo de classificação oficial dos meios de hospedagem. Os hotéis são classificados conforme o padrão de suas instalações, quanto aos níveis de conforto, serviços oferecidos e preços praticados, a partir de uma matriz de classificação, disponível em $<$ http://www.abih.com.br/principal/classificacao/regulamento_sistema.php>. Os hotéis são classificados em Super Luxo, Luxo, Superior, Turístico, Econômico e Simples. O Guia Quatro Rodas (Editora Abril) promove uma classificação que considera os empreendimentos em faixas de mercado de acordo com os padrões de serviços e instalações oferecidos. Já a Smith Travel Research (STR), dos EUA, empresa que lidera a coleta e análise de dados de desempenho do setor hoteleiro em seu país, classifica os hotéis em patamares de preço (price points) a partir da atratividade relativa do hotel em sua cidade ou região, em top, upscale, midmarket, economy e budget. (Asmussen \& Associados) 
no Brasil, ampliam o conceito de hotéis de negócio, até pouco tempo assim classificados os hotéis situados nos grandes centros, hoje também considerados os que se situam nas proximidades dos aeroportos (por outro critério classificados como hotéis de aeroporto).

No estudo de caso, das diferentes classificações apresentadas, adotaremos o conceito desenvolvido pela STR, por considerar que o critério de patamares de preço é a forma de classificar que mais se aproxima do julgamento que o mercado faz do conjunto de serviços oferecido pelos hotéis.

\subsection{Empreendimentos voltados a viajantes a negócios}

Hotéis de negócio estão cada vez mais complexos, com redes de comunicação que incluem computador com acesso à internet, fax e demais serviços de escritório. Nesses hotéis se prioriza a funcionalidade para atender às exigências desse segmento de mercado (pessoas em viagem a trabalho), que inclui participantes de eventos como feiras, convenções, exposições, treinamento ou congressos.

O motivo principal da segmentação de hotéis é a maximização do desempenho associado aos atributos do segmento alvo, que se traduza em valor para o empreendimento. No entanto, Araujo (2001) indica que um hotel não pode adotar uma estratégia com foco único, em virtude da vasta gama de serviços ofertados a um mercado igualmente vasto. A segmentação de hotéis é o resultado de novas estratégias de aprimoramento do desempenho operacional mas, para que se reduza o risco do negócio e a dependência das variações provocadas pela sazonalidade da demanda segmentada, um hotel de negócios realiza esforços de venda em vários sub-segmentos, mesmo priorizando determinado sub-segmento dentro de seu foco primário de atuação. 
Ayres; Daemon; Fernandes (1998) constataram que o turismo resultante de viagens motivadas por interesses comerciais, negócios e convenções tem sido o que mais tem crescido no Brasil, apresentando crescimento de 13\% entre 1991 e 1995, enquanto que o turismo de lazer apresentou redução de 10\% no mesmo período.

Para entender os empreendimentos voltados a viajantes de negócios é importante conhecer o perfil de seus usuários. As necessidades dos hóspedes podem ser identificadas a partir da análise de características específicas do sub-segmento ao qual pertencem, como:

- o propósito da visita e duração da estadia;

- o tempo de permanência média, o fator de dupla ocupação, a composição por faixa etária e a relação de hóspedes homens/mulheres;

- os períodos mais comumente utilizados e a frequência de hospedagem;

- o grau de sensibilidade à diária e o valor de gastos médios; e

- os equipamentos do hotel solicitados.

Lawson (1999) apresenta características dos segmentos de mercado que indicam certos padrões de comportamento, para o mercado norteamericano, em regiões que atingiram a maturidade na relação da oferta e demanda.

O estudo pode servir como um indicativo do comportamento e de tendências para mercados não maduros. No entanto seus resultados devem ser vistos com ressalvas para o mercado brasileiro, que carece de pesquisas mais amplas sobre o assunto. 


\subsubsection{Viajantes individuais}

Normalmente identificados como representantes de vendas, executivos, consultores, representantes do poder público, os viajantes individuais, em média, costumam utilizar menos pernoites de hotel do que a média, com ocupação simples (exatamente por se tratar de viajantes individuais), na maioria dos casos homens que se hospedam em dias úteis, de comportamento não-sazonal e frequência elevada. Nesse grupo encaixam-se desde viajantes com baixa quanto alta sensibilidade às tarifas. Esse tipo de viajante procura se hospedar em hotéis com suporte para negócios, em regiões próximas de seu destino ou em aeroportos, com salas de espera ${ }^{8}$ e quartos equipados com ambiente de trabalho.

\subsubsection{Viajantes em grupo}

Viajantes em grupo se dividem de acordo com o motivo da viagem, com características e necessidades específicas:

\section{[i] - Seminários profissionais, associações, convenções, ou conferências}

Seus visitantes costumam utilizar-se do número de pernoites necessárias para participarem de seu evento, com alta ocupação simples, formados em sua maioria de homens, hospedando-se em hotéis em dias úteis, com eventos normalmente acontecendo na baixa estação e de frequência periódica/regular, de baixa a moderada sensibilidade à tarifa e gastos moderados em relação à média dos viajantes à negócios. Costumam se hospedar em hotéis de preferência no próprio local do evento, portanto com grandes salas de conferência/reunião, com suporte para negócios, quartos melhores do que a média, salas de espera e de trabalho.

\footnotetext{
${ }^{8}$ Salas de espera em hotéis são conhecidas como lounge, entre os profissionais do setor.
} 


\section{[ii] - Programas de treinamento de nível gerencial}

Esses profissionais hospedam-se durante o tempo dos programas de treinamento do qual participam, com ocupação simples, com número de homens e mulheres equilibrado de acordo com o perfil da empresa, em dias úteis na baixa estação, como parte de um programa em progresso. Apresentam alta sensibilidade à tarifa e gastos moderados. Costuma-se utilizar hotéis intermediários com grandes salas de convenção, suporte para negócios, quartos simples, salas de espera e de trabalho.

\section{[iii] - Programas de incentivo e convenções empresariais}

São grupos que costumam utilizar pacotes normalmente de uma semana de duração, com elevado índice de ocupação dupla, ocorrendo majoritariamente na meia estação, de frequência periódica, apresentando baixa sensibilidade à tarifa e gastos moderados. São utilizados hotéis de alto padrão em lugares atraentes com salas de convenção.

\subsubsection{Viajante com contrato empresarial}

Normalmente são tripulantes ou hóspedes regulares que utilizam hoteis por curtos períodos, com média ocupação dupla, apresentando necessidades específicas e alta frequência de uso, portanto com tarifas especiais e atendimento personalizado. Esse viajante procura normalmente hotéis intermediários onde a localização é fundamental, como hotéis próximos a aeroportos, hospitais, instituições, universidades e centros de pesquisa.

\subsubsection{Viajante em estadia de longa permanência}

Empregados em mudança ou profissionais desenvolvendo trabalho de longa duração utilizam os serviços de hotel por várias semanas, apresentam frequência não-sazonal, média sensibilidade à tarifa e gastos 
moderados. Hotéis com UHs do tipo suítes ${ }^{9}$ ou flats são mais procurados, com áreas separadas para o desenvolvimento do trabalho.

\subsection{Indicadores de desempenho em hotéis}

Dos vários índices utilizados para medir o desempenho operacional de hotéis a ocupação e a diária média são os mais importantes para esse estudo, pois estão vinculados à receita primária do hotel e são parâmetros para o cálculo de outras receitas e despesas. Outros parâmetros que não serão objeto de estudo do presente trabalho são o total de hóspedes por apartamento, serviços de alimentação e bebidas, (A\&B), a tarifa média por serviço de $A \& B$, outras receitas, as contas fixas e variáveis, e o fundo para reposição para ativos ${ }^{10}$ (FRA).

$\mathrm{Na}$ análise dos indicadores de desempenho de hotéis é importante definir grupos homogêneos para estudo (porte e região da cidade, tipologia de hotel, características da demanda), pois os resultados, quando considerados conjuntamente para diversos grupos, podem apresentar grandes variações e levar ao erro uma análise de uma tipologia de hotel em determinada região. Enz; Canina; Walsh (2001) concluem em sua pesquisa que "faz sentido adicionar medidas de desempenho à análise para melhorar o entendimento dos fatores de comparação. Tais adições (indicadores de desempenho) permitem a empreendedores e investidores conduzir uma análise mais efetiva e melhora a tomada de decisões.” A seleção da cidade de referência (proxy de comparação), região (que defina um cluster $^{11}$ de mercado) e segmento de mercado é necessária para que se evite distorções nos resultados e melhore a informação no processo de decisório.

9 Suítes são UHs com apoio de cozinha, como usualmente encontrado em flats.

10 O Fundo para reposição de ativos é um fundo formado a partir do resultado operacional para, através de atualizações e adequações funcionais, garantir o mesmo padrão de desempenho, ao longo do ciclo operacional

${ }_{11}$ Clusters são conjuntos de elementos delimitados por um determinado critério, como localização, tempo, preço, etc. 


\subsubsection{Diária Média}

Diária Média é a tarifa por dia cobrada por apartamento ocupado ou o preço médio cobrado do conjunto de todos os apartamentos ocupados num dado período. A diária média é utilizada para análise da tendência dos preços de equilíbrio de mercado e estudo do potencial de geração de receita.

O valor das diárias varia conforme a categoria do hotel, mas, em geral, os hotéis operam sistemas de tarifas diferenciadas e sistemas de descontos, para conseguir maiores ocupações.

Segundo Luz (1999), os efeitos dos descontos (nas diárias) sobre os níveis de ocupação dependem basicamente do segmento de mercado em que os hotéis atuam. Os descontos nas tarifas de hotéis que operam com demanda por viagens de negócios, por exemplo, podem não gerar efeitos importantes sobre a demanda, pois essas viagens são geradas por necessidades profissionais, e pouco sensíveis a preço.

Existem algumas categorias tradicionais de tarifação, a saber:

- tarifas publicadas, aquelas constantes em guias, roteiros e publicações turísticas, $15 \%$ a $20 \%$ mais caras que as tarifas balcão;

- as tarifas balcão, aplicadas a hóspedes sem negociação prévia ou reserva;

- as tarifas corporate, negociadas para empresas em troca de um número mínimo de hospedagem, em média 30\% inferiores à tarifa balcão;

- as tarifas de pacotes turísticos de agências de viagens, com reduções maiores que os $30 \%$ alcançados pelas tarifas corporate. 
As tarifas corporate se prestam como proxy $^{12}$ da diária média por representar a média do comportamento do mercado, sendo utilizadas

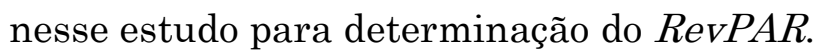

A maioria dos hotéis considera elegível a tarifas corporate as reservas para mais de dez UHs numa única vez, e fornecem essa informação sem reservas, quando solicitados.

\subsubsection{Ocupação}

A ocupação representa o número de apartamentos ocupados frente ao total de apartamentos disponíveis, e é expressa em termos porcentuais. São considerados todos os apartamentos, inclusive os cedidos como cortesia, pois apesar de não incrementar as receitas apresentam custos associados à sua utilização. É uma medida que avalia a eficiência no giro do estoque (medido em quartos disponíveis por período considerado).

Além de ser medida direta de desempenho, a ocupação é utilizada como referência no cálculo do consumo de insumos relacionados à permanência dos hóspedes, como água, energia, limpeza de apartamentos, alimentos e itens de higiene pessoal dos apartamentos, entre outros, portanto, também relacionada a parâmetros de custos variáveis.

O cálculo da ocupação é diário, indicando a sazonalidade da demanda e a ociosidade do hotel. Isso ocorre devido à rigidez desse tipo de empreendimento, pois não há como ajustar a oferta de apartamentos à demanda. No segmento de hotéis de negócio, pela curta permanência dos viajantes, ocorre uma maior ocupação durante a semana (nos dias úteis) e menor ocupação nos fins de semana.

12 Proxy é uma palavra, consagrada pelo uso, utilizada para indicar um padrão que possa ser utilizado para representar o padrão não disponível, que apresente boa aproximação com os resultados. 
Diversos estudos objetivam arbitrar a ocupação com menor margem de erro possível. Num estudo empregando técnica de redes neurais para estimar a ocupação em hotéis de Hong Kong, Law (1998) concluiu que a ocupação dos hotéis variava de acordo com os seguintes parâmetros: número de turistas em Hong Kong, tempo médio de permanência, número de hotéis, número de apartamentos por hotel, índice de ocupação dupla e porcentagem de hóspedes em hotel em relação a hóspedes acomodados em residências.

Já num estudo de longo prazo para se verificar o impacto do comportamento da economia sobre o comportamento cíclico da indústria hoteleira americana, num período de 25 anos desde 1969, Wheaton; Rossoff (1997) constataram que a demanda por diárias de hotel apresentou alta correlação com o Produto Interno Bruto norte-americano. No entanto, o volume de novos investimentos na implantação e operação de hotéis apresentaram baixa correlação com flutuações econômicas e baixa variabilidade. Podemos entender que muito se deve à característica desse investimento de se desenvolver dentro de um horizonte de longa duração a despeito de crises no curto prazo.

Segundo Rushmore (1992), quando se projeta o índice de ocupação para o horizonte de operação do hotel não se deve assumir um crescimento contínuo e desconsiderar a possibilidade de crescimento da oferta competitiva com a instalação de novos e mais modernos hotéis, mas deve-se considerar o conceito de ocupação estabilizada. Projeções que pretendam replicar os ciclos de real estate ocorridos e outros eventos, como o crescimento da oferta, não têm sustentação teórica e são de pouca valia na estimativa do comportamento futuro. 
Entretanto, é necessária uma abordagem do fluxo do RODi13 que considere o período de estabilização ${ }^{14}$ para ocupação e diárias, no início do ciclo operacional.

O planejamento do produto hoteleiro, quando faz sua projeção para a ocupação no horizonte de projeto deve considerar as tendências para a demanda na região de inserção do hotel e a sua composição, e os riscos de crescimento da oferta competitiva. No entanto, durante o ciclo operacional considera-se uma ocupação estabilizada, calculada não pelo pico ou pela depressão dos ciclos de real estate, o que denotaria um desequilíbrio entre a oferta e a demanda, mas pelo ponto de equilíbrio do mercado para projeções de longo horizonte de maturação, em que se encaixam essa tipologia de produto.

Admitindo crescimento da demanda linear no tempo, o ingresso de um novo hotel provocará uma descontinuidade no número de pernoites, em novos índices de ocupação, resultando em uma redistribuição da demanda por toda a oferta competitiva.

${ }^{13}$ RODi, Resultado Operacional Disponível, representa os recursos livres derivados para o investidor.

${ }^{14} \mathrm{O}$ período de estabilização do ciclo operacional de hotéis é o período, geralmente de duração entre 1 a 4 anos, até que o hotel atinja uma configuração de estabilidade de suas receitas, com o aumento de sua inserção de mercado e evolução das tarifas, até o patamar para o qual foi planejado. 


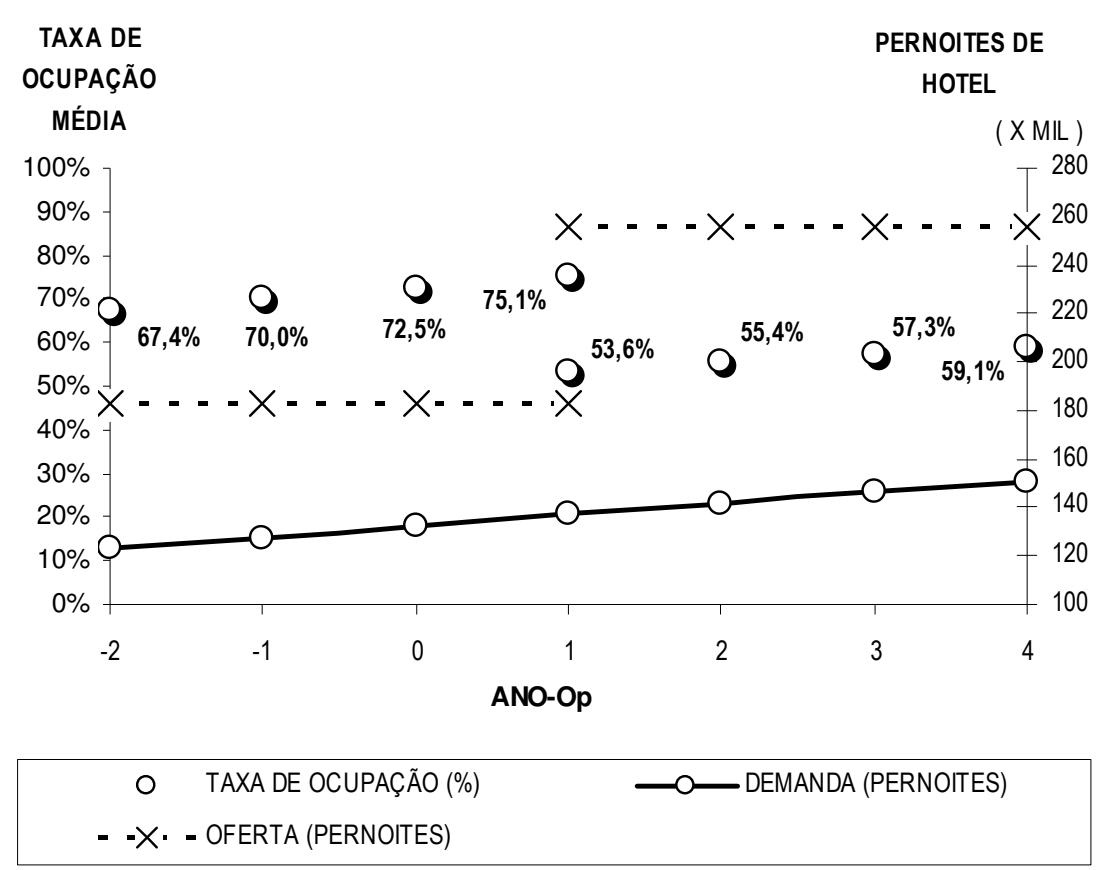

Figura 3: Exemplo do início de operações de um novo hotel

No exemplo da Figura acima, a demanda total cresce continuamente do [ano -2] ao [ano 4] mas, no momento da entrada de um novo hotel no [ano 1], a oferta total do mercado, de 500 UH's (182.500 pernoites) passa para 700 UH's (255.500 pernoites) provocando uma queda na ocupação média do conjunto competitivo, de $75,1 \%$ para $53,6 \%$.

A ocupação é o indicador de maior dificuldade de obtenção e também a mais sujeita a viés de mercado. Os hotéis consideram parte do segredo do negócio e dificilmente disponibilizam essa informação.

No estudo de caso a pesquisa realizada procurou confrontar as informações de ocupação consultando uma segunda opinião, sem distorção pela comunicação entre os participantes da pesquisa. 


\subsection{3. Índice de penetração de mercado}

Índice de penetração de mercado representa o desempenho relativo de cada empreendimento em relação ao mercado medido pela ocupação média do empreendimento em relação à ocupação média do conjunto competitivo.

A ocupação do mercado (no exemplo, $75 \%$ e na sequência, 54\%) também é conhecida como fair share da demanda total do conjunto competitivo. Fatores que definem a capacidade de penetração de mercado, que serão abordados no capítulo 4 , e a fase de estabilização de sua inserção no mercado justificam as diferenças encontradas entre os empreendimentos de mesmo conjunto competitivo, para a mesma zona de influência.

Tabela 1:ANO-Op [1], configuração sem novo hotel

\begin{tabular}{c|c|c|c|c|c|c|c|c} 
& $\begin{array}{c}\text { TOT } \\
\text { UHs }\end{array}$ & $\begin{array}{c}\text { OFERTA DE } \\
\text { PERNOITES } \%\end{array}$ & \multicolumn{2}{c|}{$\begin{array}{c}\text { UHs } \\
\text { VENDIDAS } \%\end{array}$} & $\begin{array}{c}\text { TAXA DE } \\
\text { OCUPAÇÃO }\end{array}$ & $\begin{array}{c}\text { FAIR } \\
\text { SHARE }\end{array}$ & $\begin{array}{c}\text { ÍNDICE DE } \\
\text { PENETRAÇÃO }\end{array}$ \\
\hline Hotel 1 & 80 & 29.200 & $16 \%$ & 25.456 & $19 \%$ & $87 \%$ & 21.920 & 1,16 \\
\hline Hotel 2 & 100 & 36.500 & $20 \%$ & 27.010 & $20 \%$ & $74 \%$ & 27.400 & 0,99 \\
\hline Hotel 3 & 120 & 43.800 & $24 \%$ & 34.164 & $25 \%$ & $78 \%$ & 32.880 & 1,04 \\
\hline Hotel 4 & 200 & 73.000 & $40 \%$ & 50.370 & $37 \%$ & $69 \%$ & 54.800 & 0,92 \\
\hline Mercado & 500 & 182.500 & $100 \%$ & 137.000 & $100 \%$ & $75 \%$ & 137.000 & 1,00 \\
\hline
\end{tabular}

No exemplo anterior, considerando a situação do hotel em início de operação nesse mercado (hotel [5]), e que no primeiro ano de operação atinja uma ocupação de $45 \%$, temos: 
Tabela 2: ANO-Op [1], configuração com novo hotel

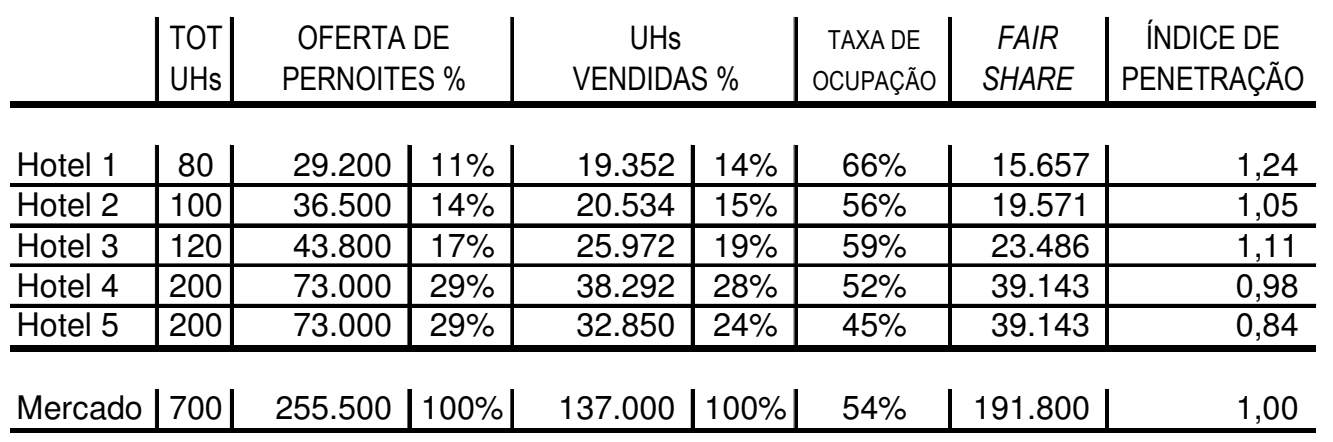

O índice de penetração alcançado para o novo hotel [5] no primeiro ano de operação é de 0,84 , mas sua participação no mercado leva os demais hotéis a novos índices de penetração, superiores aos antigos (na fase de estabilização das receitas do hotel estreante). No entanto, obtemse ocupações menores - refletindo a divisão da mesma demanda por um conjunto competitivo maior.

Utilizado como um índice de eficácia em captar hóspedes em relação ao seu conjunto competitivo, esse índice não pode ser utilizado como indicador da receita por representar apenas a eficácia na captação de hóspedes.

\subsection{4. $\operatorname{RevPAR}$}

RevPAR vem do ingês Revenue Per Available Room, que pode ser definido como a receita total de hospedagem pelo total de apartamentos disponíveis ${ }^{15}$ pelo período considerado. $\operatorname{RevPAR}$ permite avaliar e comparar o desempenho operacional de hotéis de diferentes segmentos, localizações, mercados ou qualidade de serviços.

${ }^{15} \mathrm{O} \operatorname{Rev} P A R$ pode ser calculado multiplicando-se a diária média pelo índice de ocupação, o que é equivalente a calcular o $\operatorname{RevPAR}$ pela divisão da receita total do hotel que diz respeito a hospedagem pelo total de apartamentos disponíveis. 
RevPAR pode ser utilizado na construção das faixas de flutuação do desempenho operacional do hotel. Segundo Ismail; Dalbor; Mills (2002), é importante analisar o risco de investimento, por tipo de hotel e por localização, quando avaliando oportunidades de negócio, para determinar que segmentos da indústria são mais voláteis e, portanto, de maior risco, através da utilização do $\operatorname{RevPAR}$, como indicador do comportamento (e variabilidade) do resultado operacional do hotel.

RevPAR tem sido usado como uma referência para a análise do desempenho da indústria hoteleira. Uma das razões para isso é que RevPAR aborda a Diária Média e a Ocupação ao mesmo tempo.

Para Torto Wheaton Research (1999), é fundamental para investidores de hotéis a utilização de previsões do crescimento do RevPAR, tanto no estudo da qualidade de investimentos, quanto no estudo do desempenho de hotéis, considerando-se a região de influência do hotel.

Segundo Gallagher; Mansour (2000), RevPAR captura a interação entre a Diária Média e a Ocupação em diferentes fases do ciclo de real estate para a indústria hoteleira, revelando a dinâmica da oferta e da demanda, do setor hoteleiro, em um único índice.

RevPAR é um índicador de carácter mercadológico, que procura caracterizar a receita proveniente das Uhs que o hotel vem alcançando por unidades disponíveis, independente dos custos incorridos pelo hotel e das receitas provenientes de outras fontes de renda como espaços destinados a eventos, restaurantes e demais serviços não incluídos no valor da diária. 
Brown; Dev (1999) comentam que existem duas limitações ao uso de $\operatorname{RevPAR}$ como indicador de produtividade: ela não inclui a receita proveniente de serviços de alimentação e bebidas, e não inclui a receita de serviços especiais como a de spas e de concierge ${ }^{16}$. No entanto, Jacobs (1997) comenta que o relacionamento entre $\operatorname{RevPAR}$ e o resultado operacional disponível deve ser consistente, para poder ser utilizado como indicador do desempenho do hotel.

Certos fatores que influem na análise do $\operatorname{RevPAR}$ são de difícil análise: a correta determinação da receita por apartamento, levando em conta como um hotel contabiliza certos serviços, cobrando-os diretamente ou incluindo-os na diária; diárias para grupos e taxas de cancelamento, que provocam alteração na diária média ou nas receitas do hotel; a determinação da região de inserção do hotel - o conhecimento do $\operatorname{RevPAR}$ da oferta competitiva depende da delimitação da região dentro da qual estará contida a oferta competitiva.

\subsection{Aplicação do processo de estruturação de um SIG no suporte ao planejamento de hotéis de negócios}

A estrutura de um sistema de informação geográfica aplicada a hotéis pode ser entendida pelo diagrama de fluxo dos eventos operacionais, onde se encaixam as atividades realizadas, conforme vemos na Figura 4, empregando o ciclo de informacão de um SIG visto na Figura 2 anterior.

\footnotetext{
16 concierge não tem uma tradução que o expresse corretamente: serviços oferecidos pelo hotel para atender às solicitações dos hóspedes, serviços esses não diretamente vinculados à operação do hotel, como compra de ingressos, reservas em restaurantes, etc.
} 


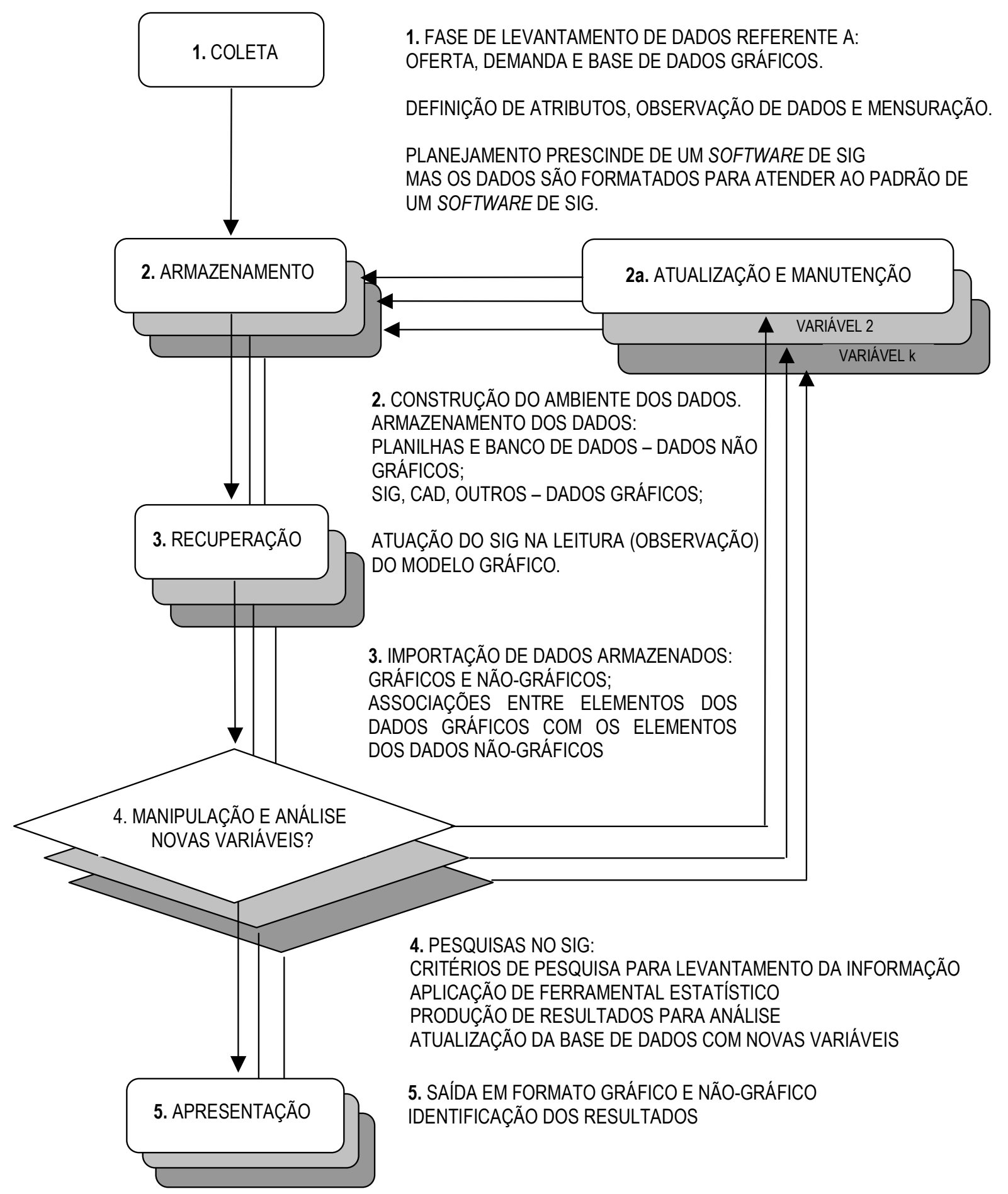

Figura 4: Diagrama de fluxo dos eventos operacionais de um SIG para o planejamento de hotéis de negócios 
$\mathrm{Na}$ fase indicada na figura como [1. COLETA] - procura-se reunir o conjunto de dados que serão utilizados pelo SIG a partir do reconhecimento do mercado.

Esse reconhecimento se dá através da observação do Sistema do Mundo Real (SMR) de modo a identificar as características que serão utilizadas nas pesquisas do banco de dados.

Entre essas características estão o levantamento de dados relacionados à oferta, como a localização pelo endereçamento ou pelas coordenadas, para associação com o banco de dados gráfico; os indicadores de desempenho que serão utilizados nas análise, como a ocupação e a diária média; e a data de início de operações, para a caracterização do estágio em que se encontra o empreendimento no ciclo operacional.

Já no levantamento de dados referente ao segmento de demanda, pelo estudo indireto - do reconhecimento de elementos atratores de demanda, consideram-se edifícios de escritórios comerciais com a sua localização, o padrão do empreendimento, o perfil da empresa que procura esse edifício (quanto à geração de contratos de hospedagem na região) e o tamanho, em área ou em número de funcionários; e o levantamento de centros de eventos em tamanho e ou em fluxo de pessoas.

Os entes que possam exercer influência sobre a escolha do hotel pelo interesse gerado nos visitantes da região são considerados e seus atributos de localização e capacidade de sediar eventos mensurados. São exemplos os centros culturais, de lazer e de compras;

Por último, dados referentes a facilidade de acesso ao local, existência de barreiras físicas ou geográficas, e a proximidade de aeroportos e de outros meios de transporte são consideradas por 
apresentar sua parcela de contribuição na decisão de da escolha do hotel para hospedagem.

$\mathrm{Na}$ fase indicada como [2. ARMAZENAMENTO] - os dados capturados são padronizados de modo a permitir atualizações e manutenções dos mesmos quanto ao empreendimento (no caso de alterações de atributos do mesmo) e ao ambiente (alterações na oferta competitiva, na demanda, em atrações, na facilidade de acesso, etc.);

Os dados não-gráficos coletados são armazenados em planilhas e em banco de dados e preparados para serem referenciados espacialmente. Já os dados gráficos são armazenados em um ambiente de SIG ou em outros aplicativos como um ambiente CAD.

$\mathrm{Na}$ fase indicada como [3. RECUPERAÇÃO], os dados espaciais e não-espaciais são acessados (recuperados) para o desenvolvimento de pesquisa. Essa fase ocorre de modo a permitir a construção de mapas e a consolidação de informações sobre o mercado de hotéis para a região através da utilização da base gráfica de suporte ao modelo. Os atributos dos dados não-gráficos são referenciados espacialmente e são feitas associações entre layers que representem o relacionamento entre esses dados.

$\mathrm{Na}$ fase indicada como [4. MANIPULAÇÃO E ANÁLISE], são efetuadas operações com os elementos coletados de modo a se identificar padrões de comportamento e flutuações das variáveis do cenário associadas à localização.

Nessa fase utilizam-se ferramentas de pesquisa para que, através do estabelecimento de critérios para operações entre layers, seja possível identificar regiões ou empreendimentos que atendam a esses critérios. A 
partir dos resultados encontrados, pode-se inferir as causas e identificar os efeitos do comportamento dos indicadores de desempenho dos hotéis.

Novas variáveis podem ser acrescentadas ao longo do fluxograma de eventos, como novos empreendimentos instalados na região, uma nova política que interfira no deslocamento, e o SIG permite uma resposta rápida frente a essas mudanças.

$\mathrm{Na}$ fase indicada como [5. APRESENTAÇÃO], os resultados da pesquisa são destacados através de operações do SIG que permitam ao planejador identificar, na forma de mapas, gráficos e resultados numéricos, a posição do hotel em relação à oferta competitiva pela relação encontrada entre atributos de desempenho (como índice de penetração de mercado e $\operatorname{Rev} P A R$ ) e pela relação de sua localização aos polos de atração de demanda. Aqui, parte das operações do SIG são direcionadas para uma planilha eletrônica de modo a facilitar a manipulação dos dados encontrados. 


\section{APRESENTAÇÃO DO CASO DE SUPORTE À PESQUISA}

O desenvolvimento do estudo sob a perspectiva do caso possibilita esclarecer a estruturação de um SIG para empreendimentos hoteleiros e consolidar os conceitos vistos até aqui.

Um caso prático permite explorar uma situação particular e ao mesmo tempo estendê-la a outras aplicações, à medida em que se avança na sua estruturação.

Portanto, o objetivo é discutir a estruturação de um SIG para empreendimentos hoteleiros voltados a viajantes de negócios, com o objetivo de reconhecer o comportamento da oferta competitiva mediante a estruturação de um SIG. É melhor caracterizada pelo caminho percorrido com uma aplicação prática, no estudo para uma região na cidade de São Paulo.

Os hotéis foram agrupados de forma a se conseguir grupos de características uniformes que possam ter seu comportamento em relação ao mercado analisado em conjunto. Os grupos foram definidos segundo o conceito desenvolvido pela STR, adotando-se o conceito de patamares de preço, por ser um critério de classificação que privilegia o julgamento pelo mercado para uma região ou cidade.

Durante as fases de coleta, manipulação e recuperação de informações, vistas no item 3.4 ocorre a construção e formação do banco de dados relacional, ou seja, a formação do conjunto de dados gráficos e não-gráficos relacionados entre si de forma que seja possível visualizá-los no espaço. 


\subsection{Construção da base de dados relacional}

A construção do banco de dados relacional para a utilização de SIG começa com a identificação das necessidades do planejador e da disponibilidade de recursos do ambiente do SIG, na fase de COLETA de dados.

Muitas empresas fornecem dados espaciais sobre os quais será criado o banco de dados relacional. Portanto, é necessário checar:

[i] - a disponibilidade de dados espaciais (mapas, cartas, plantas) em formato digital da região do estudo;

[ii] - a qualidade dos dados que se deseja georeferenciar: é importante que tenham atributos espaciais como endereçamento, CEP, coordenadas $(\mathrm{x}, \mathrm{y})$ no padrão utilizado pela base de dados espaciais;

[iii]-a possibilidade de importar dados de outro sistema ou formato.

Para o estudo de caso o banco de dados espaciais foi disponibilizado para esta pesquisa um mapeamento de atributos de feições (ruas, avenidas, distritos) para a Cidade de São Paulo17.

O processo de criação de dados com as feições e seus atributos é sustentado por uma planilha, na fase de ARMAZENAMENTO, que permita sua exportação para o ambiente do software de SIG.

$\mathrm{Na}$ planilha de dados todas as feições são referenciadas espacialmente, através do endereçamento segundo o padrão utilizado pela base de dados espaciais de São Paulo.

17 Asmussen \& Associados. 
A base de dados relacional para estruturação do SIG para hotéis de negócios começa pelo estudo da região alvo, durante a fase de RECUPERAÇÃO dos dados armazenados.

\subsection{Delimitação de uma região de estudo}

A região de estudo é caracterizada pelo conjunto competitivo de hotéis de uma dada categoria de modo a se alcançar um padrão homogêneo nos atributos dos hotéis e estudar as diferenças, em termos de indicadores de desempenho, como conseqüência dos deslocamentos entre destinos e hotéis na região do estudo.

No caso específico de um hotel, pode-se verificar sua zona de influência definida como a região, em tempo de deslocamento, que contém os destinos dos hóspedes e que é determinada por um conjunto de atributos. Segundo Lawson (1999), "a localização de um hotel deve ser apropriada para servir às necessidades do mercado alvo e deve atender a características específicas."

Pode-se relacionar alguns fatores críticos na definição da localização e na definição do padrão do hotel: [i] - fatores econômicos e de conveniência, em termos de tempo de deslocamento e facilidade de acesso, quanto maior a proximidade com relação ao local de finalidade da viagem, por exemplo, de centros comerciais ou escritórios, de locais turísticos, centros de compras; [ii] - qualidade da localização em relação à vizinhança; [iii] - disponibilidade de espaço para avaliação das alternativas de projeto; [iv] - restrições, zoneamento e exigências de órgãos públicos; [v] - custos relacionados à aquisição do terreno e custos relativos ao desenvolvimento do empreendimento. 
Esses fatores críticos permitem delimitar a zona de influência através de polígonos baseados em tempos de viagem, no deslocamento entre o hotel e o local de interesse do hóspede. Além dos tempos de viagem, Salvaneshi, 1996 apud Gonçalves; Mendes, 2002, considera que essas áreas devem ser delimitadas considerando-se a oferta competitiva existente, barreiras físicas e facilidade de acesso ao local.

Lawson (1999), acrescenta que a distância (medida em tempo de deslocamento) é usualmente crítica na determinação da zona de influência do hotel e que deve ser estabelecido o grau de tolerância conveniente em termos de duração do trânsito entre o destino final e o empreendimento. Para diferentes propósitos de deslocamentos as pessoas apresentam maior ou menor tolerância, conforme indicado na Figura 5, num estudo realizado para o mercado de hotéis dos EUA em 1999. Esses resultados podem variar conforme a cidade considerada ou conforme o perfil do público alvo, pois apresentam características específicas - como porte da cidade, estrutura viária, tipo de urbanização, etc. e conforme o hóspede -nível sócio-econômico, formação cultural, frequência de hospedagem, etc.

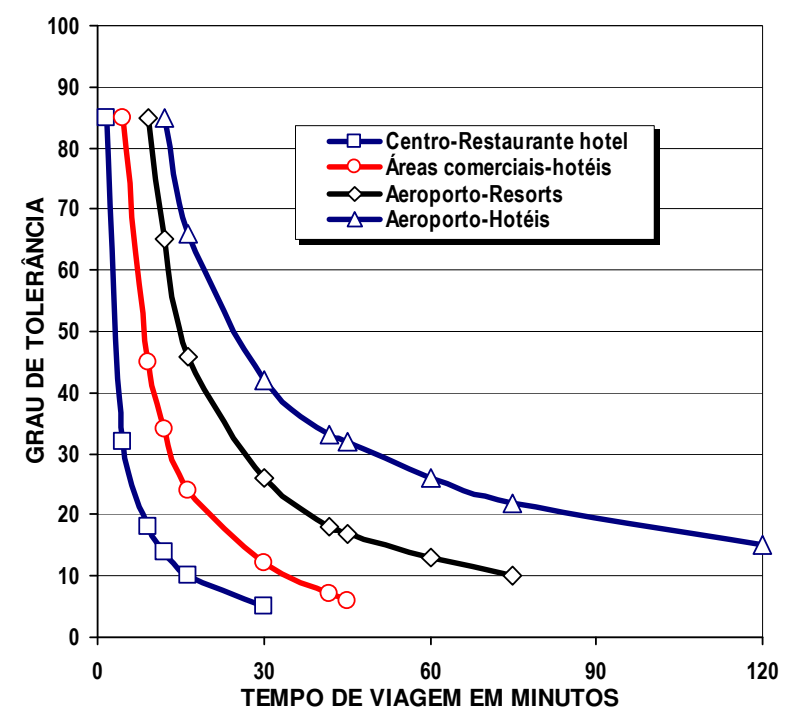

Figura 5: Graus de tolerância em diferentes origens e destinos Fonte: Lawnson, 1999 
Normalmente viajantes são menos propensos a deslocamentos de grande duração, entre o hotel e áreas comerciais e de serviços, tornandose mais restritivos a deslocamentos quanto mais sensíveis forem aos preços praticados (uma característica típica de hóspedes de hotéis econômicos).

Pela figura pode-se notar que para um hotel de cidade o grau de tolerância para o deslocamento entre o aeroporto e o hotel é de 2 a 3 vezes mais aceitável que o grau de tolerância para o deslocamento entre o hotel e escritórios ou a locais de eventos.

Uma das razões para esse comportamento é que o hóspede, para cada viagem aérea, realiza vários deslocamentos entre o hotel e seu destino final, o que o deixa menos tolerável quanto maior a frequência desses deslocamentos.

Além do tempo de deslocamento, os atributos que determinam a zona de influência podem ser classificados em atributos relacionados ao empreendimento e atributos relacionados ao ambiente em que o empreendimento está inserido.

\subsubsection{Características da região de estudo}

Para o estudo da região de estudo, é necessário identificar os fatores associados à qualidade da oferta competitiva ${ }^{18}$. Esses fatores, avaliados segundo o binômio [benefícios x custo], que definem a qualidade de um hotel, permitem o reconhecimento da oferta competitiva e podem ser entendidos como a combinação dos seguintes itens:

\footnotetext{
${ }^{18}$ Qualidade entendida, aqui, como o conjunto de atributos que confere valor ao hotel, percebidos pelo hóspede de acomodações temporárias.
} 
- qualidade das instalações, serviços, equipamentos e bandeira da operadora hoteleira, como imagem percebida pelo cliente associada ao padrão de serviços oferecido;

- padrão de ambientação, decoração, projeto arquitetônico e de interiores;

- preço que o mercado está disposto a pagar (diária média) e que reflete o padrão oferecido pelo hotel.

A região em que se localiza o empreendimento hoteleiro é um dos fatores mais importantes no desempenho do empreendimento, na medida que, em última análise, é a região que é o destino das viagens, pelas suas características específicas.

Uma exceção à regra são empreendimentos hoteleiros que se estabeleçam como um novo destino em si, para viagens de lazer ou para eventos e convenções, sendo eles próprios indutores de demanda. Já empreendimentos construídos em conjunto com parques temáticos buscam sua sustentação econômica pela demanda proporcionada pelo parque.

No caso de empreendimentos hoteleiros voltados para hóspedes em viagens a negócios, a vocação de negócios da região de sua implantação, que determina a motivação da viagem, pode ser identificada pelas seguintes características:

- escritórios instalados na região e perfil das empresas instaladas;

- capacidade e infra-estrutura para eventos como feiras e convenções; 
Além dessas características, outros fatores combinados com esses aumentam o potencial de demanda hoteleira na região:

- capacidade de atração de turismo cultural;

- infra-estrutura de serviços voltadas para lazer e compras.

\subsection{Região do estudo do caso}

Podemos avaliar, dentro da região do estudo, a zona de influência a que um hotel está sujeito, em termos de capacidade de atração de viajantes com destino nas proximidades e sua concorrência competitiva. Quanto menor a capacidade do hotel em captar hóspedes em função da distância de seus destinos finais, menor será a sua zona de influência que alguns autores subdividem em zonas primária, secundária e terciária, mas que usualmente não apresentam um comportamento descontínuo entre fronteiras, como pode sugerir esse sistema de classificação.

\subsubsection{Zona de influência como resultante do conjunto da oferta competitiva}

Para um hotel, quanto menor sua classificação, ou seja, classificação igual ou inferior à categoria midmarket, maior será a sensibilidade do hóspede às despesas em uma viagem. Essas despesas incluem, ordenados pelo peso relativo no total de despesas, o valor das diárias, custos com transporte e alimentação.

$\mathrm{Na}$ medida em que esses itens se equilibram (diárias menores em relação a transporte e alimentação), os critérios de seleção da hospedagem tendem a aumentar a importância do peso das despesas com transporte e a valorizar o atributo localização pois, contra o deslocamento pesa, além do custo do transporte, o custo do tempo perdido nesse deslocamento. 
Hóspedes de hotéis topscale têm necessidades específicas não encontradas em outros hotéis e são pouco sensíveis ao preço. Uma das consequências desse comportamento é uma maior zona de influência para um hotel dessa categoria, podendo significar uma abrangência em toda a cidade de São Paulo.

O grupo intermediário, composto pelos hotéis upscale, apresentam um comportamento semelhante aos hotéis de menor classificação, no entanto, sem perder sua habilidade de captar clientes mais exigentes, mas que dão muito valor ao fator tempo e a facilidade de deslocamento.

Desses três grupos, o segmento de hotéis upscale será estudado para identificação de seu comportamento frente aos atributos associados à sua localização. Os hotéis dessa categoria estão sujeitos a padrões similares de escolha pelos hóspedes.

\subsubsection{Cidade de São Paulo}

Para desenvolvimento deste trabalho foi escolhida a cidade de São Paulo, por se tratar do maior centro econômico do país e em função de sua clara identificação como cidade de negócios frente às demais cidades e regiões brasileiras (Figura 6). 


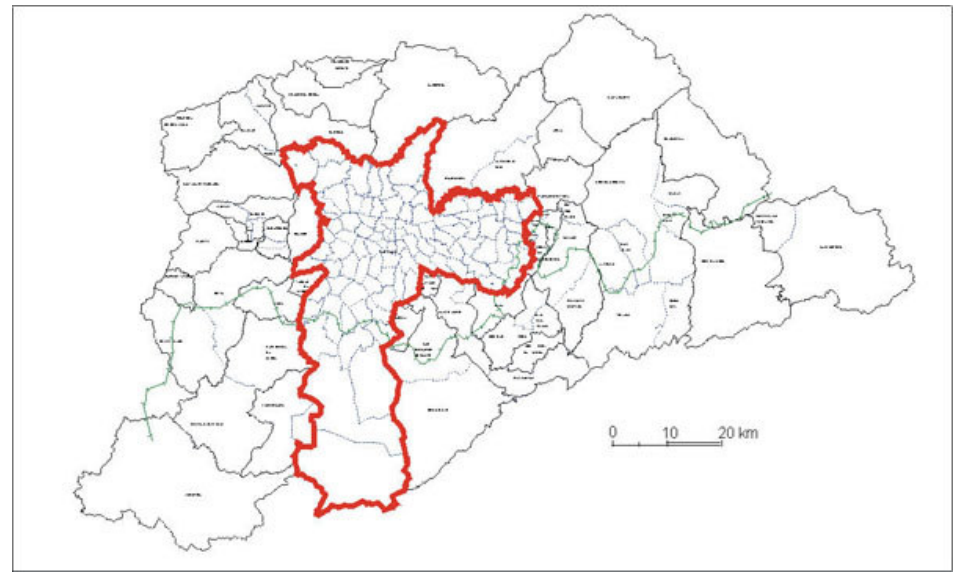

Figura 6: RMSP 1991: Divisão administrativa: municípios, distritos e subdistritos censitários

Fonte: <http://www.usp.br/fau/docentes/depprojeto/c_deak/CD/5bd/1rmsp/m04adm/index.html>

O Estado de São Paulo tem hoje 10 vezes mais estabelecimentos que o do segundo estado brasileiro (Rio de Janeiro), totalizando 2 milhões de empresas. Ainda em comparação com o segundo estado, sua população economicamente ativa e seu PIB são 3 vezes maior (18 milhões de pessoas e aproximadamente 300 bilhões US\$/ano), arrecadando 4 vezes mais em ICMS (34 milhões de reais) ${ }^{19}$.

A região metropolitana de São Paulo, com 39 municípios circunvizinhos, é uma das regiões mais populosas e dinâmicas do mundo, com quase 17,9 milhões de habitantes e respondendo por um PIB de 99,1 bilhões US\$/ano, com renda per capta de US\$ 5.545 (mesma base).

Existem investimentos programados para o próximo decênio da ordem de 20 bilhões de reais em infra-estrutura, como o Rodoanel $(180 \mathrm{~km})$, o Ferroanel $(448 \mathrm{~km})$, prolongamento da Av. Berrini até a Av.

${ }_{19}$ Disponível em < http://www.emplasa.sp.gov.br/ > acesso em 18/03/2004. Dados de 2000 . 
João Dias, o tunel Av. Morumbi-Av. Água Espraiada-Av. Francisco Morato, as linhas 4, 5 e 7 do metrô, o estacionamento do aeroporto de Congonhas e ampliação do aeroporto de Guarulhos com o novo terminal.

A cidade é o maior mercado do Mercosul, maior centro de indústrias e serviços da América do Sul, respondendo por aproximadamente $18 \%$ do PIB do Brasil. ${ }^{20}$

Considerando o setor de eventos, São Paulo recebe 150 das 170 maiores feiras do Brasil (algumas entre as maiores do mundo) e sedia 70 mil eventos/ano, totalizando mais de 15 milhões de participantes e visitantes por ano.

Os locais prioritariamente escolhidos para acolher eventos são hotéis e flats, seguidos por centros de convenções e pavilhões de exposições. Do universo de pessoas que participam de eventos, os turistas (pessoas não residentes no local dos eventos) representam 33\% do total de participantes, sendo que suas despesas estão distribuídas em hospedagem (43\%), transporte (31\%), alimentação (21\%), e outros (5\%). ${ }^{21}$

Segundo a São Paulo Convention \& Visitors Bureau apud Luz, 1999, “em 1998, 94\% dos turistas da cidade estavam em viagem de negócios, entre os quais 50\% eram participantes de eventos. Estima-se que os participantes e as pessoas que trabalham na organização e produção dos eventos sejam responsáveis pela metade da ocupação dos hotéis e flats de São Paulo.”

${ }^{20}$ Disponível em < http://www.seade.gov.br/negocios/snpct-v2.html >, acesso em 18/03/2004, dados de 2000.

${ }^{21}$ Pesquisa realizada por CTI Consultoria Turística Integrada, em conjunto com o Sebrae sob encomenda do Forum Brasileiro de Convention \& Visitors Bureau, 2001, disponível em <http://www.fbcevb.com.br/fbcevb_pesquisa.doc>, acesso em 18/03/2004 


\subsubsection{Configuração da oferta e da demanda para São Paulo}

Em São Paulo, reconhece-se a necessidade da adaptação da oferta à configuração da demanda, conforme trata Asmussen; Rocha; Melo (2001). A distribuição da oferta atual segmentada por categorias de hotel é mais concentrada nos segmentos upscale e topscale em detrimento do segmento economy. (Figura 7)

Já em mercados mais consolidados e maduros a estrutura da oferta se aproxima da estrutura piramidal da demanda, indicando um equilíbrio entre oferta e demanda.

Uma das razões para aquele desequilíbrio é a tendência de se considerar apenas hotéis de segmentos de três a cinco estrelas como aqueles procurados por viajantes de negócios. Um estudo do BNDES identificou os hotéis com maior concentração de hóspedes em viagem de trabalho ou treinamento situados nos segmentos upscale e topscale. (Ayres; Daemon; Fernandes, 1998).

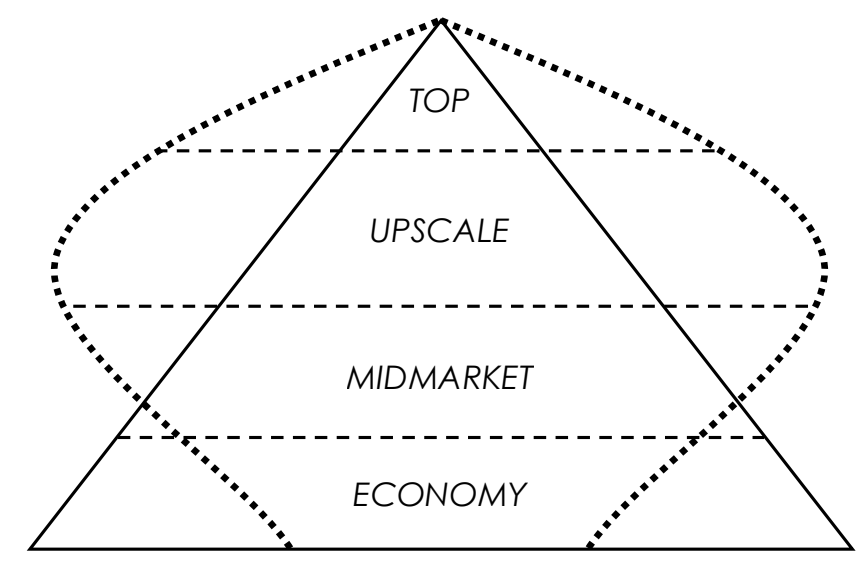

Figura 7: Configuração da oferta e demanda em São Paulo oferta: linha pontilhada; demanda: linha contínua FONTE: adaptado de Asmussen; Rocha; Melo (2001) 


\subsubsection{Região alvo do estudo}

A região alvo do estudo arbitrada para o estudo está contida nos distritos de Santo Amaro, Itaim Bibi e Campo Belo, dentro de um dos vetores de maior crescimento da mancha urbana, em processo de expansão. ${ }^{22} \mathrm{Na}$ Chácara Santo Antonio, encontra-se a maior concentração de empresas multinacionais do Brasil, e na região da Berrini, encontra-se o maior polo empresarial da América Latina, além de centros comerciais. (Figura 8)

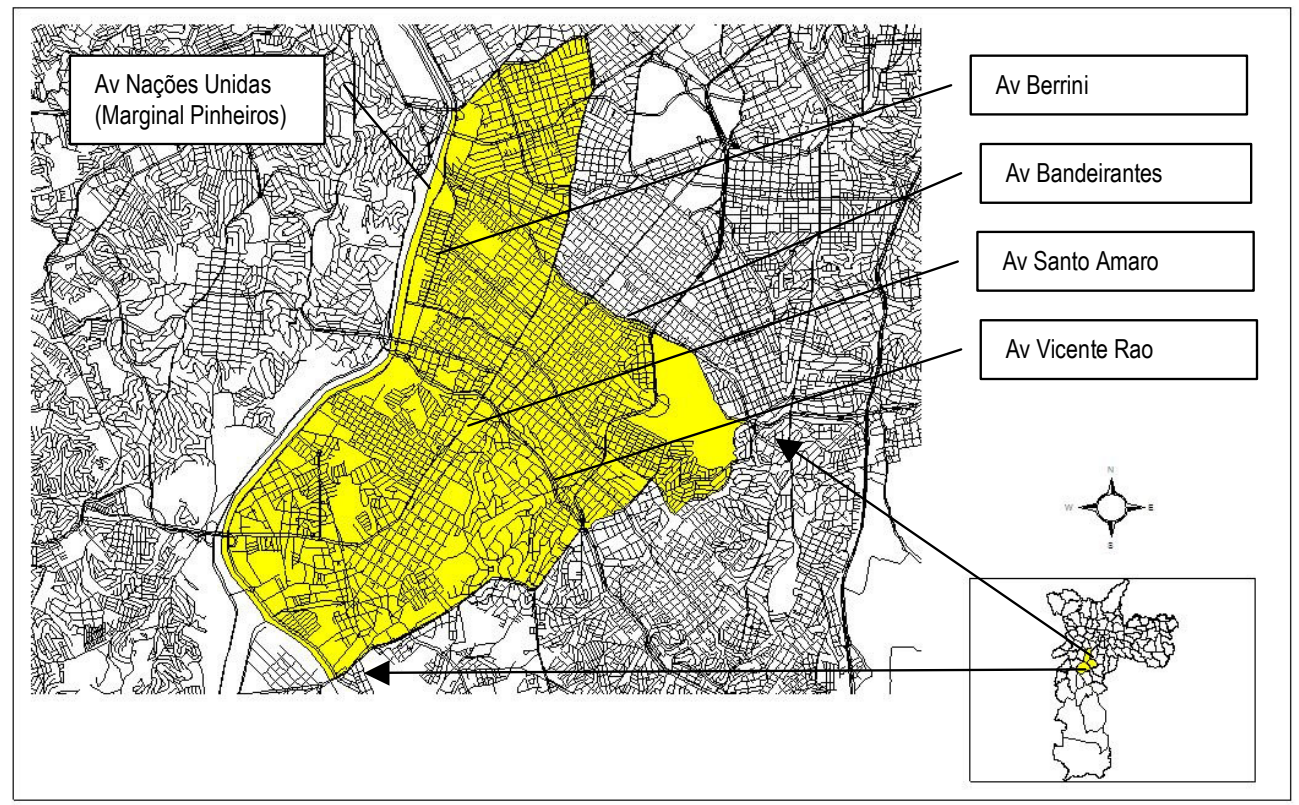

Figura 8: Região alvo do estudo

"O fortalecimento da região da Marginal Pinheiros como pólo terciário e símbolo da concentração terciária típica de uma cidade global, que parece se comprovar pelos dados analisados, também foi decorrência do processo apontado por Villaça (1999 e 2001).

22 Disponível em <http://www.usp.br/fau/docentes/depprojeto/c_deak/CD/5bd/1rmsp/m02evol/> 
Nesse estudo, Villaça comenta que o deslocamento deliberado das classes dominantes ao longo do eixo sudoeste gerou, após processo semelhante na Av. Paulista, uma concentração de empreendimentos terciários na Av. Brig. Faria Lima, e posteriormente nas avenidas Luiz Carlos Berrini e Nações Unidas, assim como posteriormente na Chácara Santo Antônio." (FERREIRA, 2003)

No mercado de escritórios de alto padrão, os maiores volumes de lançamento encontram-se na região da Berrini, Chácara Santo Antonio, Itaim e Vila Olímpia e os maiores índices de absorção de escritórios do mercado ( $80 \%$ em 2003) nas regiões da Berrini, Chácara Santo Antonio e Itaim $^{23}$. Em 2003, o volume de escritórios de alto padrão ${ }^{24}$ na região era de $600 \mathrm{mil} \mathrm{m}^{2}$ de área útil25 e, se consideramos as áreas adjacentes, esse total chegava a $800 \mathrm{mil} \mathrm{m}^{2}$.

Estão presentes na região da Berrini 364 empresas, com 46 mil funcionários e na Chácara Santo Antonio, 189 empresas com 22 mil funcionários, conforme indicado na figura 9 abaixo. Na macro-região considerando Vila Olímpia, Faria Lima, Chácara Santo Antonio, Centro Empresarial e Berrini - existem 1.426 empresas, das quais 81\% costumam hospedar funcionários ou clientes. ${ }^{26}$

${ }^{23}$ Disponível em

<http://www.joneslanglasalle.com.br/upload/publicacao/SP_balanço2003.pdf> acesso em $18 / 03 / 2004$.

${ }^{24}$ Aqui pretende-se destacar os escritórios que alojam empresas de porte médio a grande e de influência regional, nacional ou internacional.

${ }^{25}$ Disponível em <http://www.officespace.com.br/>, acesso em 18/mar/2004.

${ }^{26}$ HVS International e Escopo Geomarketing, sob encomenda do Complexo Berrini. 


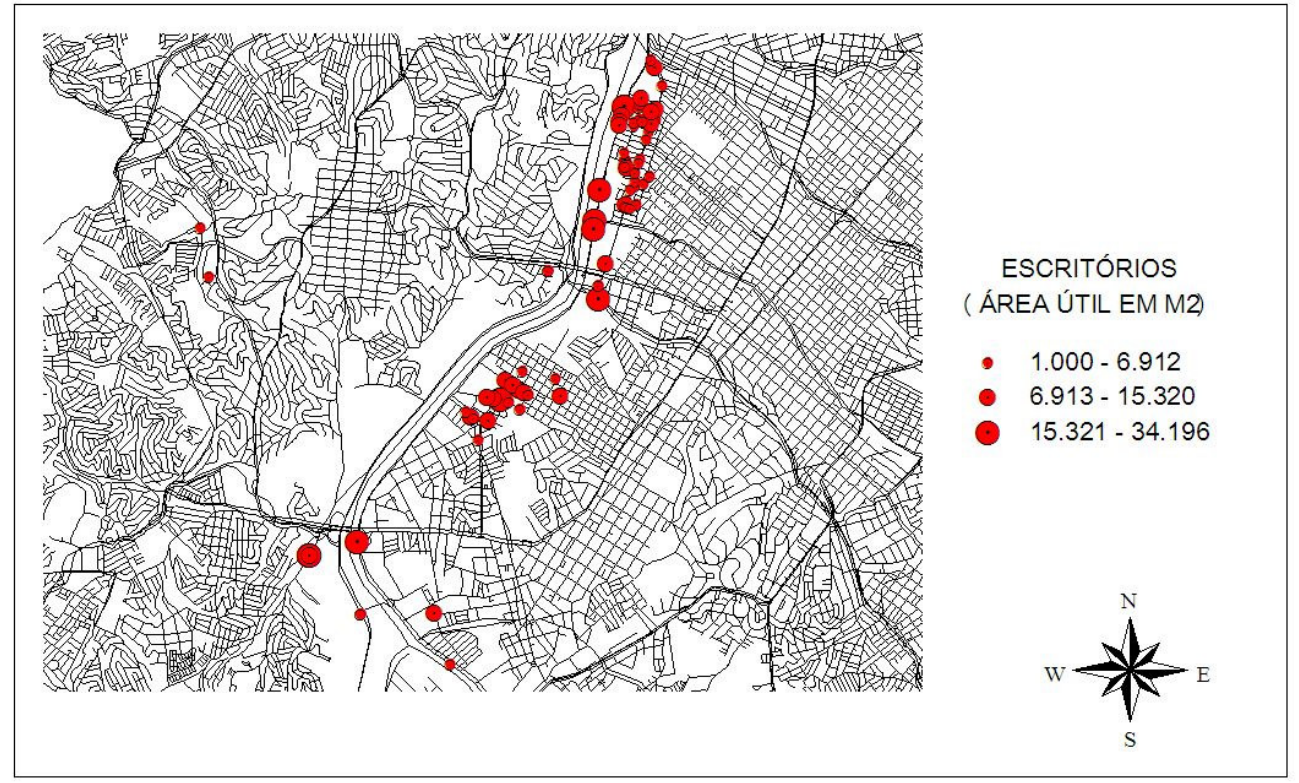

Figura 9: Empresas instaladas na Região da Berrini e Chácara Santo Antonio EDIFÍCIOS DE ESCRITÓRIOS (em m² de área útil) 
Os eventos realizados na região geram um fluxo de 4,5 milhões de pessoas/ano. Na figura 10 abaixo verifica-se a capacidade dos espaços para eventos e sua distribuição espacial.

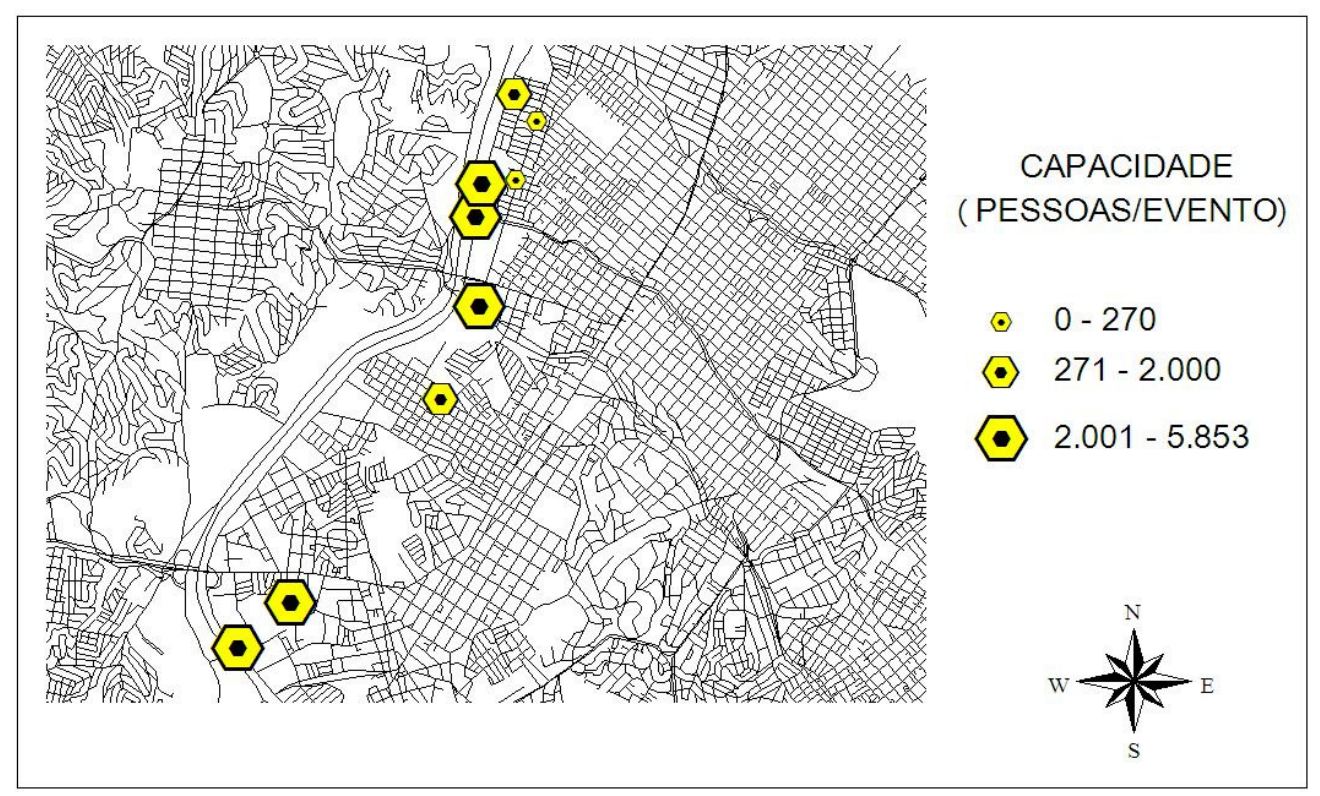

Figura 10: Espaços para eventos na Região da Berrini e Chácara Santo Antonio

Os eventos na região estão distribuídos em auditórios dos hotéis Hyatt, Hilton, Gran Meliá, Transamérica, Blue Tree Morumbi, Blue Tree Berrini, Estanplaza Berrini, Meliá Comfort Brooklin e em centros de exposição como TEC- Transamérica Expo Center (20 mil m² de área para eventos) ${ }^{27}$ e Amcham-Câmara Americana de Comércio (5 mil m² de área de eventos, 2 mil eventos e 200 mil pessoas/ano) 28 - tabela 3.

27 Conforme entrevista concedida em 07/04/2004 pela consultora Adele B. Aracema, do TEC - Transamérica Expo Center

28 Conforme entrevista concedida em 07/04/2004 pelas consultoras Carolina S. Romano e Eunice P. L. de Rezende, da AMCHAM. 
Tabela 3: Espaços para eventos na região de influência ${ }^{29}$

\begin{tabular}{c|c|c}
$\begin{array}{c}\text { NOME } \\
\text { LOCAL DE EVENTOS }\end{array}$ & ENDEREÇO COMPLETO & $\begin{array}{c}\text { CAPACIDADE } \\
\text { PESSOAS/EVENTO }\end{array}$ \\
\hline \multirow{2}{*}{ HILTON } & AV. DAS NACOES UNIDAS, 12901 & 5853 \\
\hline TRANSAMERICA EXPO CENTER & AV. DR. MARIO VILLAS BOAS RODRIGUES, 387 & 5000 \\
\hline HOTEL TRANSAMERICA & AV. DAS NACOES UNIDAS, 18591 & 4000 \\
\hline BLUE TREE TOWER MORUMBI & AV. ROQUE PETRONI JR., 1000 & 3000 \\
\hline GRAN MELIA & AV. DAS NACOES UNIDAS, 12559 & 2474 \\
\hline BLUE TREE TOWER BERRINI & R. QUINTANA, 1012 & 1724 \\
\hline AMCHAM & R. DA PAZ, 1431 & 1500 \\
\hline ESTANPLAZA BERRINI & AV. ENG LUIS CARLOS BERRINI, 853 & 270 \\
\hline MELIA CONFORT BROOKLIN & R. HEINRICH HERTZ, 14 & 170 \\
\hline
\end{tabular}

Além dos eventos realizados em hotéis e centros de convenções, espetáculos, shows e eventos culturais de abrangência nacional, realizados no Teatro Alfa, Credicard Hall, Via Funchal e Tom Brasil, são responsáveis por um fluxo de 2 milhões de pessoas/ano ${ }^{30}$.

29 Pesquisa de campo realizada entre os meses de novembro/2003 e fevereiro/2004.

${ }^{30}$ HVS International e Escopo Geomarketing, sob encomenda do Complexo Berrini. 


\section{CARACTERIZAÇÃO DA DEMANDA NA ZONA DE INFLUÊNCIA}

Para estudo da demanda na zona de influência de um hotel deve-se considerar a posição da oferta competitiva (Figura 11) e os atributos de seus indicadores de desempenho.

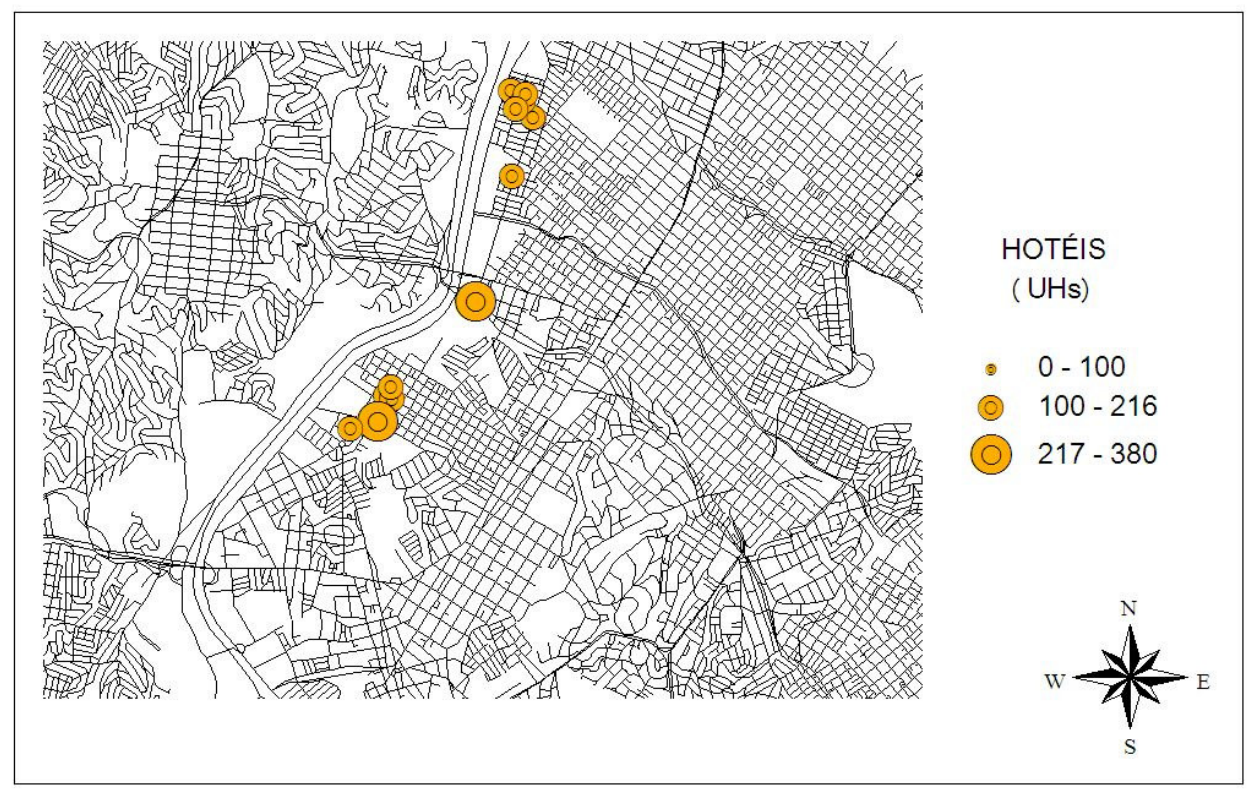

Figura 11: Posição da oferta competitiva

(quatro estrelas, conhecido também como upscale ou superior)

A demanda deve ser considerada prioritariamente dentro da ótica do segmento de mercado considerado. Para tanto, pode-se estudar a demanda segundo o propósito da viagem e o padrão do empreendimento. 
Pelo propósito da viagem, como:

- em viagens a negócios, identifica-se como propósito da viagem visitas a escritórios de empresas e indústrias; participação em congressos, feiras, eventos e exposições;

- em viagens a lazer, podem ser consideradas como propósito da viagem atrações turísticas de interesse histórico (museu, monumentos, edificações), cultural (tradições, folclore, festas tradicionais) e de riqueza natural (praia, montanha, campo, florestas, reservas).

Pelo padrão do empreendimento, como:

- empreendimentos de alto padrão, considerados assim os empreendimentos que associam status, através da exclusidade de serviços e de amenidades, ao valor percebido pelo mercado: enquadram-se nessa categoria os hotéis de cinco estrelas (topscale);

- empreendimentos de padrão intermediário, que buscam oferecer um produto diferenciado, dentro de um patamar de preços: nessa categoria se encontram alguns hotéis de três e quatro estrelas;

- empreendimentos de padrão simples, que buscam competir dentro de um segmento de mercado que considera prioritariamente preço em relação a serviços e amenidades, formada por hotéis com o mínimo de equipamentos, com estrutura econômica. 


\subsection{Fator gerador de demanda}

Em relação ao fator gerador de demanda, mesmo em cidades de demanda por viagens de negócios, deve-se considerar outros eventos na medida em que apresentam um padrão de comportamento e têm representatividade no total da demanda por hospedagem de uma dada região.

No caso de demanda gerada por viagens de lazer, a mesma é identificada por atrativos do local, como natureza, parques temáticos, museus, arquitetura ou pela criação de um conjunto de atributos que tornam o empreendimento único, sendo ele mesmo gerador de demanda, como no caso de resorts de lazer. Seu comportamento normalmente apresenta sazonalidade intensa, com períodos de alta demanda de três a quatro meses por ano, em feriados e nos fins de semana.

Já a demanda gerada por viagens de negócios e de convenções ocorre pela freqüência de feiras, congressos e convenções, e pela proximidade de empresas de atuação regional, nacional e internacional.

Neste último caso, o fluxo de executivos é freqüente e estável ao longo do ano, com baixa demanda em feriados e nos fins de semana. No entanto, no caso de feiras, congressos, convenções, a demanda é concentrada durante a duração do evento, mas inexistente nos dias de montagem/desmontagem, reduzindo a ocupação média.

Para reduzir essa sazonalidade, hotéis normalmente buscam atender à demanda por eventos e à demanda por viagens de negócios conjuntamente e oferecem outros espaços para eventos que possam ocorrer de modo a complementar os períodos onde seu espaço principal para eventos estaria em montagem/desmontagem. 
Além desses fatores, o estudo dos estabelecimentos da região aos quais se destinam as viagens permite reconhecer outros padrões de hospedagem como viagens para tratamento médico com acompanhantes, cursos, concursos, visita a parentes, etc.

É importante ressaltar que SIGs não são utilizados para o estudo de eventos isolados, sem correlação com outros atributos. Weatherford; Kimes (2003), quando comparam métodos de previsão da receita de hotéis ressaltam que, em função dos eventos atípicos (como promoções, convenções, condições climáticas, feriados, acidentes ou guerras), os dados de receita vinculados a esses eventos não devem ser considerados.

No entanto, quando o hotel é voltado a viajantes de negócios e na composição de sua receita a parcela devida a promoções e convenções é importante, apresentando um padrão de ocorrência, esta deve ser estimada, pois deixa de ser um evento atípico.

\subsection{Análise da demanda pela oferta competitiva instalada}

Os hotéis que estão voltados ao segmento de negócios na região em estudo são apresentados na tabela 4 que segue. Na estruturação de um SIG, os dados foram coletados e armazenados em banco de dados não gráficos referenciados espacialmente. 
Tabela 4: Relação de hotéis, data de inauguração e número de $\mathrm{UHs}^{31}$

\begin{tabular}{|c|c|c|c|c|c|}
\hline Nome & & Endereço & $\mathbf{N}^{\circ}$ & Inaug. & UHs \\
\hline Blue Tree Towers Berrini & Rua & Quintana & 1012 & 1998 & 184 \\
\hline Blue Tree Towers Morumbi & Av & Roque Petroni jr & 1000 & 2000 & 344 \\
\hline Blue Tree Towers Nacoes Unidas & Rua & Fernandes Moreira & 1371 & 1999 & 186 \\
\hline$\overline{\text { Brooklin River Side Flat }}$ & Rua & Indiana & 1155 & 2001 & 103 \\
\hline Estanplaza Berrini Plaza & Av & Eng. Carlos Berrini & 853 & 1999 & 130 \\
\hline Estanplaza International & Rua & Fernandes Moreira & 1293 & 2001 & 146 \\
\hline Estanplaza Nações Unidas & Rua & Guararapes & 1889 & 1995 & 112 \\
\hline Formule1 Morumbi & Av & Roque Petroni jr & 800 & 2006 & 378 \\
\hline Gran Estanplaza Berrini & Rua & Arizona & 1517 & 2002 & 214 \\
\hline Gran Meliá São Paulo & Av & das Nações Unidas & 12559 & 1995 & 300 \\
\hline Grand Hyatt Sao Paulo & $\mathrm{Av}$ & das Nações Unidas & 13301 & 2002 & 470 \\
\hline Hilton Berrini & Av & Nacoes Unidas & 12901 & 2001 & 567 \\
\hline Ibis Morumbi & Av & Roque Petroni jr & 800 & 2006 & 376 \\
\hline Meliá Confort Berrini & Rua & Quintana & 934 & 2002 & 200 \\
\hline Meliá Confort Office Park & Rua & Verbo Devino & 1323 & 2001 & 380 \\
\hline Parthenon Nacoes Unidas & Rua & Professor Manuelitto de Ornellas & 104 & 2000 & 168 \\
\hline Parthenon Royal Brooklin & Rua & Sansao Alves dos Santos & 367 & 1999 & 172 \\
\hline The Park Way All Suite & Rua & Joel Carlos Borges & 60 & 1990 & 60 \\
\hline The Time & Rua & Hans Oersted & 115 & 1993 & 113 \\
\hline Transamérica São Paulo & Av & das Nações Unidas & 18591 & 1986 & 400 \\
\hline Transamerica Flat Nações Unidas & Rua & Americo Brasilense & 2163 & 2000 & 143 \\
\hline Tryp Meliá Nacoes Unidas & Rua & Fernandez Moreira & 1264 & 2004 & 400 \\
\hline Tryp WTC Meliá & Rua & Heinrich Hertz & 14 & 1999 & 216 \\
\hline
\end{tabular}

Para que possamos estudar a demanda, os empreendimentos foram divididos em grupos quanto ao padrão do empreendimento a que pertencem:

- Hotéis de alto padrão (topscale): Grand Estanplaza Berrini, Gran Meliá São Paulo, Grand Hyatt São Paulo, Hilton Berrini, Transamérica São Paulo. Esses hotéis apresentaram no ano de 2003 uma diária média ${ }^{32}$ de $\mathrm{R} \$ 343$, e ocupação média de 43,7\%. São hotéis de porte grande, de oferta média de 390 unidades. Excluindo-se o Transamérica, que apresenta 18 anos de operação, e o Gran Meliá, com 9 anos de operação, os demais são hotéis ainda em fase de estabilização de suas receitas, com 1 a 2 anos de operação.

31 Pesquisa de campo realizada durante os meses de novembro/2003 a fevereiro/2004.

32 Todos os dados referente a diária média estão em $\mathrm{R} \$$ da data base da pesquisa, novembro/2003. 
- Hotéis intermediários (upscale e midmarket): hotéis Blue Tree Towers Berrini, Morumbi e Nações Unidas, Estanplaza Berrini, International e Nações Unidas, Meliá Confort Berrini e Office Park e Tryp WTC Meliá. Esses hotéis apresentam uma diária média em torno de $173 \mathrm{R} \$$ e uma ocupação média de $65,4 \%$.

- Hotéis econômicos (economy e budget): Transamérica Flat Nações Unidas, Parthenon Royal Brooklin e Nações Unidas. A diária média é de $116 \mathrm{R} \$$ e a ocupação média é de 70,7\%, sem considerar os empreendimentos que ainda não foram inaugurados, Tryp Meliá Nações Unidas, em 1 de maio de 2004, Formule1 e Ibis, em 2006.

\subsection{Demanda latente}

A demanda latente representa a demanda não atendida pela oferta competitiva, que se verifica nas seguintes situações:

- excesso de demanda, nos picos de ocupação, ou crescimento orgânico da demanda não acompanhado por novos investimentos em infra-estrutura hoteleira;

- inexistência de oferta competitiva na região de influência primária.

Não existindo hotéis no padrão desejado, essas demandas são atendidas por hotéis de padrões não desejados inicialmente, ou em regiões mais distantes que a pretendida. Quando um novo empreendimento, que se encaixa na categoria que se encontra em excesso de demanda entra no mercado, ocorre um novo equilíbrio da demanda e, eventualmente, um reposicionamento da oferta afetada negativamente por esse novo empreendimento. 


\subsection{Demanda induzida}

Demanda induzida, ou demanda provocada pela inserção do hotel, ocorre em função de novos espaços para eventos e serviços oferecidos pelo hotel ou mesmo pela entrada em operação de novos empreendimentos geradores de demanda na região, como aeroportos, escritórios, centros de lazer ou centros de compras.

\subsection{Análise da demanda na zona de influência primária}

A fonte primária de dados para análise da demanda local é a ocupação e a diária média. Rushmore (1992) comenta que a partir da arbitragem desses indicadores de desempenho, pode-se arbitrar as receitas do hotel.

A análise da demanda local pode ser construída seguindo uma rotina adaptada do modelo de sete etapas de Rushmore (1992), onde se pode identificar a necessidade da análise dos atributos espaciais: 
[i] - Definição da zona de influência (Figura 12) - região geográfica contendo a oferta de acomodações temporárias na isócrona ${ }^{33}$ considerada tolerável quanto ao tempo de locomoção entre destino final e o local do futuro hotel. Essa fronteira considera o tempo de viagem; os métodos de locomoção; barreiras físicas ou geográficas; o(s) segmento(s) demanda atendido(s) na região e a localização da oferta competitiva;

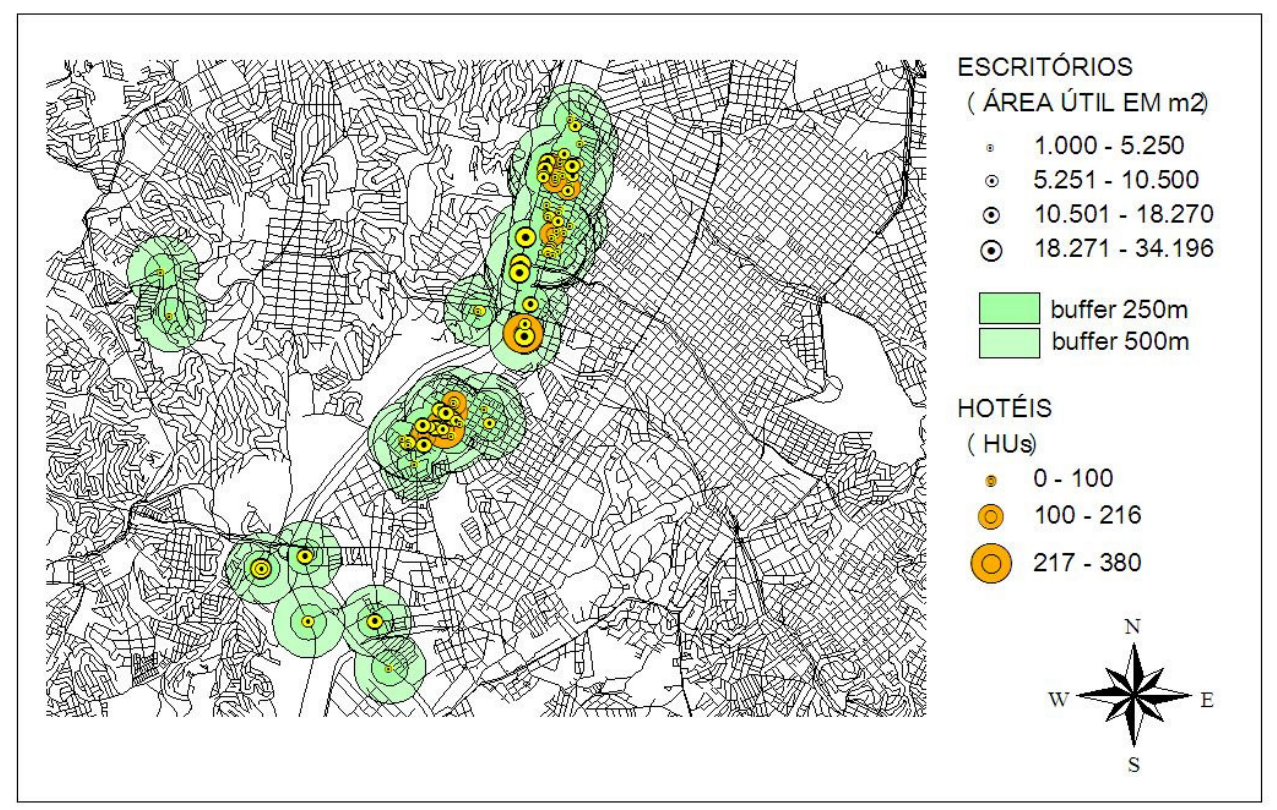

Figura 12: Definição da zona de influência.

${ }^{33}$ Com buffers pequenos, de até $500 \mathrm{~m}$, a isócrona foi aproximada pela isométrica. 
[ii] - Caracterização do segmento de mercado primário para que se estude seu comportamento quanto à sazonalidade, tempo médio de permanência, número de pessoas por quarto, serviços do hotel mais utilizados, sensibilidade em relação ao preço (Tabela 5);

Tabela 5: Sensibilidade da demanda (empresas) em relação ao preço, para hospedagem de funcionários e visitantes

\begin{tabular}{c|c|c}
$\begin{array}{c}\text { ÁREAS DE } \\
\text { TRABALHO }\end{array}$ & \multicolumn{2}{|c}{$\begin{array}{c}\text { GASTOS COM HOSPEDAGEM } \\
\text { MINIMO }\end{array}$} \\
\hline \multicolumn{3}{|c}{ MÁXIMO } \\
\hline Alexandre Dumas & $\mathrm{R} \$ 60,00$ & $\mathrm{R} \$ 190,00$ \\
\hline Berrini & $\mathrm{R} \$ 80,00$ & $\mathrm{R} \$ 200,00$ \\
\hline Centro Empresarial & $\mathrm{R} \$ 70,00$ & $\mathrm{R} \$ 100,00$ \\
\hline Faria Lima & $\mathrm{R} \$ 100,00$ & $\mathrm{R} \$ 1.200,00$ \\
\hline Vila Olímpia & $\mathrm{R} \$ 70,00$ & $\mathrm{R} \$ 150,00$ \\
\hline
\end{tabular}

Fonte: HVS International e Escopo Geomarketing, sob encomenda do Complexo Berrini, dados de 2003. 
[iii] - Identificação da oferta competitiva primária e secundária (Figura 13), para estudar a demanda não atendida (latente) pela oferta primária que estaria migrando para a oferta secundária;

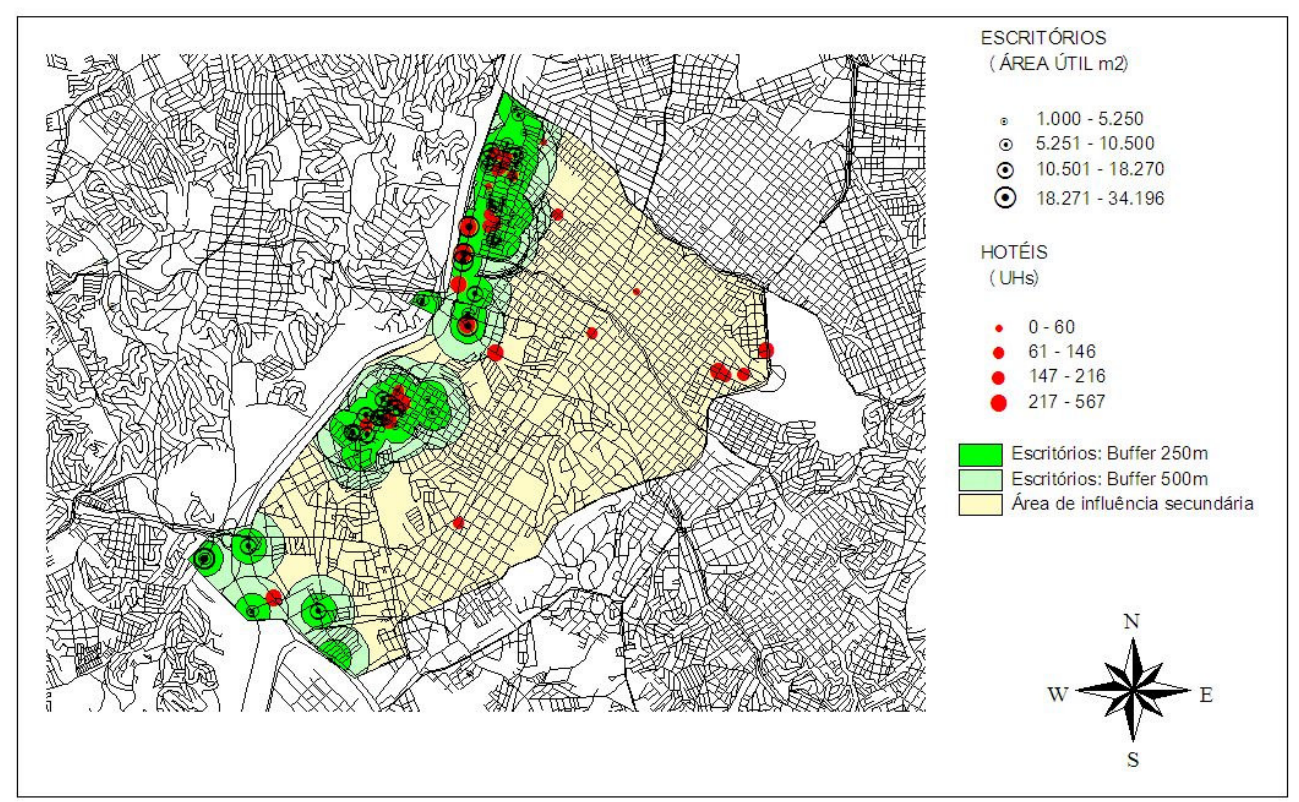

Figura 13: Zona de influência na região

A zona de influência é limitada por barreiras físicas (aeroporto e vias de acesso principais - Avenida Bandeirantes, Avenida Washington Luís), geográficas (rio Pinheiros), tempo de deslocamento (15 minutos), entorno (áreas residenciais, áreas industriais). 
A oferta competitiva primária resulta de seleção processada pelo SIG resultante dos critérios de entrada considerados. Para o estudo de caso, a partir da definição de um conjunto de critérios para seleção da oferta competitiva:

- Data de inauguração (sem readequações e atualizações funcionais) posterior a 1990;

- Número de UHs superior a 100 unidades;

- Diária corporativa maior que $R \$ 80,00$ e menor que $R \$$ 200,00;

- Padrão Superior.

Os critérios, traduzidos para a linguagem do aplicativo usado ${ }^{34}$, resultam na seleção da oferta competitiva. (Figura 14-em amarelo ):

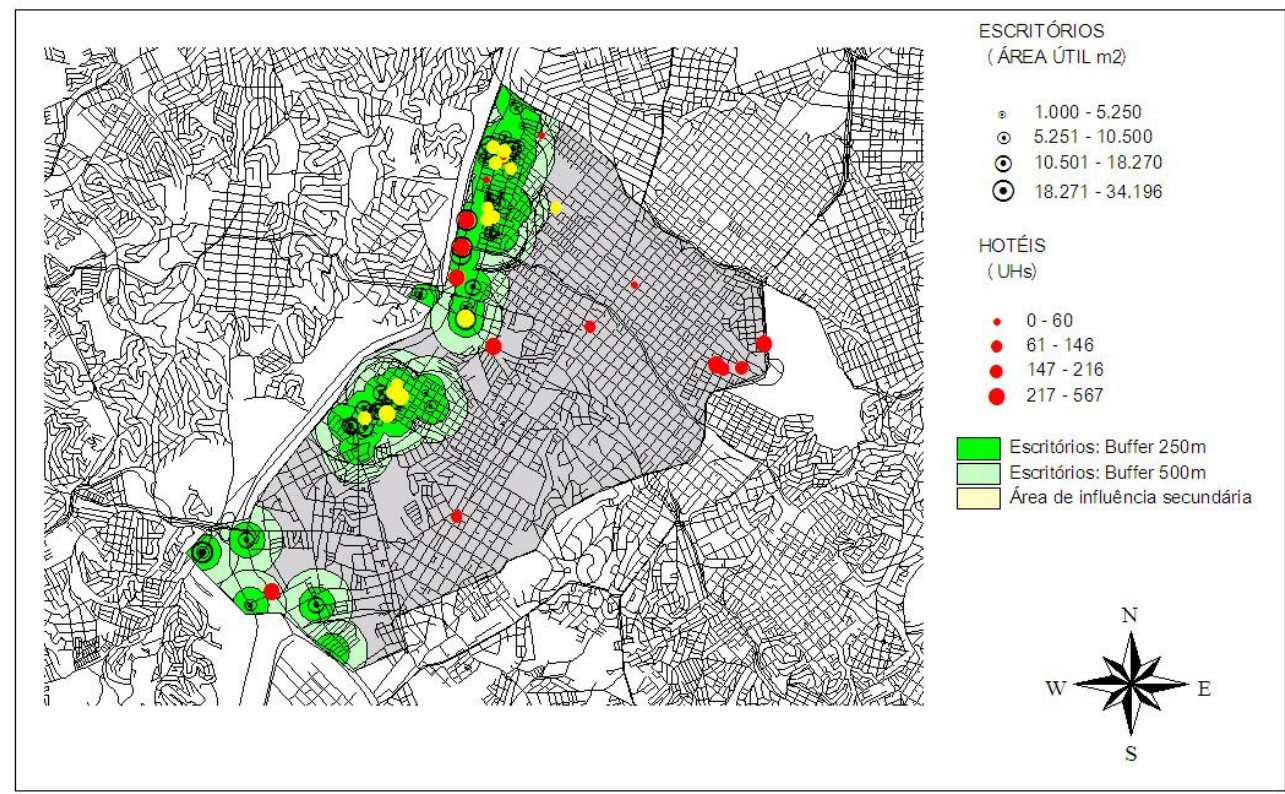

Figura 14: oferta competitiva instalada através da manipulação de dados e apresentação de informações

${ }^{34}$ No software ArcView, ( [Inaug] $\left.>1990\right)$ and ([Uh] >=100) and ([Dcorp] $\left.>=80\right)$ and $([$ Dcorp $]<=200))$ and $([$ Aa $]=~ " U P S ")$ 
[iv] - Estimação da ocupação e da segmentação da oferta competitiva (em cidades de demanda por viagens de negócio), para o período de pelo menos um ano, para servir de base inicial da projeção da ocupação (Tabela 6) ${ }^{35}$. Podemos observar, para o estudo da Embratur, que o segmento de diária média entre os patamares de $\mathrm{R} \$ 90$ e $\mathrm{R} \$ 190$, formaram o grupo de maior participação do segmento de viagens de negócios (comercial corporativo, comercial individual, grupo de eventos e tripulação).

\begin{tabular}{|c|c|c|c|c|c|}
\hline \multicolumn{3}{|c|}{ Hotéis de Cidade } & \multirow[t]{2}{*}{ Resorts } & \multirow[t]{2}{*}{ Flats } & \multirow[t]{2}{*}{ Total } \\
\hline $\begin{array}{c}\text { Diária média } \\
\text { acima de } \\
\mathrm{R} \$ 190\end{array}$ & $\begin{array}{c}\text { Diária média } \\
\text { entre } R \$ 90 \\
\text { e } R \$ 190\end{array}$ & $\begin{array}{c}\text { Diária média } \\
\text { abaixo de } \\
\mathrm{R} \$ 90\end{array}$ & & & \\
\hline
\end{tabular}

\section{SEGMENTAÇÃO DA DEMANDA POR CATEGORIA - 2002}

\begin{tabular}{l|r|r|r|r|r|r} 
Comercial Corporativo & $40,6 \%$ & $46,3 \%$ & $32,8 \%$ & $3,4 \%$ & $57,6 \%$ & $45,6 \%$ \\
\hline Comercial Individual & $13,7 \%$ & $16,0 \%$ & $26,2 \%$ & $4,4 \%$ & $18,5 \%$ & $17,4 \%$ \\
\hline Turistas Operadoras & $6,0 \%$ & $9,2 \%$ & $12,8 \%$ & $32,4 \%$ & $9,6 \%$ & $11,7 \%$ \\
\hline Turistas Individual & $9,4 \%$ & $6,7 \%$ & $10,9 \%$ & $30,2 \%$ & $6,7 \%$ & $9,6 \%$ \\
\hline Grupo de eventos & $24,3 \%$ & $17,0 \%$ & $10,8 \%$ & $23,9 \%$ & $4,6 \%$ & $11,3 \%$ \\
\hline Tripulação & $4,0 \%$ & $2,6 \%$ & $4,8 \%$ & $0,3 \%$ & $1,7 \%$ & $2,4 \%$ \\
\hline Outros & $2,0 \%$ & $2,2 \%$ & $1,7 \%$ & $5,4 \%$ & $1,3 \%$ & $2,0 \%$ \\
\hline
\end{tabular}

OCUPAÇÃO E DIÁRIA MÉDIA POR CATEGORIAS - 2002

\begin{tabular}{l|r|r|r|r|r|r} 
Taxa de ocupação & $46 \%$ & $49 \%$ & $60 \%$ & $49 \%$ & $49 \%$ & $50 \%$ \\
\hline Diária Média & 318,0 & 126,0 & 67,0 & 283,0 & 113,0 & 161,0 \\
\hline RevPAR & 145,0 & 61,0 & 41,0 & 139,0 & 55,0 & 80,0 \\
\hline
\end{tabular}

NACIONALIDADE DOS HÓSPEDES POR CATEGORIA - 2002

\begin{tabular}{l|r|r|r|r|r|r} 
Brasileiros & $45,30 \%$ & $79,60 \%$ & $83,60 \%$ & $87,40 \%$ & $74,20 \%$ & $75,30 \%$ \\
\hline Estrangeiros & $54,70 \%$ & $20,40 \%$ & $16,40 \%$ & $12,60 \%$ & $25,80 \%$ & $24,70 \%$ \\
\hline
\end{tabular}

Tabela 6: Caracterização de segmento de mercado para hotéis de cidade Fonte: Embratur (dados hotelaria 2002) e HIA - Hotel Investment Advisors

${ }^{35}$ Os dados da pesquisa realizada pela Embratur em 2002 em cidades de negócio refletem os resultados encontrados para São Paulo, conforme entrevista concedida por Nilton Beschtold - Everest Com.Serv.hotelaria ltda. em 12/dezembro/2003. No entanto, a ocupação (67\%) encontrada para a região do estudo é maior, resultando em um RevPAR de $\mathrm{R} \$ 82,41$. 
[v] - Quantificação da demanda diária por acomodações, a partir das ocupações por hotel da oferta competitiva, para o período de um ano, na zona de influência do estudo, a partir da análise dos dados extraídos da pesquisa:

- $2.238 \mathrm{UH} \times 365$ dias = oferta competitiva de 816.870 pernoites;

- $68 \%$ (ocupação) x $816.870=$ demanda de 555.470 peronoites.

[vi] - Estimativa da demanda latente, provocada pela inserção do hotel:

Observando as áreas de influência primária podemos inferir que na região da Berrini bem como na região da Chácara Santo Antonio as áreas de influência primária de maior significância (onde se localizam as maiores áreas de escritórios) são atendidas por hotéis da oferta competitiva.

No entanto, próximo ao Hotel Transamérica (extremo sul da zona de influência) existe um conjunto da oferta competitiva que não é atendida. Provalvelmente a inserção de um hotel nessa região provocaria uma migração da demanda atendida pelos hotéis da Chácara Santo Antonio, e uma parte da demanda que se hospeda no Hotel Transamérica, de categoria Luxo, por falta de outra opção nas proximidades.

[vii] - Quantificação da demanda total por acomodações, totalizando a demanda existente e a demanda latente, e redefinir um novo patamar de equilíbrio da oferta e demanda para acomodar o novo projeto de hotel.

Além do estudo para a inserção do empreendimento hoteleiro, é importante estudar a formação da ocupação estabilizada do hotel nos 
anos do ciclo em que o empreendimento vai ganhando o seu espaço de mercado e as rendas vão se estabilizando. Passado esse período, dentro do ciclo operacional, com extensão para o ciclo de exaustão, o empreendimento estará operando em regime. (Rocha Lima, 1995)

De todas as etapas para análise da demanda local, a estimação da ocupação é a mais crítica. Kim; Olsen (1999) comentam que na indústria hoteleira, a informação precisa das tendências da ocupação, RevPAR e diária média são fatores críticos para o sucesso das análises de valor de hotéis. Nesta pesquisa a ocupação foi estimada a partir do cruzamento de informações fornecidas por diferentes fontes (hoteis, consultorias e mercado de eventos);

\subsection{Arbitragem da demanda para o horizonte do projeto}

Para se estimar o potencial de demanda para a indústria hoteleira deve-se comparar a ocupação atual com o potencial de ocupação futuro. DeRoos (1999) utiliza para isso o que chama de "ocupação natural", ou seja, um cálculo baseado em projeções do crescimento da demanda através da análise de ocupação ajustadas (sem efeito da sazonalidade) que não provoque alteração no valor das diárias médias futuras.

Maher; Canter (1998) utilizam, para determinação do potencial de demanda, um método de regressão que considera, ao longo do período analisado, as variações na demanda por diárias de hotel para o mercado segmentado num determinado período, no nível de empregos na indústria hoteleira, no nível de empregos em geral, no fluxo de passageiros de viagens aéreas e no fluxo de pessoas em convenções.

No entanto, utilizar processos de regressão construídos para projetar o potencial da demanda, a partir de dados históricos são de pouca valia para construção de cenários futuros. "Reconhecer o andamento da 
economia e dos mercados no passado pode permitir levantar evidências e fazer vínculo delas com fatos econômicos ou políticos, bem como associar essas evidências a comportamentos dos mercados, para os quais se pode inferir uma certa tendência de previsibilidade, no sentido de que venham a se repetir, em ondas.” (Rocha Lima, 2004)

Para arbitrar a demanda ao longo do horizonte de operação do empreendimento hoteleiro um SIG aplica-se ao estudo na medida em que permite compreender os vetores de crescimento da demanda e oferta ao longo dos anos, como apresentado por Asmussen; Rocha; Melo (2002). É possível perceber a tendência de migração dos empreendimentos hoteleiros desde de 1960 até a decada de 2003 (Figura 15)
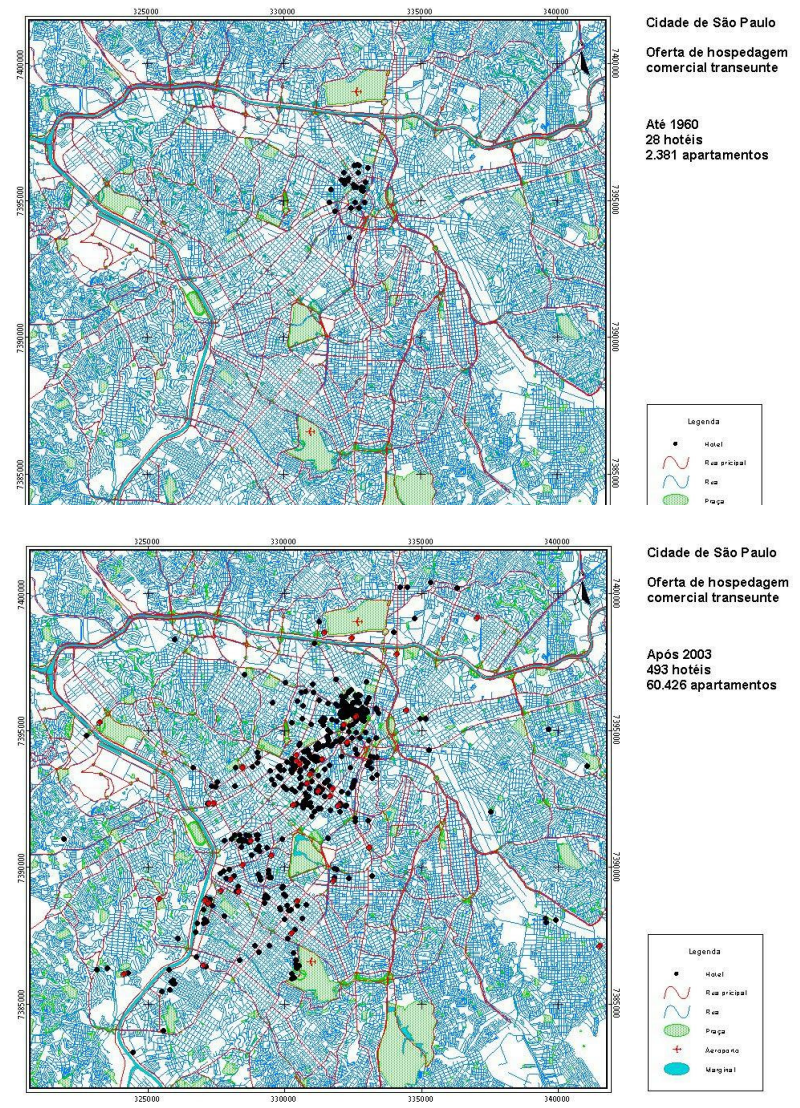
Oferta de hospedagem
comercial transeunte

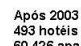
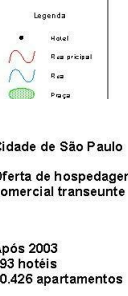

Figura 15: Evolução da oferta de hospedagem comercial transeunte em São Paulo Fonte: Asmussen \& Associados 


\section{PRODUÇÃO DE RESULTADOS PARA ANÁLISE}

O estabelecimento de bandas de flutuação dos resultados tem por finalidade dar subsídio à arbitragem das variáveis do cenário para suportar o planejamento do produto hoteleiro.

O uso de SIG (na fase de MANIPULAÇÃO e ANÁLISE) permite inferir o comportamento do mercado indiretamente pela identificação do desempenho dos empreendimentos em uma dada região de influência. Essa forma de levantar os indicadores de desempenho do cenário introduz no estudo a necessidade de:

- reconhecimento das variáveis do cenário para o momento da análise;

- arbitragem do comportamento de váriáveis do cenário para a duração do empreendimento;

- Avaliação das bandas de flutuação das variáveis da análise.

No estudo dessas variáveis, as flutuações podem ser abordadas no ambiente do mercado em que o empreendimento está localizado ou no ambiente do empreendimento ${ }^{36}$.

No ambiente do mercado é importante o reconhecimento dos eventos da economia que concorrem para melhorar a inserção do empreendimento e consequentemente a melhora de seu desempenho operacional.

\footnotetext{
36 No ambiente do empreendimento, existe a possibilidade de controle e implantação de medidas corretivas, a tempo de promover atualizações e adequações funcionais sem perda de qualidade do investimento - não se trata do planejamento do produto hoteleiro na fase de implantação, e portanto não é abordado neste trabalho.
} 
No estudo de caso os atributos relacionados ao uso do SIG devem ser considerados juntamente com uma faixa de flutuação sinalizando as fronteiras que contém os valores de maior probabilidade de ocorrência.

Com as fronteiras de flutuação das variáveis do cenário é possível gerar os subsídios que permitirão avaliar seu padrão de estabilidade, quando da determinação de seus indicadores de qualidade do investimento.

A partir das amostras que correspondem ao critério de seleção utilizado no ambiente do SIG em [5.5 Figura 14], podemos: identificar os limites para desvios das variáveis do cenário (Figura 16) - no caso dos valores mínimos; utilizar o patamar máximo após o período de estabilização das receitas, quando o empreendimento tem um posicionamento mais agressivo em relação à concorrência - pois está configurado de acordo com a percepção de valor de seu público alvo para os primeiros anos, sem precisar de atualizações e adequações funcionais.

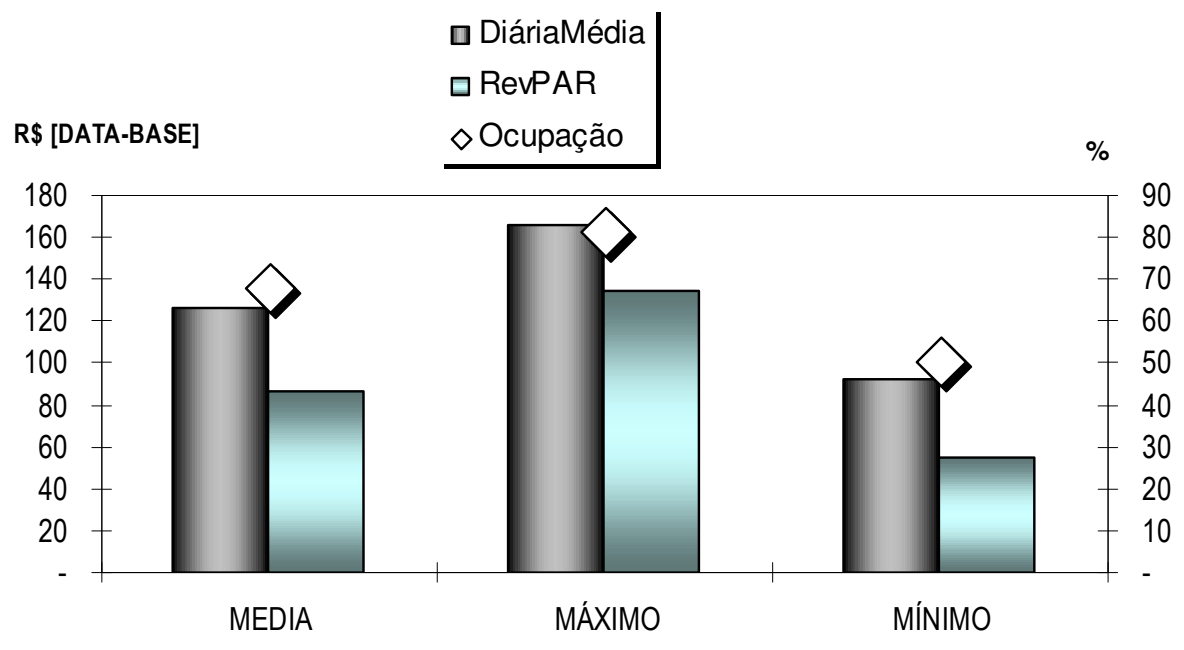

Figura 16: Faixas de intervalo para diária média, ocupação e RevPAR obtido pela aplicação do SIG 
Para um intervalo de confiança de $90 \%$ os resultados mostram que a média das Diárias Médias para uma amostra de 11 elementos, se situará entre $\mathrm{R} \$ 114,60$ e $\mathrm{R} \$ 138,00$. Já o RevPAR se situará, para o mesmo intervalo de confiança e mesmo conjunto de amostras, entre $\mathrm{R} \$ 73,90$ e $\mathrm{R} \$ 98,90$ (Figura 17).

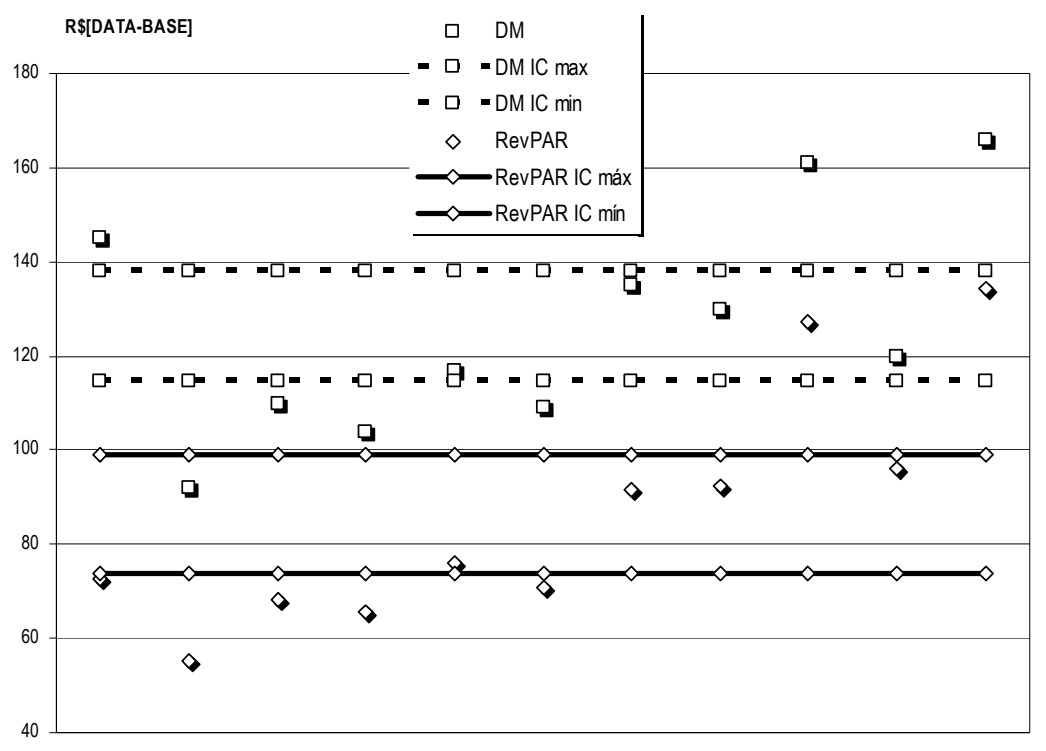

Figura 17: Intervalo de Confiança para Diária Média e RevPAR

Esses resultados permitem o estudo do desempenho operacional para cenários de diferentes contornos, na arbitragem da inserção no mercado e patamar de estabilização do $\operatorname{Rev} P A R$. As faixas indicadas na Figura 19 indicam que, com 90\% de confiança, a média das amostras estará contida entre seus limites, para o valor das diárias médias e para o valor de RevPAR - para empreendimentos do mesmo conjunto competitivo. 
Mesmo assim, o impacto do crescimento da oferta com a entrada de um novo empreendimento provocará um novo equilíbrio da divisão do mercado pelos hotéis.

\subsection{Resultados possíveis a partir do uso do SIG}

Em mercados maduros Jones (1999) comenta que é possível que todos os segmentos de mercado já estejam atendidos e que o investimento em um novo empreendimento seja alto, em virtude de barreiras criadas contra a entrada de novos competidores e pela valorização imobiliária em tais mercados. Nesse caso, novos investimentos são direcionados à reforma de antigos empreendimentos para adequá-los a novos parâmetros de demanda, com vistas a manter a qualidade econômica do investimento.

Em mercados em consolidação pode não existir barreiras à entrada de novos competidores. Nessa situação, a procura pela melhor localização garante uma vantagem que não poderá ser suplantada por empreendimentos similares. Um novo empreendimento que se instale na região buscará outros atrativos que lhe garantam competitividade.

O mercado da região do estudo de caso apresenta-se em processo de consolidação pois apresenta valorização imobiliária ainda em curso e ausência de hotéis voltados para negócios de categoria econômica. No entanto, existem lançamentos programados que acrescentarão à oferta da região 400 UHs, em maio de 2004, e mais 754 UHs, em meados de 2006;

Reportando ao estudo de caso, item [5.5 - v] temos a tabela 7: 
Tabela 7: Oferta competitiva instalada

\begin{tabular}{lrrrrr}
\hline & UHs & OCUP. & \multicolumn{1}{c}{ oferta } & demanda & I P \\
\hline HOTEL 1 & 184 & $78,6 \%$ & 67.160 & 52.769 & 1,16 \\
HOTEL 2 & 344 & $81,4 \%$ & 125.560 & 102.242 & 1,21 \\
HOTEL 3 & 186 & $65,2 \%$ & 67.890 & 44.264 & 0,96 \\
HOTEL 4 & 130 & $62,0 \%$ & 47.450 & 29.419 & 0,92 \\
HOTEL 5 & 146 & $64,8 \%$ & 53.290 & 34.532 & 0,96 \\
HOTEL 6 & 112 & $60,0 \%$ & 40.880 & 24.528 & 0,89 \\
HOTEL 7 & 200 & $80,0 \%$ & 73.000 & 58.400 & 1,18 \\
HOTEL 8 & 216 & $68,0 \%$ & 78.840 & 53.611 & 1,01 \\
HOTEL 9 & 380 & $49,8 \%$ & 138.700 & 69.073 & 0,74 \\
HOTEL 10 & 168 & $62,9 \%$ & 61.320 & 38.544 & 0,93 \\
HOTEL 11 & 172 & $71,0 \%$ & 62.780 & 44.574 & 1,05 \\
& & & & & \\
\hline Total & 2.238 & $67,6 \%$ & 816.870 & 551.955 & 1,00 \\
\hline
\end{tabular}

Para um hotel (HOTEL 12) que inicia sua operações na região em que se situa esse conjunto competitivo e com as mesmas características (mais de $100 \mathrm{UHs}$, categoria upscale, inaugurado após 1990, com diária média entre $R \$ 80$ e $R \$ 200$ ), quando atingir um índice de penetração do mercado (IP) de 1,00 temos (tabela 8):

Tabela 8: Oferta competitiva instalada com um novo hotel [12]

\begin{tabular}{lrrrrr}
\hline & UHs & OCUP. & \multicolumn{1}{c}{ oferta } & demanda & I P \\
\hline HOTEL 1 & 184 & $75,2 \%$ & 67.160 & 50.512 & 1,11 \\
HOTEL 2 & 344 & $77,9 \%$ & 125.560 & 97.869 & 1,15 \\
HOTEL 3 & 186 & $62,4 \%$ & 67.890 & 42.371 & 0,92 \\
HOTEL 4 & 130 & $59,3 \%$ & 47.450 & 28.161 & 0,88 \\
HOTEL 5 & 146 & $62,0 \%$ & 53.290 & 33.055 & 0,92 \\
HOTEL 6 & 112 & $57,4 \%$ & 40.880 & 23.479 & 0,85 \\
HOTEL 7 & 200 & $76,6 \%$ & 73.000 & 55.902 & 1,13 \\
HOTEL 8 & 216 & $65,1 \%$ & 78.840 & 51.318 & 0,96 \\
HOTEL 9 & 380 & $47,7 \%$ & 138.700 & 66.118 & 0,71 \\
HOTEL 10 & 168 & $60,2 \%$ & 61.320 & 36.895 & 0,89 \\
HOTEL 11 & 172 & $68,0 \%$ & 62.780 & 42.667 & 1,01 \\
HOTEL 12 & $\mathbf{1 0 0}$ & $\mathbf{6 4 , 7 \%}$ & $\mathbf{3 6 . 5 0 0}$ & $\mathbf{2 3 . 6 0 8}$ & $\mathbf{1 , 0 0}$ \\
& & & & & \\
\hline Total & 2.238 & $64,7 \%$ & 853.370 & 551.955 & 0,96 \\
\hline
\end{tabular}




\subsubsection{Estudo da demanda}

A demanda por determinada categoria de oferta pode variar com o tempo, por alterações na vocação da região ou migação dessa demanda para outras regiões.

A degradação de regiões urbanas ou valorização de outras áreas são fatores que provocam migração da demanda hoteleira para outras regiões, reduzindo as ocupações para um mesmo patamar de tarifas ou levando a um reposicionamento da oferta através da redução das tarifas para o patamar imediatamente inferior. Em qualquer um dos casos o RevPAR cai, consequentemente provocando uma queda na qualidade do empreendimento.

Esse movimento pode ser melhor percebido analisando o posicionamento de novos competidores. Em São Paulo, Asmussen; Rocha; Melo (2001) comentam que até o fim dos anos setenta a região central concentrava toda a oferta significativa. Hoje essa região concentra a maior parte da oferta da categoria econômica. Processos de migração para outras regiões como as regiões da Paulista, Jardins, Faria Lima, Berrini, Marginal, Vila Olímpia e Moema, entre outros, vem ocorrendo desde então, o que tem provocado essa alteração no perfil da demanda. (Figura 17 citada no fim do capítulo 5)

\subsubsection{Estudo de eventos macroeconômicos}

São eventos associados à conturbações no ambiente no qual se insere o empreendimento, de ordem macroeconômica. Situações estruturais do setor ou movimentos macroeconômicos podem vir a provocar variações no $\operatorname{Rev} P A R$.

No entanto, não é escopo deste trabalho a arbitragem desses eventos já que o uso de SIG para eventos macroeconômicos envolve uma 
série de considerações e análises de pouca valia para um comportamento e desempenho considerados homogêneos.

Rocha Lima (2000) comenta que essa estabilidade é uma das metas de gestão e, do ponto de vista conceitual, não há meio lógico de estabelecer quebras de desempenho em função de perda de qualidade ao longo de sua vida. "para que o cenário tenha sustentação, há necessidade de impor a premissa de comportamento em regime uniforme entendendo que a estratégia gerencial mais coerente indica que esta seja a meta no ciclo operacional - ganhar sua posição de mercado - e mantê-la.”

\subsubsection{Estudo da possibilidade de alteração no perfil da região}

Mudanças na infraestrutura urbana, na legislação sobre uso e ocupação do solo ou mesmo na implantação de novos empreendimentos podem provocar alterações no perfil de uma região.

A região da Nova Faria Lima e dos túneis Sebastião Camargo e presidente Jânio Quadros, com os investimentos em infraestrutura efetuados apresentou, além da valorização dos terrenos da região, a migração de empresas de outras regiões (como da Avenida Paulista) imprimindo um novo perfil de ocupação, em torno de escritórios de alto padrão.

$\mathrm{Na}$ região em estudo a área em torno da avenida Berrini tem apresentado ocupação exclusivamente de escritórios criando uma área sem atrativos após o horário comercial. Essa experiência levou a prefeitura de São Paulo a alterar os critérios para ocupação da Avenida Águas Espraiadas, estabelecendo lá um limite máximo de 70\% de áreas destinadas a escritórios, alterando os padrões de ocupação da região. 
Certos empreendimentos quando implantados também podem provocar mudanças no perfil de uma região na medida em que atraem serviços e empreendimentos complementares ou mesmo empreendimentos concorrentes, criando uma nova identidade associada ao local.

A estruturação de um SIG permite ao planejador, após a decisão sobre a implantação do empreendimento, acompanhar a evolução do perfil da região e através de medidas de gestão evitar uma situação não favorável, que prejudicasse o desempenho operacional, conforme visto no item [6.3].

\subsubsection{Estudo aplicado à dinâmica do mercado imobiliário de hotéis}

Estudos sobre a dinâmica do mercado de real estate são recentes e são poucos os trabalhos sobre a dinâmica do mercado imobiliário de hotéis. No entanto, não foram encontrados estudos sobre o assunto para o Brasil.

Um aspecto importante a destacar sobre empreendimentos hoteleiros, durante a operação, é a velocidade de reação do mercado às mudanças da economia. Diferentemente de outros empreendimentos, com contratos de longa duração, hotéis oferecem um produto altamente perecível, isto é, caracterizado por contratos diários (pelo uso de acomodações). Além da sazonalidade semanal e anual, percebe-se de imediato o reflexo do comportamento da economia, e seu impacto nas receitas do hotel.

Quan; Sehgal (2002) comentam que hotéis têm comportamento diferente de outros ativos de base imobiliária, no que se refere à velocidade de resposta a variações inflacionárias, por se organizar a partir 
de contratos diários. Por outro lado, alterações no equilíbrio entre oferta e demanda são percebidas imediatamente. No entanto, concluem os autores que os hotéis de melhor desempenho operacional foram os que conseguiram diversificação em sua operação, em função da região em que se encontravam e do segmento em que atuavam. Essa conclusão indica a importância do atributo localização e segmentação do produto hoteleiro.

Apesar de Smith; Lesure (1996) comentarem que projeções para o comportamento esperado de determinado segmento hoteleiro e região têm sua eficácia reduzida após um período de seis meses a um ano e meio (pois mesmo resultados de crescimento da ocupação atrairiam empreendedores a novos lançamentos, aumentando a oferta instalada e provocando uma queda nas ocupações e no $\operatorname{Rev} P A R$ ), deve-se considerar, desde a fase de planejamento tático, um FRA devidamente calibrado, de modo a suprir os investimentos necessários para adequação e atualização funcionais que mantenham a qualidade do empreendimento, pela capacidade de manter um padrão de geração de renda estabilizado. Com isso, mesmo variações mais intensas no comportamento da demanda têm reduzido impacto nesses empreendimentos, em relação ao padrão médio da oferta competitiva.

\subsubsection{Estudo sobre movimentos de difusão geográfica da demanda}

Ao longo do tempo desenvolve-se um processo de reposicionamento dos hotéis, no encalço de migrações da demanda e da mudança de suas características (demanda). Esse reposicionamento pode-se dar de forma contínua: [i] - mantendo-se o centro dessa concentração e expandindo para áreas contínuas em torno desse centro; [ii] - através de uma relocação do foco do destino da demanda provocando com isso um deslocamento dos novos hotéis em torno dessa nova área; [iii] - ou através de alterações das características da demanda e da entrada de hotéis mais 
modernos, forçando os antigos hotéis a um reposicionamento quanto ao seu segmento de mercado e tarifas praticadas.

Em São Paulo observam-se, de 1950 até 1980, dois eventos distintos do impacto da localização ao longo do tempo: o reposicionamento de hotéis antigos instalados em áreas centrais que passaram a concorrer com novos hotéis e a disputar um novo perfil de demanda; e a migração dos investimentos em hotéis para novos pólos geradores de demanda. Para Asmussen; Rocha; Melo (2001), o componente geográfico será determinante no desempenho futuro do mercado de hospedagem de São Paulo, pois a crescente polarização da oferta ao redor de áreas específicas, chamadas clusters urbanos, não permite tratar a cidade como um mercado único.

\subsubsection{Monitoramento e controle no planejamento, através de SIGs}

São fatores que afetam o mercado da indústria hoteleira o estado da mercado para a região (em expansão, declínio ou estagnação), a relação entre a posição da oferta competitiva, os custos e disponibilidade de novos financiamentos, as políticas e programas governamentais de incentivo e a regulamentação governamental quanto à tributação e regras de depreciação e as características das atividades econômicas da região de influência do hotel.

Segundo Rocha Lima (1993a), hotéis são afetados positivamente por movimentos de crescimento econômico, pois acabam sendo centros de captação da nova renda agregada via os sistemas de locação, com receitas, na maior parte das vezes, vinculadas à receita operacional. No sentido inverso, a recessão provoca a redução de empregos e a desocupação de espaços (em hotéis diminuindo a ocupação), que não admitem reciclagem (devido à rigidez estrutural do empreendimento) e cuja recuperação é impossível. 
Segundo Cahill (1988), a indústria hoteleira difere de outros empreeendimentos de base imobiliária pela elevada sensibilidade aos movimentos de crescimento econômico, pois os contratos de vendas de hospedagem realizadas pelos hotéis são para períodos curtos, normalmente entre dois e quatro dias, em contraste a contratos de locação em prédios de escritório ou lojas de shopping, de prazos superiores a um ano.

Essa dinâmica de comportamento de empreendimentos associada a momentos de expansão ou retração econômica é chamada de ciclos de real estate. Phyrr; Roulac; Born (1999), sugerem que a base para que se entenda o desempenho de empreendimentos, para uma região, segmento de mercado ou localização, envolve o conhecimento das relações dos ciclos de real estate. Seu estudo e a informação daí resultante podem ser utilizadas no ambiente do SIG para suporte à construção de cenários estressados, que permitam a antecipação de estratégias, evitando-se a perda da qualidade do produto hoteleiro.

Phyrr; Roulac; Born (1999), Wheaton; Rossoff (1998) e também Cahill (1988), dividem o ciclo de real estate para o mercado de demanda por hospedagem em fases distintas. São assim chamados de ciclos por terem apresentado um comportamento em seus estudos, ao longo do tempo, com características semelhantes ao de uma função senoidal, contendo fases, picos e vales, amplitudes e pontos de inflexão. Apesar do mercado não poder ter seu comportamento ajustado por uma função ${ }^{37}$, o reconhecimento desse comportamento auxilia na construção de cenários considerando-se o impacto de novas combinações de eventos ao longo do

37 Por comportamento do mercado entende-se que é o fruto uma evolução constante e baseado, entre outros fatores, nos fatos que o antecederam. Portanto, os dados gerados por um novo evento são agregados ao arcabouço de informações utilizadas para tomada de decisões alterando qualquer padrão que se poderia extrair de eventos anteriores. 
horizonte do empreendimento. As fases podem ser definidas como crescimento, declínio e recuperação e os extremos como ápice e depressão. Cada uma dessas etapas é detalhada a seguir:
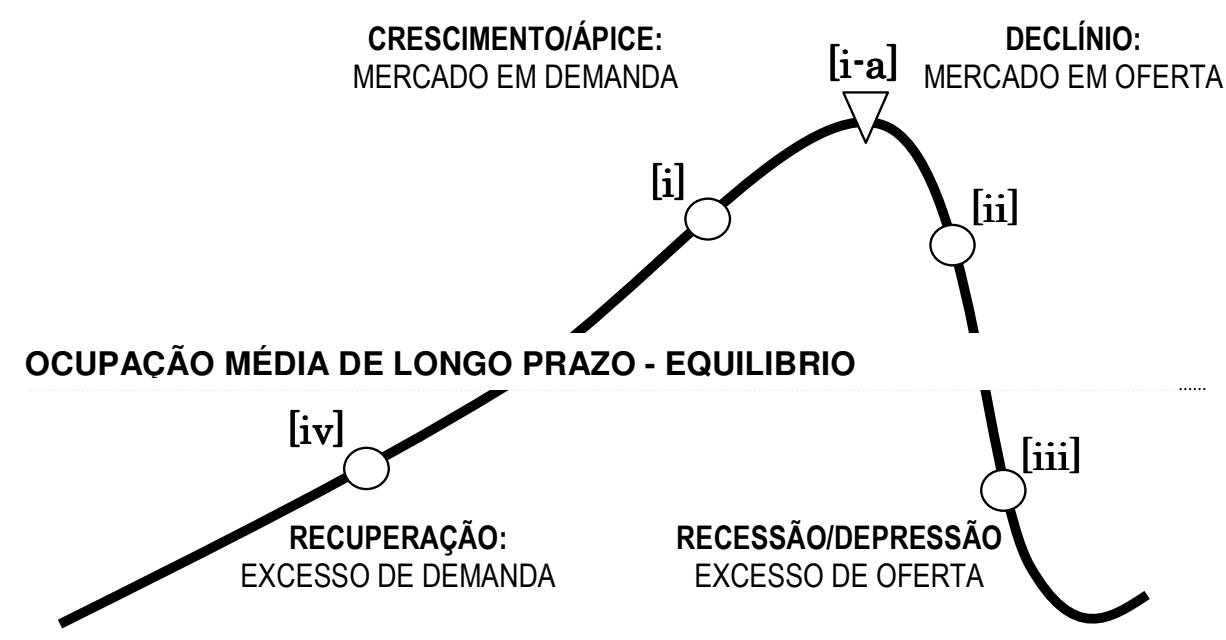

Figura 18 - Fases dos ciclos de Real Estate

FONTE: adaptado de Phyrr; Roulac; Born (1999) e Rocha Lima Junior (2004).

[i] - Crescimento (ou expansão): o valor de mercado ${ }^{38}$ do hotel é crescente, pois apresenta crescentes ocupações e valorização das diárias; as exigências por parte de investidores são estáveis ou diminuem e, em economias estáveis, existe disponibilidade de crédito para projetos de hotéis que se destaquem ${ }^{39}$;

\footnotetext{
${ }^{38}$ Valor de mercado entendido como o preço pelo qual o mercado estaria disposto a transacionar o empreendimento.

${ }^{39}$ Com relação a financiamentos o estudo de Cahill foi realizado no mercado americano não se aplicando ao Brasil. No Brasil, além dos financiamentos pelo BNDES, outras modalidades de financiamentos devem tornar-se mais comuns à medida que a economia se recupere, que a redução da taxa de juros reais permita que mais empreendimentos financiados sejam economicamente aceitáveis e que outros eventos, como os políticos e sociais, sejam percebidos pelo mercado como vetores de redução de risco para novos investimentos.
} 
[i-a] - Ápice: o valor do hotel passa de crescente para estável, pois as ocupações e valor das diárias estabilizam em patamares elevados; investidores tem uma percepção positiva quando ao fluxo de caixa futuro do hotel e financiamentos estão disponíveis para novos projetos em geral;

[ii] - Declínio (ou contração): há um declínio no valor do hotel, reflexo da percepção do declínio nas ocupações, apesar do valor das diárias permanecer estável; investidores exigem um prêmio maior (taxa de atratividade) por identificar um risco maior nesse tipo de investimento e as fontes de financiamento reduzem a disponibilidade de crédito buscando reduzir sua exposição a esse tipo de investimento;

[iii] - Depressão (ou recessão): Menores valores do hotel, por apresentar este menores ocupações e redução do valor das diárias, eventualmente descontos, promoções ou mesmo acirramento da concorrência; investidores aumentam suas exigências e novos financiamentos são quase impossíveis;

[iv] - Recuperação: tendência de melhora no valor do hotel, pois já se percebe um crescimento nas ocupações e na recuperação do valor das diárias; a captação de recursos junto a investidores já é possível a taxas menores, mas financiamentos ainda são escassos.

O comportamento dessas fases é específico para cada região e segmento de demanda, podendo ocorrer fases diferentes ao mesmo tempo em determinada região para segmentos diferentes, ou mesmo de determinado segmento hoteleiro em regiões diferentes. Pelas características do segmento da demanda o ciclo de investimento em hotéis muitas vezes atua independente do comportamento econômico de determinada cidade, estado ou mesmo do país em que se localiza. 


\section{CONCLUSÕES}

Sistemas de informação geográfica (SIGs) são uma importante ferramenta na avaliação dos atributos associados à localização de um empreendimento, com aplicação verificada neste trabalho para hotéis mas extensível para outras tipologias de empreendimentos como escritórios comerciais, shopping centers, edifícios habitacionais.

O uso de SIGs permite visualizar os atributos dos empreendimentos em sua dimensão espacial. O valor de variáveis do cenário que sejam influenciadas por atributos de outras feições (empreendimentos geradores de demanda, oferta competitiva, infraestrutura viária e de serviços, etc.) pode ser acompanhado através de um SIG, de modo a reduzir o risco de um posicionamento incorreto frente a seu segmento de mercado.

A estruturação do SIG para o planejamento do produto hoteleiro mostrou a necessidade de padronização entre as diversas fontes de informações. Os resultados da estruturação do SIG mostraram melhores condições para manutenção e atualização de seus dados quando o desenvolvimento do sistema contemplou um software de planilha eletrônica na construção de seu banco de dados. Usando o apoio da planilha eletrônica, foi possível criar um ambiente de trabalho que facilitou a convergência entre os diversos formatos de dados e que também permitiu a automatização de seus processos de atualização, para então converter a base de dados padronizada para o formato (dbf) utilizado no ambiente do software de SIG.

Em relação à manipulação e análise dos dados e na apresentação da informação, para o caso em estudo, aplicável à fase de planejamento de 
um empreendimento hoteleiro, observou-se um ganho em termos de tempo de processamento e em termos de velocidade de resposta, em relação ao processo manual de manipulação de dados, no planejamento de empreendimentos hoteleiros, que não permite manutenção ou atualizações da base de dados sem ter que recomeçar todo o trabalho.

Hotel de negócios apresenta a característica particular de ser um produto prioritariamente voltado a um público que não tem residência permanente na sua área de operação. No entanto, para essa tipologia de hotéis, conhecendo-se a oferta competitiva instalada, seus indicadores de desempenho, a fase de desenvolvimento da região e as características dessa ocupação (da região), pode-se reduzir os riscos da arbitragem de variáveis (sujeitas à influência de proximidade entre diferentes feições) do cenário utilizada pelo planejamento de um novo hotel.

A avaliação da demanda pelo estudo do perfil das empresas e de locais de eventos é um caminho que deve ser considerado em complemento à avaliação da demanda pelo estudo da oferta competitiva, para hotéis voltados a viajantes de negócios.

Infra-estrutura de serviços encontrada na região de implantação do hotel são atrativos importantes que podem significar a diferença entre hotéis que não se utilizam de estratégias de diferenciação de seu produto (todos os hotéis de negócios excetuando-se hotéis da categoria luxo - que buscam elementos de exclusividade no atendimento e nos equipamentos).

Esses elementos, quando ausentes, mesmo em regiões em que os hotéis se estabeleçam próximos ao destino final do hóspede, podem resultar em um desempenho final inferior para esses hotéis, em relação à oferta competitiva instalada que, apesar de mais distante (dentro da zona 
de influência), esteja melhor servida de uma infra-estrutura de serviços na região.

Infra-estrutura de serviços, no entanto, deixa de ser importante na medida em que um hotel é planejado para atender à categoria econômica ou simples. Para viajantes de negócios que buscam hotéis dessa categoria, o custo do transporte compõe com o da hospedagem a maior fatia de suas despesas - de modo a direcionar a escolha pelo custo do deslocamento ao invés do tempo de deslocamento, para hotéis de mesma categoria.

Dependendo do perfil e porte da cidade analisada a zona de influência pode apresentar grandes variações. Uma cidade de pequeno porte pode inclusive ser atendida por hotéis de cidades vizinhas, mas com melhor infra-estrutura de serviços.

SIGs podem ser utilizados na análise de atributos de todos os tipos de elementos da zona de influência que, de algum modo, relativamente às distâncias entre o hotel e esses elementos, influem no desempenho do hotel.

Com os dados consolidados pelo estruturação do SIG e sua manipulação e análise, vista no estudo de caso, a construção de cenários de inserção do hotel é facilitada pela multiplicidade de opções geradas pela combinação com uma feramenta de planilha eletrônica.

No estudo de alternativas é de grande valia a análise de efeitos discretos de variação dos índices de penetração de mercado para o empreendimento proposto - para definição de estratégias de colocação do produto no mercado e estabelecer mecanismos de controle para o caso de ajustes que se façam necessários durante o monitoramento de suas 
receitas, principalmente na fase inicial de estabilização até seu patamar de ocupação natural.

A utilização do SIG transcende a uma tipologia de empreendimento, que, como no caso dos hotéis sobre os quais já se apregoou o segredo de seu sucesso como "localização, localização e localização" 40 , seu uso pode encontrar aplicação em outros empreendimentos imobiliários e de base imobiliária.

Pode-se concluir, através dos resultados alcançados, que sistemas de informação geográfica tem um papel importante na identificação e determinação das variáveis do cenário relacionadas à localização do empreendimento, bem como inferir tendências de comportamento das mesmas variáveis baseadas nos atributos de relacionamento entre os entes de expressão espacial - aqui identificados como hotéis (no estudo da oferta e da demanda, pela oferta), escritórios e centros de convenção (no estudo da demanda).

$\mathrm{Na}$ avaliação da opção por um SIG deve-se levar em conta a avaliação dos ganhos potenciais - incluindo aqui a questão da continuidade dos negócios, e os custos dessa escolha - contra a avaliação de outras estratégias de negócios.

${ }^{40}$ Conrad Nicholson Hilton. (Ê25/12/1887 - †3/1/1979) 


\section{ANEXOS}

\section{A. LISTA DE EDIFÍCIOS DE ESCRITÓRIOS NA REGIÃO}

AMPLIADA (inclui áreas de regiões circunvizinhas)

(Formatado no padrão utilizado pelo SIG)

\begin{tabular}{|c|c|c|c|c|}
\hline NR & Nome & ENDERECO SIG & INÍCIO & A.U. \\
\hline 1 & Alice Maria Sampaio Ferreira & 1645 ENG LUIS CARLOS BERRINI & 2003 & 6.912 \\
\hline 2 & Aruanda & 34 R ANDRE AMPERE & 1996 & 1.606 \\
\hline 3 & Attílio Tinelli & $\begin{array}{l}375 \text { R DR GERALDO CAMPOS } \\
\text { MOREIRA }\end{array}$ & 2000 & 4.998 \\
\hline 4 & Bandeirantes & 828 ENG LUIS CARLOS BERRINI & 1978 & 4.207 \\
\hline 5 & Baronesa de St. Sève & 1909 R GUARARAPES & 1992 & 4.200 \\
\hline 6 & Beatriz Monteiro de Carvalho & 1758 R FLORIDA & 1992 & 3.663 \\
\hline 7 & Berrini 1681 & 1681 ENG LUIS CARLOS BERRINI & 2003 & 8.606 \\
\hline 8 & Berrini 500 & 40 PC PROF JOSE LANNES & 2000 & 12.750 \\
\hline 9 & Berrini 550 & 550 ENG LUIS CARLOS BERRINI & 1997 & 7.584 \\
\hline 10 & Berrini 901 & 901 ENG LUIS CARLOS BERRINI & 1996 & 5.528 \\
\hline 11 & Berrini Lavra & 1140 ENG LUIS CARLOS BERRINI & 1992 & 2.200 \\
\hline 12 & Berrini Sul & 42 R LUIGI GALVANI & 1999 & 4.524 \\
\hline 13 & Berrini Trade Center & 1700 ENG LUIS CARLOS BERRINI & 1994 & 5.600 \\
\hline 14 & $\begin{array}{l}\text { Bolsa de Imóveis do Estado de São } \\
\text { Paulo }\end{array}$ & 11541 DAS NACOES UNIDAS & 1997 & 18.149 \\
\hline 15 & Brasilinterpart & 11633 DAS NACOES UNIDAS & 1987 & 15.102 \\
\hline 16 & Brumadinho & $\begin{array}{l}109 \text { R DR GERALDO CAMPOS } \\
\text { MOREIRA }\end{array}$ & 1990 & 4.278 \\
\hline 17 & $\begin{array}{l}\text { Centro Administrativo Bandeirantes - } \\
\text { BI. A }\end{array}$ & 105 ENG LUIS CARLOS BERRINI & 1996 & 7.848 \\
\hline 18 & $\begin{array}{l}\text { Centro Administrativo Bandeirantes - } \\
\text { BI. B } \\
\end{array}$ & 267 ENG LUIS CARLOS BERRINI & 1986 & 4.820 \\
\hline 19 & Century Plaza & 142 R JAMES WATT & 1996 & 3.960 \\
\hline 20 & CENU - Torre Oeste & 12901 DAS NACOES UNIDAS & 1999 & 27.642 \\
\hline 21 & City-Salem & $\begin{array}{l}167 \text { R ALCIDES LOURENCO DA } \\
\text { ROCHA }\end{array}$ & 1990 & 3.698 \\
\hline 22 & Flórida & 1 ENG LUIS CARLOS BERRINI & 1985 & 4.003 \\
\hline 23 & Haydee Ferraz de Camargo & 753 R QUINTANA & 1989 & 4.284 \\
\hline 24 & Hormino Maia & $\begin{array}{l}433 \text { R SANSAO ALVES DOS } \\
\text { SANTOS }\end{array}$ & 1996 & 2.080 \\
\hline 25 & Itaju & 120 R SAMUEL MORSE & 2002 & 5.160 \\
\hline 26 & Itamambuca & 200 R LUIGI GALVANI & 1997 & 4.906 \\
\hline 27 & Jafet & $\begin{array}{l}\text { 42 R GERALDO FLAUSINO } \\
\text { GOMES }\end{array}$ & 1987 & 4.080 \\
\hline 28 & Jorge Oliva & 350 R ARANDU & 1998 & 3.761 \\
\hline 29 & Jorge Wallace Simonsen & 11711 DAS NACOES UNIDAS & 2002 & 8.146 \\
\hline
\end{tabular}




\begin{tabular}{|c|c|c|c|c|}
\hline NR & Nome & ENDERECO SIG & | INícIo & A.U. \\
\hline 30 & Maria Cecília da Cunha Bueno & 1737 R FLORIDA & 1993 & 1.360 \\
\hline 31 & Morumbi Office Tower & 999 ROQUE PETRONI JR & 1993 & 20.630 \\
\hline 32 & Morumbi Plaza & 150 DR CHUCRI ZAIDAN & 1984 & 15.320 \\
\hline 33 & Morumbi Square - BI. B & 80 DR CHUCRI ZAIDAN & 1993 & 3.272 \\
\hline 34 & Morumbi Square - BI. C & 80 DR CHUCRI ZAIDAN & 1993 & 6.578 \\
\hline 35 & Nações Unidas & 11857 DAS NACOES UNIDAS & 1992 & 8.100 \\
\hline 36 & Olympic Tower - Brooklin Novo & $\begin{array}{l}\text { 164 R DR GERALDO CAMPOS } \\
\text { MOREIRA }\end{array}$ & 2000 & 4.472 \\
\hline 37 & Palace Berrini & 716 ENG LUIS CARLOS BERRINI & 1998 & 8.846 \\
\hline 38 & Panambi & $\begin{array}{l}\text { 61 R GERALDO FLAUSINO } \\
\text { GOMES }\end{array}$ & 1982 & 6.188 \\
\hline 39 & Paulista de Seguros III & $\begin{array}{l}78 \text { R GERALDO FLAUSINO } \\
\text { GOMES }\end{array}$ & 1984 & 10.500 \\
\hline 40 & Plaza Centenário & 12995 DAS NACOES UNIDAS & 1995 & 34.196 \\
\hline 41 & Presidente Arthur Bernardes & 1500 ENG LUIS CARLOS BERRINI & 2000 & 4.356 \\
\hline 42 & Raul da Cunha Bueno & 1855 R GUARARAPES & 1985 & 3.536 \\
\hline 43 & River Park & $\begin{array}{l}\text { 240 R DR GERALDO CAMPOS } \\
\text { MOREIRA }\end{array}$ & 1991 & 8.730 \\
\hline 44 & Ronaldo Sampaio Ferreira & 34 PC JOAO ALONSO & 2003 & 10.837 \\
\hline 45 & Sales Vanni & 84 R JAMES WATT & 2000 & 2.197 \\
\hline 46 & Sudameris & 1297 ENG LUIS CARLOS BER & 1997 & 6.180 \\
\hline 47 & Tapajós & $\begin{array}{l}\text { 85 R GERALDO FLAUSINO } \\
\text { GOMES }\end{array}$ & 1988 & 2.352 \\
\hline 48 & Uchoa Borges & $\begin{array}{l}\text { 76 R SANSAO ALVES DOS } \\
\text { SANTOS } \\
\end{array}$ & 1987 & 3.480 \\
\hline 49 & Urca & 1178 ENG LUIS CARLOS BERRINI & 2002 & 3.000 \\
\hline 50 & WTC (World Trade Center) & 12551 DAS NACOES UNIDAS & 1995 & 32.728 \\
\hline 51 & Alexandre Dumas & 2086 R ALEXANDRE DUMAS & 2003 & 2.450 \\
\hline 52 & Andorra & 1400 R VERBO DIVINO & 1994 & 5.250 \\
\hline 53 & Birmann 10 & 1400 R VERBO DIVINO & 1992 & 13.100 \\
\hline 54 & Birmann 11 & 1711 R ALEXANDRE DUMAS & 1996 & 10.779 \\
\hline 55 & Birmann 12 & 1711 R ALEXANDRE DUMAS & 1996 & 12.501 \\
\hline 56 & Birmann 23 & 1207 R VERBO DIVINO & 1996 & 3.869 \\
\hline 57 & Birmann 8 - Aron Birmann & 2200 R ALEXANDRE DUMAS & 1988 & 14.546 \\
\hline 58 & Cardinal & 2022 R ALEXANDRE DUMAS & 2003 & 2.700 \\
\hline 59 & Carrefour & 255 R PAUL VALERY & 1982 & 11.158 \\
\hline 60 & $\begin{array}{l}\text { Centro Administrativo Santo Amaro - } \\
\text { Bl. A }\end{array}$ & $\begin{array}{l}100 \text { ALFREDO EGIDIO DE SOUZA } \\
\text { ARANHA }\end{array}$ & 1976 & 3.947 \\
\hline 61 & $\begin{array}{l}\text { Centro Administrativo Santo Amaro - } \\
\text { Bl. B }\end{array}$ & $\begin{array}{l}100 \text { ALFREDO EGIDIO DE SOUZA } \\
\text { ARANHA }\end{array}$ & 1990 & 12.759 \\
\hline 62 & $\begin{array}{l}\text { Centro Administrativo Santo Amaro - } \\
\text { Bl. C }\end{array}$ & $\begin{array}{l}100 \text { ALFREDO EGIDIO DE SOUZA } \\
\text { ARANHA }\end{array}$ & 1993 & 7.907 \\
\hline 63 & $\begin{array}{l}\text { Centro Administrativo Santo Amaro - } \\
\text { Bl. D } \\
\end{array}$ & $\begin{array}{l}100 \text { ALFREDO EGIDIO DE SOUZA } \\
\text { ARANHA }\end{array}$ & 1990 & 13.563 \\
\hline 64 & $\begin{array}{l}\text { Centro de Convenções Américo } \\
\text { Brasiliense }\end{array}$ & 1664 R AMERICO BRASILIENSE & 2001 & 8.224 \\
\hline 65 & Centro Empresarial Transatlântico & 1488 R VERBO DIVINO & 1990 & 17.854 \\
\hline 66 & Condomínio Verbo Divino & 1356 R VERBO DIVINO & & 5.600 \\
\hline
\end{tabular}




\begin{tabular}{|c|c|c|c|c|}
\hline NR & Nome & ENDERECO SIG & | Iníclo & A.U. \\
\hline 67 & Corporate Plaza & 2100 R ALEXANDRE DUMAS & 1991 & 10.800 \\
\hline 68 & Dumas Tower & 1658 R ALEXANDRE DUMAS & 2003 & 7.545 \\
\hline 69 & Dumez & $\begin{array}{l}75 \text { ALFREDO EGIDIO DE SOUZA } \\
\text { ARANHA }\end{array}$ & 1976 & 2.600 \\
\hline 70 & JP Man & 489 R BRANCO DE MORAES & & 1.000 \\
\hline 71 & Master Tower & 2171 R AMERICO BRASILIENSE & 2000 & 4.095 \\
\hline 72 & Santo Antônio & 1207 R VERBO DIVINO & 2003 & 4.500 \\
\hline 73 & São Paulo Plaza & 1547 VERBO DIVINO & 2002 & 7.910 \\
\hline 74 & South Point Offices & $\begin{array}{l}177 \text { ALFREDO EGIDIO DE SOUZA } \\
\text { ARANHA }\end{array}$ & 1996 & 3.280 \\
\hline 75 & Stelvio Mazza & 1601 R ALEXANDRE DUMAS & 1998 & 4.200 \\
\hline 76 & The Market Hall & $\begin{array}{l}153 \text { PROF ALCEU MAYNARD DE } \\
\text { ARAUJO }\end{array}$ & 1994 & 2.716 \\
\hline 77 & Verbo Divino & 1661 R VERBO DIVINO & 1993 & 14.183 \\
\hline 78 & CENESP - BI. A & 215 MARIA COELHO DE AGUIAR & 1977 & 22.752 \\
\hline 79 & CENESP - BI. B & 215 MARIA COELHO DE AGUIAR & 1977 & 22.752 \\
\hline 80 & CENESP - BI. Belvedere & 215 MARIA COELHO DE AGUIAR & 1977 & 1.400 \\
\hline 81 & CENESP - BI. C & 215 MARIA COELHO DE AGUIAR & 1977 & 22.752 \\
\hline 82 & CENESP - BI. D & 215 MARIA COELHO DE AGUIAR & 1977 & 22.752 \\
\hline 83 & CENESP - BI. E & 215 MARIA COELHO DE AGUIAR & 1997 & 22.752 \\
\hline 84 & CENESP - BI. F & 215 MARIA COELHO DE AGUIAR & 1989 & 22.752 \\
\hline 85 & CENESP - BI. G & 215 MARIA COELHO DE AGUIAR & 1977 & 7.500 \\
\hline 86 & Panamérica Park - BI. II & 1000 GUIDO CALOI & 2001 & 4.684 \\
\hline 87 & Panamérica Park - BI. IV & 1000 GUIDO CALOI & 2001 & 5.013 \\
\hline 88 & Panamérica Park - BI. IX & 1000 GUIDO CALOI & 2001 & 4.527 \\
\hline 89 & Panamérica Park - BI. VIII & 1000 GUIDO CALOI & 2001 & 5.511 \\
\hline 90 & America Business Park - Atlanta & 5200 MARGINAL PINHEIROS & 2000 & 4.287 \\
\hline 91 & America Business Park - Dallas & 5200 MARGINAL PINHEIROS & 2001 & 5.052 \\
\hline 92 & America Business Park - Miami & 5200 MARGINAL PINHEIROS & 2000 & 5.563 \\
\hline 93 & $\begin{array}{l}\text { America Business Park - } \\
\text { Philadelphia }\end{array}$ & 5200 MARGINAL PINHEIROS & 2000 & 5.163 \\
\hline 94 & Columbus Tower II & 58 R KARL RICHTER & 2001 & 1.960 \\
\hline 95 & \begin{tabular}{|l} 
Torre Passarelli \\
\end{tabular} & 122 R EDWARD JOSEPH & 1999 & 3.250 \\
\hline 96 & Birmann 20 & 17991 DAS NACOES UNIDAS & 1994 & 18.270 \\
\hline 97 & Birmann 9 - Herbert Levy & $\begin{array}{l}\text { 125 R ENG FRANCISCO PITA } \\
\text { BRITTO }\end{array}$ & 1990 & 14.753 \\
\hline 98 & Digital Trading Center & 19739 DAS NACOES UNIDAS & 1990 & 4.620 \\
\hline
\end{tabular}




\section{B. LISTA DE EMPREENDIMENTOS HOTELEIROS NA REGIÃO}

(Inclui hotéis em construção e terreno de propriedade de hotel)

\begin{tabular}{|c|c|c|c|c|c|c|}
\hline ID & Nome & & Endereço & $\mathbf{N}^{\circ}$ & Inaug. & UHs \\
\hline 1 & Blue Tree Towers Berrini & Rua & Quintana & 1012 & 1998 & 184 \\
\hline 2 & \begin{tabular}{|l} 
Blue Tree Towers Morumbi \\
\end{tabular} & $A v$ & Roque Petroni jr & 1000 & 2000 & 344 \\
\hline 3 & Blue Tree Towers Nações Unidas & Rua & Fernandes Moreira & 1371 & 1999 & 186 \\
\hline 4 & Brooklin River Side Flat & Rua & Indiana & 1155 & 2001 & 103 \\
\hline 5 & Clarion Berrini & Rua & Alcides Lourenço da Rocha & 136 & 2004 & 128 \\
\hline 6 & Estanplaza Berrini & Av & Eng. Carlos Berrini & 853 & 1999 & 130 \\
\hline 7 & Estanplaza International & Rua & Fernandes Moreira & 1293 & 2001 & 146 \\
\hline 8 & Estanplaza Nações Unidas & Rua & Guararapes & 1889 & 1995 & 112 \\
\hline 9 & Formule1 Morumbi & Av & Roque Petroni jr & 800 & 2006 & 378 \\
\hline 10 & Free Hotel & Av & Adolfo Pinheiro & 1145 & $\mathrm{n} / \mathrm{d}$ & 88 \\
\hline 11 & Free Hotel & Rua & Princesa Isabel & 340 & $\mathrm{n} / \mathrm{d}$ & 116 \\
\hline 12 & Gran Estanplaza & Rua & Arizona & 1517 & 2002 & 214 \\
\hline 13 & Gran Meliá São Paulo & Av & das Nações Unidas & 12559 & 1995 & 300 \\
\hline 14 & Grand Hyatt Sao Paulo & Av & das Nações Unidas & 13301 & 2002 & 470 \\
\hline 15 & Hilton Berrini & Av & Nacoes Unidas & 12901 & 2001 & 567 \\
\hline 16 & Ibis Morumbi & Av & Roque Petroni jr & 800 & 2006 & 376 \\
\hline 17 & Le Meridian & Rua & Rosa Gaeta Lázara & 267 & $s / p$ & $\mathrm{n} / \mathrm{d}$ \\
\hline 18 & Marriott & Rua & Guararapes & $s / n$ & $s / p$ & $\mathrm{n} / \mathrm{d}$ \\
\hline 19 & Meliá Confort Berrini & Rua & Quintana & 934 & 2002 & 200 \\
\hline 20 & Meliá Confort Brooklin & Rua & Heinrich Hertz & 14 & 1999 & 216 \\
\hline 21 & Meliá Confort Office Park & Rua & Verbo Divino & 1323 & 2001 & 380 \\
\hline 22 & Parthenon Nacoes Unidas & Rua & Professor Manuelitto de Ornellas & 104 & 2000 & 168 \\
\hline 23 & Parthenon Royal Brooklin & Rua & Sansao Alves dos Santos & 367 & 1999 & 172 \\
\hline 24 & The Park Way All Suite & Rua & Joel Carlos Borges & 60 & 1990 & 60 \\
\hline 25 & The Time & Rua & Hans Oersted & 115 & 1993 & 113 \\
\hline 26 & Transamerica Flat Nações Unidas & Rua & Americo Brasilense & 2163 & 2000 & 143 \\
\hline 27 & Transamérica São Paulo & Av & das Nações Unidas & 18591 & 1986 & 400 \\
\hline 28 & Tryp Meliá Nacoes Unidas & Rua & Fernandez Moreira & 1264 & 2004 & 400 \\
\hline
\end{tabular}




\section{BIBLIOGRAFIA}

ANDRADE, N.; BRITO, P. L.; JORGE, W. E. Hotel: planejamento e projeto. Editora Senac. São Paulo, 2003.

ARAUJO, A. O. Contribuição ao estudo de indicadores de desempenho de empreendimentos hoteleiros, sob o enfoque da gestão estratégica. 160p. Tese de doutorado - Faculdade de Economia, Administração e Contabilidade da USP. São Paulo, 2001.

ASMUSSEN, M. W.; ROCHA, R. M.; MELO, Y. P., Jr. O setor hoteleiro em São Paulo: origem, panorama atual e perspectivas de comportamento. Trabalho apresentado em seminário no curso de pós-graduação em Engenharia de Construção Civil, na disciplina PCC 5036 Planejamento estratégico, formatação e meios de financiamento de empreendimentos de base imobiliária e concessão de exploração de serviços. Escola Politécnica da Universidade de São Paulo. São Paulo, maio 2002.

AYRES, M. L. A.; DAEMON, I. G.; FERNANDES, P. C. S. Hotel de negócios. BNDES Setorial, n.8, p.1-10, Set.1998.

BIRKIN, M. et al. Intelligent GIS - Location decisions and strategic planning. GeoInformation International. John Wiley \& Sons Inc. New York, 1996.

BROWN, J. R.; DEV, C. S. Looking beyond RevPAR: productivity consequences of hotel strategies. Cornell Hotel and Restaurant Administration Quarterly, v.40, n.2, p.23-33, Abr. 1999.

CAHILL, M. Investing in the hotel real estate cycle, The Bottomline - Journal of the International Association of Hospitality Accountants, p.22-26, Abr./Mai. 1988.

CANNON, S. E. Integrating desktop GIS into the real estate market analysis: a primer and comparison of available options. Real Estate Finance, p.21-37, Spring 1996.

CASTLE III, G. H. A status report: front-line uses of GIS in public and private sector real estate today. Property Tax Journal, v.12, n.1, p.77-83, Chicago: Mar. 1993.

CASTLE III, G. H. et al. GIS in Real Estate: integrating, analyzing, and presenting locational information. Appraisal Institute. EUA, 1998. 
DEROOS, J. A. Natural occupancy rates and development gaps. Cornell Hotel and Restaurant Administration Quarterly, v.40, n.2, p.14-22, Abr. 1999.

ENZ, C. A.; CANINA, L.; WALSH, K. Hotel-industry averages: An inaccurate tool for measuring performance. Cornell Hotel and Restaurant Administration Quarterly, v.42, n.6, p.22-32, Dez. 2001.

ESRI. Using ArcView GIS - The geographic information system for everyone. Environmental Systems Research Institute, Inc. Thomas G. Lane. EUA, 1996.

FERREIRA, J. S. W. São Paulo: o mito da cidade-global. 336p. Tese de doutorado - Faculdade de Arquitetura e Urbanismo da USP. São Paulo, 2003.

FREW, J.; WILSON, B. Estimating the connection between location and property value. Journal of Real Estate Practice and Education, v.5, n.1, p.17-25, 2002.

FRYREAR, R.; PRILL, E.; WORZALA, E. M. The use of geographic information systems by corporate real estate executives. The Journal of Real Estate Research, v.22, n.1/2, p.153-164, 2001.

FUNG, D. S.; KUNG, H.; BARBER, M. C. The application of GIS to mapping real estate values. The Appraisal Journal, p.445-452, Out. 1995.

GALLAGHER, M.; MANSOUR, A. An analysis of hotel real estate market dynamics. Journal of Real Estate Research, v.19, n.1/2, p.133-164, 2000.

GONÇALVES, A. B.; MENDES, A. B. Caracterização de áreas de influência de lojas de retalho alimentar de pequena dimensão com base em diagramas de Vorondi ponderados. IV Encontro de Utilizadores de Informação Geográfica. Proceedings ESIG'2002. Lisboa, 2002.

GUIDARA JUNIOR, P. Aspectos peculiares em projeto de banco de dados geográficos com ênfase na extração de metadados. 1999. 163p. Dissertação (Mestrado) - Escola Politécnica, Universidade de São Paulo. São Paulo, 1999.

IRELAND, M. W.; O'CONNOR, P. M. Location analysis for commercial properties. Assessment Journal, v.9, n.6, p.21-26, Nov./Dez. 2002. 
ISMAIL, J. A.; DALBOR, M. C.; MILLS, J. E. Using RevPAR to analyze lodging-segment variability. Cornell Hotel and Restaurant Administration Quarterly, v.43, n.6, p.73-80, Dec. 2002.

JOERGER, A.; DEGLORIA, S. D.; NODEN, M. A. Applying geographic information systems. Cornell Hotel and Restaurant Administration Quarterly, v.40, n.4, p.48-59, Ago. 1999.

JONES, P. Operational issues and trends in the hospitality industry. Hospitality Management, v.18, p.427-442, 1999.

KIM, K. H.; OLSEN, M. D. Determinants of successful acquisition processes in the US lodging industry. Hospitality Management, v.18, p.285-307, 1999.

KRUGMAN, P. Introduction. In: KRUGMAN, P.; FUJITA, M.; VENABLES, A. The spatial economy: cities, regions, and international trade. M.I.T. Press. (em fase de elaboração). Acesso em 8 out. 2003, disponível em <http://web.mit.edu/krugman/www/fkvintro.html>

LAWSON, F. Hotels and resorts: planning, desing and refurbishment. Architectural Press. Oxford, Inglaterra, 1999.

LAW, R. Room occupancy rate forecasting: a neural network approach. International Journal of Contemporary Hospitality Management, v.10 p.6, p.234, 1998.

LUZ, M. C. V. Análise Setorial: a indústria hoteleira. Gazeta Mercantil, São Paulo: Abr. 1999.

MAHER, W. J.; CANTER, T. A. An analysis of supply and demand for the U.S. hotel industry, Real Estate Finance, p.45-56, Fall 1998.

MARCONDES, P. Z. Avaliação da introdução da componente temporal aos sistemas de informações geográficas. 2001. 165p. Dissertação (Mestrado) - Escola Politécnica, Universidade de São Paulo. São Paulo, 2001.

PHYRR, S. A.; ROULAC, S. E.; BORN, W. L. Real estate cycles and their strategic implications for investors and portfolio managers in the global economy. Journal of Real Estate Research, v.18, n.1, p.7-68, 1999.

QUAN, D. C.; SEHGAL, A. The performance of lodging properties in an investment portfolio. Cornell Hotel and Restaurant Administration Quarterly, v.43, n.6, p.81-89, dez. 2002. 
QUINTANILHA, J. A. (Coord.) Sistemas de Informação Geográfica. In: Sistema de Informação ao Geoprocessamento. Laboratório de Geoprocessamento, Escola Politécnica da USP. (Departamento de Engenharia de Transportes.) São Paulo: 2003. Disponível em: <http://www.ptr.usp.br/Cursos/SIG_GPS/sig/fdc06p02.htm>. Acesso em: 5 ago. 2003.

ROCHA LIMA JUNIOR, J. Arbitragem de valor de hotéis. São Paulo: EPUSP, 2000. (Boletim Técnico da Escola Politécnica da USP. Departamento de Engenharia de Construção Civil $\mathrm{BT} / \mathrm{PCC} / 267)$.

ROCHA LIMA JUNIOR, J. Decidir sobre investimentos no setor da construção civil. São Paulo: EPUSP, 1998. (Boletim Técnico da Escola Politécnica da USP. Departamento de Engenharia de Construção Civil - BT/PCC/200).

ROCHA LIMA JUNIOR, J. Decisão e planejamento: fundamentos para a empresa e empreendimento na construção civil. São Paulo: EPUSP, 2004. (Texto Técnico da Escola Politécnica da USP. Departamento de Engenharia de Construção Civil - TT/PCC/25).

ROCHA LIMA JUNIOR, J. Fundos de investimento imobiliário e títulos de investimento de base imobiliária. São Paulo: EPUSP, 1994. (Boletim Técnico da Escola Politécnica da USP. Departamento de Engenharia de Construção Civil - BT/PCC/130).

ROCHA LIMA JUNIOR, J. Princípios para análise de qualidade de empreendimentos: o caso dos empreendimentos de base imobiliária. São Paulo: EPUSP, 1995. (Boletim Técnico da Escola Politécnica da USP. Departamento de Engenharia de Construção Civil - BT/PCC/153).

ROCHA LIMA JUNIOR, J. Securitização de portfolios de base imobiliária. São Paulo: EPUSP, 1993b. (Boletim Técnico da Escola Politécnica da USP. Departamento de Engenharia de Construção Civil - BT/PCC/99).

RODRIGUEZ, M.; SIRMANS, C. F.; MARKS A. P. Using geographic information systems to improve real estate analysis. The Journal of Real Estate Research, v.10, n.2, p.163-173, 1995.

RUSHMORE, S. Hotels and motels: a guide to market analysis, investment analysis, and valuations. Appraisal Institute. EUA, 1992. 
RUSHMORE, S. et al. Gazing into the crystal ball. Hotel and Motel Management, v.215, n.16, p.76, Set. 2000.

SAAB, W. G.; DAEMON, I. G. O segmento hoteleiro no Brasil. BNDES Setorial, n.13, p.127-156, Rio de Janeiro: Mar. 2001.

SMITH, R. A.; LESURE, J. D. Don't shoot the messenger Forecasting lodging performance. Cornell Hotel and Restaurant Administration Quarterly, v.37, n.1, p.80-88, Fev. 1996.

THRALL, G. I. GIS Applications in real estate and related industries. Journal of Housing Research, v.9, n.1, p.33-59, 1998b.

THRALL, G. I. et al. Economy geography. 3. ed. New York: John Wiley \& Sons, Inc., 1998a.

THRALL, G. I.; PITTMAN, R. H. Improving real estate market research. Real Estate Issues, p.1-7, Spring/Summer 1992.

TORTO WHEATON RESEARCH. Hotel market outlook. Torto Wheaton Research. p.1-13, Boston: Ago. 1999.

WEATHERFORD, L. R.; KIMES, S. E. A comparison of forecasting methods for hotel revenue management. International Journal of Forecasting, v.19, p.401-415, 2003.

WEBER, B. R. The use of GIS and OLAP for accurate valuation of developable land. Journal of Real Estate Portfolio Management, v.7, n.3, p.253-280, Jul./Set. 2001.

WHEATON, W. C.; ROSSOFF, L. The cyclic behavior of the US lodging industry. Real Estate Economics, v.26, n.1, p.430-436, 1998.

ZADDACK, G. N. Real estate applications for GIS: a review of existing conditions and future opportunities. Real Estate Issues, p.13-19, Winter 1998/1999. 